Portland State University

PDXScholar

Spring 5-20-2015

\title{
Sound Effects: Age, Gender, and Sound Symbolism in American English
}

Timothy Allen Krause

Portland State University

Follow this and additional works at: https://pdxscholar.library.pdx.edu/open_access_etds

Part of the Other Linguistics Commons

Let us know how access to this document benefits you.

\section{Recommended Citation}

Krause, Timothy Allen, "Sound Effects: Age, Gender, and Sound Symbolism in American English" (2015). Dissertations and Theses. Paper 2304.

https://doi.org/10.15760/etd.2301

This Thesis is brought to you for free and open access. It has been accepted for inclusion in Dissertations and Theses by an authorized administrator of PDXScholar. For more information, please contact pdxscholar@pdx.edu. 
Sound Effects: Age, Gender, and Sound Symbolism in American English

by

Timothy Allen Krause

A thesis submitted in partial fulfillment of the requirements for the degree of

\author{
Master of Arts \\ in \\ Teaching English to Speakers of Other Languages
}

Thesis Committee:

Tucker Childs, Chair

Jenny Mittelstaedt

Jeff Conn

Portland State University

2015 


\section{SOUND EFFECTS: AGE, GENDER, AND SOUND SYMBOLISM}

(C) 2015 Timothy Allen Krause 


\begin{abstract}
This mixed-method study investigated the correlation of sound symbolic associations with age and gender by analyzing data from a national survey of 292 American English speakers. Subjects used 10 semantic differential scales to rate six artificial brand names that targeted five phonemes. Subjects also described the potential products they imagined these artificial brand names to represent. Quantitative analysis alone provided insufficient evidence to conclude that age or gender affect sound symbolism in American English. While 26 out of 60 scales showed a monotonic shift among the means of the three age groups, only three were statistically significant. The evidence of differences between genders was similarly weak; only five scales out of 60 showed a statistically significant difference when comparing genders. Analysis of the qualitative data, however, suggested both monotonic generational shifts as well as generational blips in sound-symbolic associations. Of particular interest is the possible influence of pop culture, fashions, and fads, and society's shifting focus from broadcast to narrowcast media. The implications of this research are relevant for both theory (empirical evidence for iconicity in language) and application (e.g., devising brand names that communicate particular attributes to specific demographics).
\end{abstract}




\section{Acknowledgments}

I wish to thank my advisor Dr. Tucker Childs for his careful guidance and good humor; Portland State University's Department of Applied Linguistics and especially the James R. Nattinger Graduate Teaching Fellowship for the resources to pursue this inquiry; my committee members, Dr. Jenny Mittelstaedt and Dr. Jeff Conn, for their review and constructive feedback; Dr. Kimberley Brown, Dr. John Hellerman, Dr. Tetyana Sydorenko, and Dr. Keith Walters for additional feedback in the preparation of my research; my colleague Emily Minnette for her help in rating the qualitative data; my parents, Larry and June Krause, whose legacy made possible my return to graduate school; and my husband, Robert Dell, who has provided abundant encouragement and unwavering support of my pursuit of an encore career in applied linguistics and TESOL. 


\section{Table of Contents}

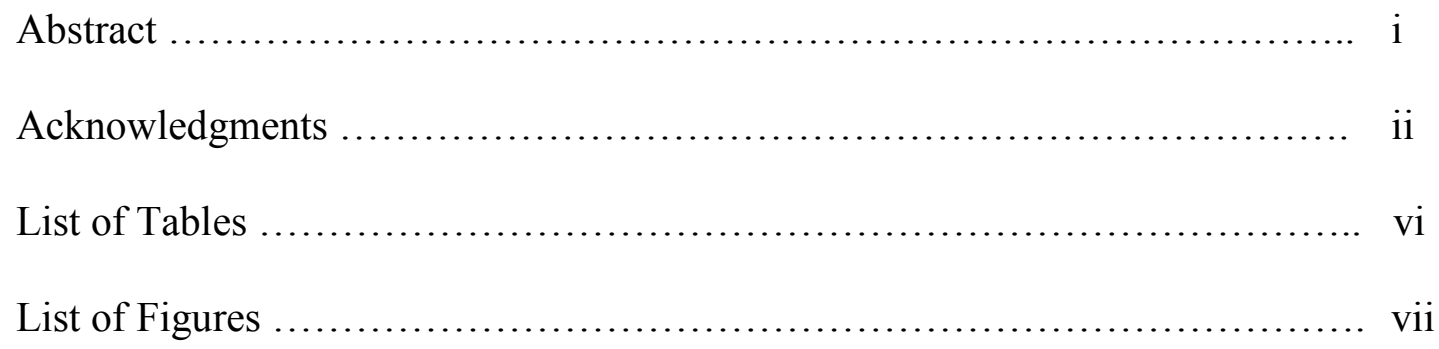

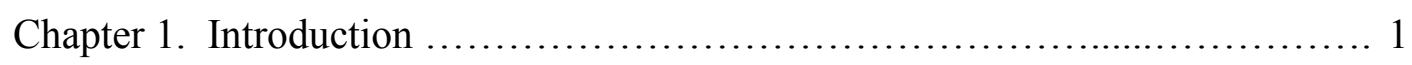

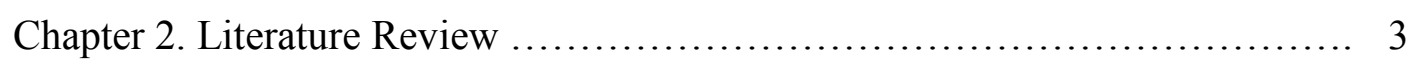

2.1 Sound Symbolism .................................................................. 3

2.2 Language Variation and Change ............................................. 8

2.2.1 Variation by Age ..................................................... 9

2.2.2 Variation by Gender ................................................. 10

2.3 Variation in Sound Symbolism ............................................... 12

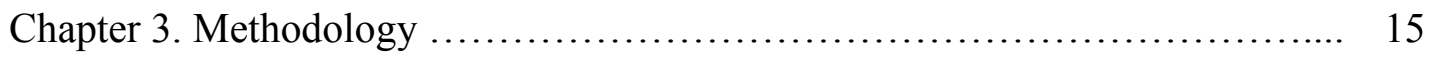

3.1 Pilot Study …........................................................................ 15

3.2 Participants ...................................................................... 16

3.3 Data Gathering ................................................................... 17

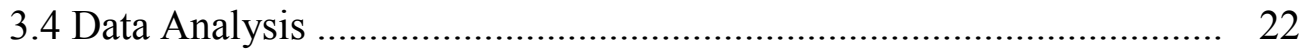

3.4.1 Quantitative Data ................................................... 22

3.4.2 Qualitative Data ...................................................... 23

Chapter 4. Results ............................................... 24

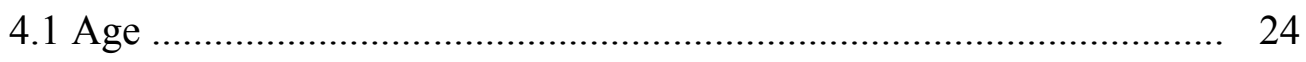




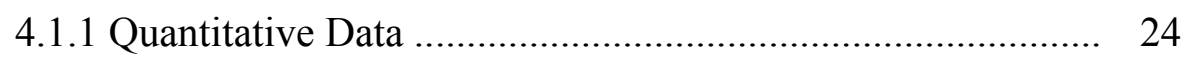

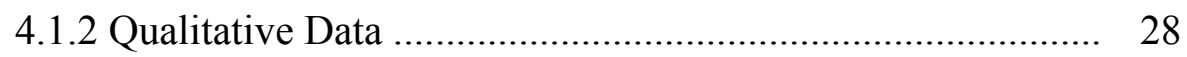

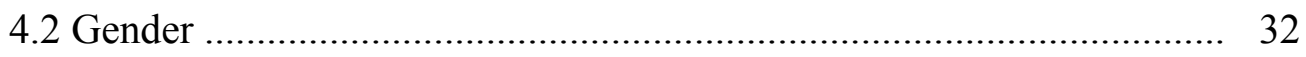

4.2.1 Quantitative Data ............................................................... 32

4.2.2 Qualitative Data ............................................................ 37

Chapter 5. Discussion ................................................ 41

5.1 Quantitative Results .................................................................... 42

5.2 Qualitative Results ...................................................................... 45

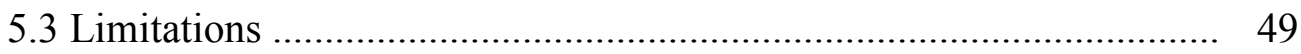

Chapter 6. Conclusions ............................................... 53

6.1 Recommendations for Future Research .......................................... 53

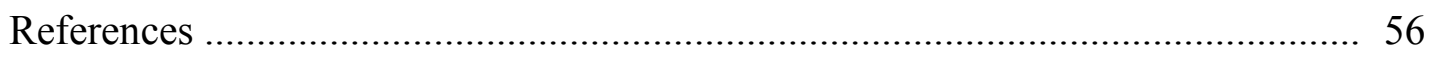

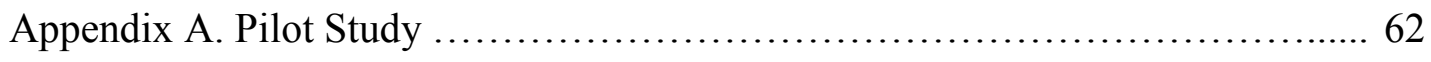

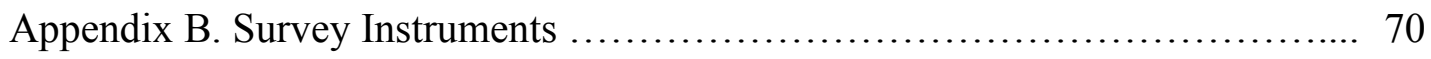

Appendix C. Survey Distribution .......................................... 79

Appendix D. Letter of Exemption from Portland State University

Human Subjects Research Review Committee ......................... 81

Appendix E. Means, Modes, and Medians, by Age ........................... 82

Appendix F. Means, Modes, and Medians, by Gender ....................................... 88

Appendix G. Results of Kruskal-Wallis Test, for Age ........................................... 91

Appendix H. Results of Mann-Whitney U Test, for Gender ................................... 93 
Appendix I. Results of Category Coding of Qualitative Data ............................. 95

Appendix J. Comparison of Qualitative Results ............................................... 101 


\section{List of Tables}

3-1 Demographic Distribution of Subjects ............................................... 17

3-2 Phonemes Targeted in this Study .......................................................... 19

4-1 Significant Results of Statistical Tests for Variation of Means,

by Age

4-2 Significant Results of Statistical Tests for Variation of Means,

by Age Clusters

4-3 Significant Results of Statistical Tests for Variation of Means,

by Gender

4-4 Distribution of Instances of Statistically Significant Variables, by Scale and Stimulus 


\section{List of Figures}

4-1 Statistically Significant Variation of Means, by Age ................................ 26

4-2 Statistically Significant Variation of Means, by Age Clusters .................... 28

4-3 Three Most Frequently Referenced Product Categories, by Age, Percent of Those Responding ......................................................... 29

4-4 Statistically Significant Variation of Means, by Gender ........................... 34

4-5 Three Most Frequently Referenced Product Categories, by Gender,

Percent of Those Responding ........................................................ 37 


\section{Chapter 1. Introduction}

Does a mil sound smaller than a mal? Does the brand name Vahnah sound more effective than the same product called Nahnah? Are the answers to these questions the same for twenty-somethings as they are for their grandparents? What about for males and females? Is sound symbolism a socially conditioned phenomenon?

The non-arbitrary connection of meaning to sound commonly known as sound symbolism is a sometimes controversial topic among linguists. Over time, however, the field has accumulated evidence that sound symbolism, also known as phonosemantics, is more than mere coincidence. While sound symbolism is commonly observed in languages around the world, not all associations have been found to be universal, varying from language to language and even region to region.

Some of the driving force behind the more recent studies exploring how sound symbolism functions has come from the fields of marketing and brand name creation. Marketers have utilized the skills of linguists to determine which combinations of sounds convey the appropriate attributes for the products they are selling. Imagine, for example, the differences in perception of Viagra, Levita, Uprima, and Cialis—brand names for different products that do essentially the same thing but seem to imply to the consumer different experiences simply by the way they sound (see discussion of Jespersen below).

One might think that marketers by now would have applied generalizations about sound symbolic associations in a more specific and systematic way, adding this strategy to their targeting of niche demographics such as age and gender in the same way that they 
choose particular linguistic features or cultural icons when attempting to attract a particular type of consumer. Because these demographic measures are found to be common factors in language variation, it would be logical to presume that age and gender would be variables that influence sound symbolism as well. Gender would be expected to cause synchronic variation while age would provide diachronic variation in aspects such as pronunciation, vocabulary, and the like. This assumption, however, has yet to be confirmed because little work has been done in this area, on behalf of the marketing industry or otherwise. In studies related to sound symbolism, age and gender demographics generally have been either unreported or incidental to other research questions. The purpose of this study, then, was to add to the existing body of research by investigating what effect age and gender have on sound symbolism in American English. A study of how demographic factors such as these affect sound symbolism can contribute to the understanding of how closely tied sound symbolism is to social structure, with implications that are relevant to both theory (empirical evidence for iconicity in language) and application (e.g., devising brand names that communicate particular attributes to specific demographics). 


\section{Chapter 2. Literature Review}

This study primarily draws on two areas of linguistics, namely sound symbolism and language variation. In this chapter, I begin with a brief overview of sound symbolism, sometimes referred to in the literature as phonosemantics or iconicity. Then I address the relevant areas of sociolinguistics pertaining to language varying by age and gender. I conclude this chapter by discussing what the existing literature says about the link between these two areas of concern and what this study may contribute to this body of research.

\subsection{Sound Symbolism}

As far back as ancient Greece, philosophers postulated that an individual phoneme carries with it an inherent meaning that shapes and informs the word. In Cratylus, Plato foreshadowed the study of sound symbolism by discussing what is thought of as a "correctness" to names, with Socrates suggesting the sound associated with the letter $r$ expresses motion (e.g., Klink, 2009). Contemporary linguists have been more precise in defining sound symbolism as the non-arbitrary correlation between sound and meaning (Magnus, 2013). The manifestations of these associations are referred to as phonesthemes, the case in which "a sound unit such as a phoneme, syllable, feature, or tone is said to go beyond its linguistic function as a contrastive non-meaning-bearing unit, to directly express some kind of meaning," more typically attributed to morphological or syntactic units (Nuckolls, 1999, p. 228). In English, for example, /fl-/ initial words often denote linear motion, such as in flow and fly; / kr-/ initial words often denote sudden impact, such as in crash and crush; and /gl-/ initial words often denote 
diffusion of light, such as in glow and glimmer (e.g., Bolinger 1940; Reilly, Biun, Cowles \& Peele, 2008). Like compound words, new lexical items can be created by accretion when phonesthemes combine, and semantic shift can occur when the meaning of one sound becomes associated with other sounds as the word evolves. Thus, over time, a phoneme may acquire a sound symbolic association it did not previously have.

The idea of sound symbolism, however, is not without controversy. Some scholars are critical of the notion and reject the premise. "The number of pictorial, imitative, or onomatopoetic non-derived words in any language is vanishingly small," asserted Newmeyer (1993, p. 758). Locke further reasoned that if word meaning were dependent on sound symbolism, then speakers should be able to immediately define words simply by their sounds, and there would exist only one language (1690/2013). To critics of sound symbolism, sound and meaning are primarily seen as arbitrarily associated and, therefore, any meaning can be represented by any set of sounds (Saussure, 1916/1959). Any apparent connection between sound and meaning, they argued, is a statistical aberration. "The linguistic sign is arbitrary," Saussure (1916/1959, p. 67) famously wrote, leading linguists for decades to rebuff any implicit accord between sound and meaning in language (Magnus, 2013).

Jespersen (1922), however, considered Saussure's assertions too extreme, campaigning instead for a middle ground, seeing the association more as a continuum:

Sounds may in some cases be symbolic of their sense, even if they are not so in all words.... There is no denying, however, that there are words which we feel instinctively to be adequate to express the ideas they stand for, and others the 
sounds of which are felt to be more or less incongruous with their signification. (pp. 397-398)

Subsequently, researchers have amassed a growing amount of empirical evidence in support of some degree of sound symbolism (Magnus, 2013), particularly in studies requiring subjects to match sounds represented by artificial words with definitions (Parise \& Pavani, 2011). Sound-to-meaning correspondences have been documented relating to size, speed, color, sound, and — more recently in the field of marketing and brandinghuman qualities and emotional attributes such as being daring and courageous. Sapir (1929), for example, wrote:

vocalic and consonantal contrasts tended with many, indeed with most, individuals to have a definite symbolic feeling — significance that seemed to have little relation to the associative values of actual words; that it made surprisingly little difference whether the phonetic contrast was contained in a phonetically "possible" or a phonetically "impossible" context; and that the certainty of the symbolic distinction tended to vary with the nature of the phonetic contrast. (p. 228)

In his experiments, Sapir found an overwhelming correlation (81\%) between size and sound using minimal pairs of artificial words contrasting /i/ and /a/, the former conveying a sense of smaller objects and the latter a sense of larger objects. This experiment has been replicated and extended many times in many languages with similar results, consistently showing that high front vowels (where the highest point of the tongue is in the front of the mouth) are associated with the properties of being clear, thin, bright, or 
flat, while low back vowels (where the highest point of the tongue is in the back of the mouth) have been associated with properties of being dark, large, thick, heavy, or obscure (e.g., Fischer-Jorgensen, 1978; Jakobson \& Waugh, 1987; Newman, 1933; Klink, 2000, 2003). Further support for Sapir's finding is provided by Ultan (1978), who reported that among the languages he surveyed that utilized diminutive endings, nearly $90 \%$ formed the diminutive using high front vowels.

Although vowels have been the focus of many of the studies, there are also cases where consonants have been shown to add consistent information to the meaning of the words, not only as an individual phoneme, such as /s/, but also in clusters, such as /st/, and sometimes whole groups, such as fricatives that include /s z $\int 3 /$ (e.g., Bloomfield, 1933, Hinton, Nichols, \& Ohala, 1994). Fricatives as a group (consonants in which there is partial closure of articulators but the airstream is not fully blocked), for example, were judged to be harsh, rough, active, sharp, difficult, or angular, while stops or plosives as a group (consonants in which there is complete closure of articulators so that all airflow from the mouth ceases, such as $/ \mathrm{p} /$ and $/ \mathrm{k} /$ ) were associated with qualities of abrupt, tight, rugged, or inhibited (Greenberg \& Jenkins, 1966/1990). In a 2003 study, Kelley, Leben, \& Cohen found that "fricatives sound symbolically faster than stops and that voiceless consonants are smaller and more luxurious than voiced consonants" (p. 4) (the latter typically representing sounds in which the vocal cords vibrate whereas in the former they do not, as in the difference between /v/ and /f/). Furthermore, Kelley, Leben, \& Cohen were able to assign attributes of sad, alive, insecure, and daring to particular clusters of features with surprising consistency. For example, 
$/ \mathrm{v} /$ was found to be substantially more alive and daring than /b/. However, in non-continuant sounds the opposite effect was found whereby voiced stops $/ \mathrm{b} \mathrm{d} \mathrm{g/} \mathrm{were} \mathrm{less} \mathrm{alive} \mathrm{and} \mathrm{daring} \mathrm{than} \mathrm{voiceless} \mathrm{stops} / \mathrm{p} \mathrm{t} \mathrm{k/.} \mathrm{(p.} \mathrm{6)}$

Thus, both consonants and vowels can have predictable and varied meanings.

Sound symbolism is sometimes concentrated in a single word class (Childs, 1994). For example, ideophones, especially common among African languages, are characterized by unusual properties such as raised pitch, reduplication, obscure origins, and such. As a whole, they rely on non-arbitrary relations between sound and meaning more than the rest of the lexicon. For example, in Igbo, a medial $/ \mathrm{k} / \mathrm{or} / \mathrm{g} /$ adds the context of back-and-forth, as in regerege ('swinging side to side') and kwakakwaka ('shaking side to side') (Maduka, as cited in Childs, 1994). Another example is the category of mimetics in Japanese that includes onomatopoeia for animal sounds as well as words related to events and states that are not dependent on sound (Imai, Kita, Nagumo, \& Okada, 2008). Here, combinations of the phonemes $/ \mathrm{g} /$ or $/ \mathrm{k} /$ with $/ \mathrm{r} /$ are often associated with rotation, voiced initial consonants are associated with larger masses while voiceless initial consonants are associated with smaller masses, and reduplication indicates repetition of an event. For example, koro ('a light object rolling'), guru ('a heavy object rotating around an axis'), and potapota ('thin/little liquid hitting a solid surface repeatedly') (p. 55).

Although sound symbolism is found in all languages to varying degrees with shared patterns among some languages (particularly in the subtypes of onomatopoeia and synesthesia), most specific (conventional) sound symbolic associations have not been 
found to be universal (Childs, 1994, 2014). This means that the /gl-/ cluster in English that is often associated with meanings involving something visual, especially in association with diffused light (Bloomfield, 1933), is not consistent through all languages. In fact, in another language, the /gl-/ cluster may convey a meaning that is completely unconnected to its English counterpart, if it exists at all. Even within a language, sound symbolism has been found to be subject to regional variation (Wright, 2012). Therefore, instead of searching for universals in sound symbolism, what may be more interesting and possibly more useful to examine is how it functions from a perspective of language variation.

\subsection{Language Variation and Change}

Language change involves differences in features over time, be it morphology, phonology, or syntax. In other words, contrasts are found in the speech, either that of a group or an individual, from different points in time (Chambers, Trudgill, \& SchillingEstes, 2004). There may be a phonological change, such as the Great Vowel Shift in English in which certain vowels underwent an upward chain shift, for example, changing goat from [go:t] to [go:t] (from GAUT to GOAT). The change may be morphological, such as when pease once meant 'one pea' or 'multiple peas' instead of the distinction made today between pea and peas. The change may also be a semantic shift, such as in how gay today rarely means 'happy' but rather 'homosexual'. Furthermore, there are now more speakers of English as a second language than native English speakers, creating new varieties of World Englishes with different, but still intelligible accents, vocabulary, and even syntax (McKay, 2012). 
While there are challenges to studying phonetic variation in particular, when the variables of individual styles are controlled, the remaining differences are no longer linguistic, but social (Gordon \& Heath, 1998). Socially significant variation may originate in language contact; influences of culture, communications, and technology; economic and political pressures; and movement, including invasion, migration, and colonization. Demographic factors such as age and gender also play important roles in shaping language change and variation (Chambers, Trudgill, \& Schilling-Estes, 2004).

2.2.1 Variation by Age. When looking at variation by age, three distinct phenomena are considered. First, there are instances of age-grading, which are ephemeral "changes in the use of a variant that occur at a particular age in successive generations" (Chambers, 2009, p. 200). These include, for example, common nursery words, such as horsie, that are later unconsciously eliminated from adult speech. These variants do not represent an evolution of language, but rather cyclic periods of what is, essentially, generational slang that speakers adopt and later leave behind. In this manner, language change for the individual is abrupt even as the larger community remains unchanged (Meyerhoff, 2011).

Second, there is lifespan change, or change over time within an individual that takes place after the critical period (the time in which language learning generally is considered the easiest, typically childhood up to adolescence) and is consistent with a gradual change over time in the speaker's larger community (Meyerhoff, 2011). Lifespan change has been observed in longitudinal studies such as Harrington (2007), who measured speech data from annual broadcasts by Queen Elizabeth II from 1952 to 2002 
and noted a gradual vowel shift unexplained by physiological maturation of the vocal system or age-graded changes. Other examples include the change from apical to dorsal $/ \mathrm{R} /$ in Montreal French (Sankoff \& Blondeau, 2007), as well as changes in word choice and linguistic style over an individual's lifetime (Pennebaker \& Stone, 2003). Because the individual's speech change is generally consistent with the community's speech change, this type of age-related phenomena may not be detectable in this study.

Finally, there is generational change, or change over time so that the speech of one's parents or ancestors is different from one's own speech, which, in turn, is not the same as later generations' speech. In this scenario, a variable continues to evolve with each subsequent generation, and change is more extensive than within the speech of one individual (Meyerhoff, 2011). As an example, vocabulary not only changes across generations, but may also undergo semantic shifts in reaction to changes in phonological structure, leading to new meanings and forms (Magnus, 2013). For instance, the shift from $/ \mathrm{r} /$ to $/ \mathrm{R} /$ in Montreal, which began as a lifespan change, became so pervasive as to illustrate a generational change (Meyerhoff, 2011). This, in particular, is the type of agerelated language variation that this study was interested in exploring because if there are changes in phonology over time, there may also be accompanying shifts in sound symbolism as the sound associated with a meaning is replaced by another.

2.2.2 Variation by Gender. Differences in speech between males and females have been some of the most consistent findings in sociolinguistic research (e.g., Gordon \& Heath, 1998; Newman, Groom, Handelman, \& Pennebaker, 2008). In a summary of the research through the 1980s, Labov (1990) supplied two principles reflecting a 
traditional view of gender-preferential phenomena in language: men use nonstandard forms of speech more frequently than women, and women more frequently use the incoming variant. In one example, Gordon \& Heath (1998) suggested an asymmetry in which not only do men and women favor different vowel spaces, but women lead linguistic changes. They presented examples such as the case in Belfast where females more frequently led the shift from low to high front vowels while males led the shift toward backing and rounding of / $\mathrm{a} /$. More recently, however, linguists have further clarified these cases as being less the effect of a speaker's gender and more a result of their cultural and social roles and networks as men and women (Meyerhoff, 2011).

This is not to completely rule out sex-based biological factors. Ohala, for example, in work where he employed the term frequency code, suggested patterns for meaning based on contrasts with fundamental frequency, or pitch. He wrote, for example, that high frequencies associated with high front vowels and palatal consonants (and even high tones in tonal languages) conveyed the idea of smallness in size, politeness, deference, or submission. Ohala stated, "The phonetic generalization that can be made is that the expression of size utilizes speech sounds whose characteristic acoustic frequencies vary inversely with size of the thing designated" (1997, p. 2). How this biological connection between sound and symbolism is socialized, and its variation by gender, is a debate for another paper. Suffice it to say that between males and females, there exist what are largely subconscious preferences in language use extending across various functions. Whether social or biological, variation by gender is not uncommon. 


\subsection{Variation in Sound Symbolism}

Because age and gender are two variables that commonly influence language variation, it is logical to speculate that similar influences would extend to sound symbolism. In other words, phonosemantic variation would be expected between older and younger speakers and between male and female speakers. Yet little empirical evidence has been presented to support this conclusion since few studies of sound symbolism have collected or reported the effects of age or gender. Those studies that have looked at variable sound symbolism have used convenience samples that did not represent a cross section of the population.

In the cases where the effects of age and gender were addressed, the findings have been mixed. Newman (1933) reported no effect for age, but his subjects were young students within a narrow range of ages, not representing multiple generations. In examining whether there are sound-meaning correspondences related to human qualities such as sad, alive, insecure, and daring, Kelly, Leben, \& Cohen (2003) also reported no effect for age, sex, or even geographic location in the U.S. Yet in a study of the effects of culture, environment, age, and musical training on choices of visual metaphors for sound — an experiment not unrelated to sound symbolism—Walker (1987) observed that age was a factor, albeit a minor one in relation to the other variables studied, in which results for the group of elementary age students were statistically different than for the group of adults. Furthermore, a significant amount of contemporary sound symbolism research has focused on promoting commercial products, specifically in the niche of brand name creation (e.g., Klink, 2000; Lowrey \& Shrum, 2007). In a study of gender 
responses to new product brand names, Klink (2009) found evidence similar to earlier work (e.g., Sapir, 1929) indicating a general female preference for front versus back vowels (although not a male preference for back vowels). He concluded, however, that "the gender effect dissipates as the importance of the product's masculinity-femininity attribute decreases" (p. 323). In other words, Klink implies a correlation between a product's perceived masculine-feminine attributes and the sound symbolic associations assigned by each gender, and that this correlation is all the more evident when the product's attribute is more strongly masculine or feminine.

But the waters here are muddy. In an attempt to make their subjects more comfortable with assessing artificial words, researchers such as Klink asked them to imagine that the artificial words presented were new brand names under consideration for a product such as a sport utility vehicle or a knife. These studies focused on implications for marketing and, as such, their intent was to learn how sound symbolism influenced brand preferences concerning a specific product rather than to analyze responses on a purely phonosemantic basis. It is unclear if this degree of specificity influenced the subjects' responses by conflating participants' associations of the product (e.g., the inherent qualities of the sport utility vehicle or the knife) that they were asked to imagine with their interpretation of the sound symbolism of the artificial words presented to them. Klink argued that these products have "seemingly little masculinity-femininity attribute importance" (2009, p. 333), but no test was reported to determine first whether, for example, a sport utility vehicle would be perceived as feminine and a knife as masculine, or if study participants would generally consider these objects to be gender neutral. It is 
uncertain if those underlying assignations influenced the subjects' choices for preferred brand names, passing along any perceived masculine or feminine attributes to the artificial names and the phonemes they represented.

The lack of convincing evidence for an effect of age and gender on sound symbolism, therefore, may be due more to a lack of explicit investigation than an absence of correlation. The purpose of this study, then, was to examine the correlation of sound symbolic associations with age and gender. Specifically, this study asked the following research question: Is age or gender a significant factor in how sound symbolism is perceived by speakers of American English?

This study tested two hypotheses:

1. There will be a statistically significant difference in sound symbolic associations between younger and older individuals.

2. There will be a statistically significant difference in sound symbolic associations between males and females. 


\section{Chapter 3. Methodology}

To explore language variation in sound symbolism, I conducted a mixed-method analysis of data collected via an online survey of speakers whose L1 was American English. Participants were asked to rate artificial words on semantic differential scales of polar-opposite adjectives (e.g., whether a word with a initial sound /k/ seems harder or softer than the same word beginning with a different sound, such as /v/) as well as to suggest the product they had imagined the artificial word to represent. I examined the resulting data for statistically significant differences in responses between males and females and among three generational age groups, as well as the interaction among these variables. In this chapter, I first discuss the preparatory pilot study. Then I describe the solicitation of the participants and their demographics. I conclude with a review of the strategies for gathering and analyzing the data.

\subsection{Pilot Study}

Before beginning the experiment, I conducted a pilot study in order to identify potential problems with the instrument's design, specifically in terms of its size and structure, question context and format, the choice of artificial words, and the general logistics and security of the online survey technology. Appendix A discusses the results in detail. The amount and quality of data, along with general feedback from the pilot study participants about their experiences, shaped the final survey instrument, which appears in Appendix B. 


\subsection{Participants}

To conduct this study, I recruited participants primarily via notices placed on a variety of Craig's List websites across the U.S., research study recruitment websites, and social media. Appendix C provides a comprehensive list of these resources. Although geographic region was not specific to the research questions of this study, I asked participants to report their respective state of residence in order to ensure a diverse sample of American English speakers and to be able to consider this factor in future analyses. A total of 532 individuals attempted the survey, and data from 292 participants were ultimately used in this study. These 292 participants were those who completed all 60 scales of the survey and self-identified as speaking American English as their L1; were currently residing in the U.S.; self-identified as exclusively male or female; and indicated they were 18-23 years old, 26-48 years old, or 51 years or older. ${ }^{1}$

Table 3-1 shows the distribution of survey participants by demographic variable. The columns represent the three generational age groups while the rows represent the two genders grouped by geographic region. The Eastern U.S. includes states situated primarily in the Eastern Time Zone; the Western U.S. includes states situated primarily in the Pacific Time Zone. The Central U.S. includes states situated primarily in either Central or Mountain Time Zones. While my goal was to have at least five participants in each combination of age, gender, and geographic region, this was not achieved in the

\footnotetext{
${ }^{1}$ Allowing for two-year gaps between segments to better isolate each division, the three age groups roughly correspond to three contemporary generations, namely Millennials, Generation Xers, and Baby Boomers (McCrindle \& Wolfinger, 2011; CNN, 2011).
} 
case of Millennial-aged males from the Central U.S., of which there were only three survey participants. Furthermore, because participants were recruited largely via social media originating from my personal, Oregon-based connections, the representation of participants from the Western U.S. was significantly higher than other geographic locations. Because this was not a variable that I was measuring, I did not control for geographic distribution in this sample.

Table 3-1

Demographic Distribution of Subjects

Millennials 18-23 years old
Generation Xers Baby Boomers

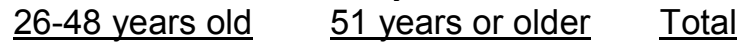

Eastern U.S.

Males

Females

5

$\frac{11}{16}$

Central U.S. Males

Females

3

$\frac{8}{11}$

Western U.S. Males

Females

10
$\frac{17}{27}$

Total

$\begin{array}{ll}\text { Males } & 18 \\ \text { Females } & \frac{36}{54}\end{array}$

9

$\frac{29}{38}$

8

$\frac{19}{27}$

19

$\frac{59}{78}$

36

$\frac{107}{143}$

\section{6 \\ $\frac{21}{27}$}

$\begin{array}{cc}5 & 16 \\ 18 & \frac{45}{61}\end{array}$

$11 \quad 40$

$\frac{34}{45} \quad \frac{110}{150}$

$22 \quad 76$

$\frac{73}{95} \quad \frac{216}{292}$

\subsection{Data Gathering}

Data were gathered via an online survey written in English using Portland State University's secure Qualtrics survey platform. No identifying information was collected. Instead, each survey participant automatically received a computer-generated identification number along with the date and time the survey was submitted. Prior to 
completing the questionnaire, participants were provided with proper disclosures for human subject participation, which can be found in the survey instrument in Appendix B, as approved by Portland State University's Human Subjects Research Review Committee (HSRRC) Institutional Review Board (IRB). A copy of its approval letter appears in Appendix D.

The survey contained 75 questions. Participants began by answering nine demographic questions regarding age, gender, L1 and additional languages spoken, where they grew up and how many years they spent there; where they live now and how many years there; and level of education. Participants then were asked to rate six artificial words on 10 semantic differential scales, which can be described as bipolar seven-step scales defined by verbal opposites (Osgood, May, \& Miron, 1975). A multi-point scale was chosen in order to provide for an indication of both direction and intensity of judgment (Osgood, Suci, \& Tannenbaum, 1959/1969). For each artificial word, participants were also asked to specify what product they imagined the artificial word represented. According to information provided by the Qualtrics software, the survey took most participants between five and 15 minutes to complete.

Questions regarding sound symbolism addressed the phonemes /i a k n v/. The vowels represented general characteristics of high front and low back phonemes commonly utilized in previous studies of sound symbolism, a choice made to facilitate comparison of my results with those of existing research (e.g., Sapir, 1929, Jakobson \& Waugh, 1987; Klink, 2000, 2003). In addition, these vowels offered significant contrast in sounds even when allowing for allophones and individual interpretations of spelling 
that could arise when a participant is reading an artificial word rather than hearing it pronounced aloud. Accommodating for these potential variations permitted an unambiguous written survey rather than a more complicated version requiring audio recordings or a live interview.

Table 3-2 shows the distribution of the contrasting qualities of the phonemes selected as the focus of this study. Here, each phoneme of the study is classified as either voiced or voiceless (or, in the case of vowels, open or close) as well as defined by its point of articulation and manner of articulation.

Table 3-2

Phonemes Targeted in this Study

\begin{tabular}{lllll}
\hline Phoneme & $\begin{array}{l}\text { Voiced or } \\
\text { Voiceless }\end{array}$ & $\begin{array}{l}\text { Close or } \\
\text { Open }\end{array}$ & $\begin{array}{l}\text { Point of } \\
\text { Articulation }\end{array}$ & $\begin{array}{l}\text { Manner of } \\
\text { Articulation }\end{array}$ \\
\hline$/ \mathrm{k} /$ & voiceless & - & velar & stop \\
$/ \mathrm{n} /$ & voiced & - & alveolar & nasal \\
$/ \mathrm{v} /$ & voiced & - & labio-dental & fricative \\
$/ \mathrm{li} /$ & - & close & high front & unrounded \\
$/ \mathrm{a} /$ & - & open & low back & unrounded
\end{tabular}

The consonant sounds were chosen to represent a variety of distinct manners of articulation, namely a stop, a nasal, and a fricative. They also represented both voiced and unvoiced options as well as variations in place of articulation. These particular vowel and consonant combinations, including the consistent medial consonant $/ t /$, were also chosen 
because, while their pairings did represent possible sound combinations allowed in English phonology, they did not represent actual known words in the English lexicon. Furthermore, the medial / $t$ / is one of the most frequent consonants used in English and has little effect on the sounds of adjacent vowels. While / $t /$ in this environment is often pronounced /d/, this was not deemed to be a problem. Either sound would provide a consistent consonant, and neither was a phoneme that was being studied. All together, these highly contrastive sounds provided the articulatory and perceptual distance that permitted a simple written survey rather than a more complicated version requiring audio recordings.

In the survey, these phonemes were presented to participants in the form of six contrasting artificial words, with the target consonants in the initial position followed by reduplicated target vowels separated by the medial consonant $/ t /$, and with initial capitalization to represent brand names, as below:

$\begin{array}{lll}\text { Keetee } & \text { Neetee } & \text { Veetee } \\ \text { Kahtah } & \text { Nahtah } & \text { Vahtah }\end{array}$

Participants were asked to rank each of these six artificial words independently according to 10 different scales. Four of these scales were drawn from existing sound symbolism research (e.g., Sapir, 1929) and could therefore serve as a point of comparison with existing data. These included:

$\begin{array}{ll}\underline{\text { i } /} & \underline{\text { a } /} \\ \text { fast } & \text { slow } \\ \text { light } & \text { heavy }\end{array}$




$\begin{array}{ll}\text { soft } & \text { hard } \\ \text { thin } & \text { thick }\end{array}$

Three additional scales were based on research by Magnus (1999) that suggested the following associations of meaning for the consonants represented in this study. While Magnus's research presented a number of possible associations for each phoneme, I chose the more frequent association and paired it with an antonym to create the following bipolar adjective scales, as below:

$\begin{array}{ccc}/ \mathrm{k} / & \text { closed } & \text { open } \\ / \mathrm{n} / & \text { narrow } & \text { wide } \\ / \mathrm{v} / & \text { energetic } & \text { lazy }\end{array}$

I chose the remaining three scales because they represented spectrums of judgment that have commonly polarized society, areas that I believed would also illustrate common divides among age groups and between genders, and would therefore show a change in sound symbolism among those variables. These included:

$\begin{array}{ll}\text { liberal } & \text { conservative } \\ \text { religious } & \text { secular } \\ \text { rural } & \text { urban }\end{array}$

In previous studies designed for marketing purposes, researchers often offered contextual information, asking participants to imagine the word as a brand name for a specific product, such as a sport utility vehicle, a knife, or a computer. To isolate the participant's opinion solely on a word's particular sound without any possible influence of pre-determined subject matter, I asked participants simply to imagine the artificial 
words were potential brand names for a new product without actually identifying the product. The survey instrument in Appendix B includes the preamble presented to the participants describing this fictitious marketing scenario. For each of the six stimuli, I concluded by asking participants to identify what product or products they were imagining to be associated with the artificial word.

\subsection{Data Analysis}

3.4.1 Quantitative Data. I analyzed the resulting quantitative data for variation in responses by the independent variables of age and gender, and interaction of the two together. I began by compiling descriptive statistics, such as mean, median, and mode, for each of the demographic groups. These data appear in Appendices E and F. I used SPSS Statistics software to review histograms and conduct Kolmogorov-Smirnov and ShapiroWilk assumption tests. Because many of the histograms depicted data that were not normally distributed, and none of the results of the assumption tests exceeded 0.05 , I analyzed the ordinal data using nonparametric tests ${ }^{2}$ - namely, the Kruskal-Wallis oneway analysis of variance (for age) and the Mann-Whitney U test (for gender) - in order to ascertain if the differences, if any, were statistically significant $(\mathrm{p}<0.05)$. The results of

\footnotetext{
${ }^{2}$ Because data of several histograms appeared to be normally distributed, I was curious to know what might be learned if parametric tests were used. Therefore, I also used SPSS to perform an independent $\mathrm{T}$ test (for gender) and an ANOVA test (for age). The results were nearly identical as those of the nonparametric tests, and so I proceeded to focus on the more conservative, non-parametric tests of the data.
} 
the Kruskal-Wallis test appear in Appendix G, while the results of the Mann-Whitney U test appear in Appendix H.

As another way to better distinguish among the three age groups, I also extracted a subset consisting of 67 records composed of 21 of the youngest Millennials (18-20 years old), 24 of the oldest Baby Boomers (66-84 years old), and 22 of Generation Xers clustered at the middle-age point (36-38 years old). Again, I conducted a Kruskal-Wallis test followed by post-hoc Mann-Whitney U tests to determine differences that were statistically significant $(\mathrm{p}<0.05)$.

3.4.2 Qualitative Data. I analyzed the qualitative data in two ways. First, I performed a simple word count using online software at textfixer.com to determine the most frequently appearing words for each of the stimuli, ignoring generic terms (e.g., something, product, use) and common words (e.g., the, is, to). Second, another rater (a Millennial female) and I (a Generation X male) assigned each qualitative response to one or more categories using a standard product taxonomy (Google, 2014), as well as noting frequently occurring themes or attributes (e.g., fast, soft, clean, foreign). The coding data appear in Appendix I. Empty responses, or indeterminate responses such as "Nothing" or "I couldn't think of anything," were disregarded, resulting in variable numbers of responses for each artificial brand name. Discrepancies between raters were negotiated and resolved without issue. The frequency of each category then was determined as a percentage of responses to that question. 


\section{Chapter 4. Results}

In this chapter, I present the results of the analysis, first by age, then by gender. Within each section, I discuss both quantitative and qualitative data.

\subsection{Age}

4.1.1 Quantitative Data. Six artificial words rated on 10 scales yielded data from a total of 60 scales. Among the means by age, an arbitrary difference of 0.25 or greater was found on 37 of the 60 scales, or $61.7 \%$ of the time. Twenty-six of the 60 scales (43.3\%) were monotonic, meaning that the means increased or decreased from youngest to oldest. Among the modes, variation of at least one point on the seven-point scale appeared in 27 of the 60 scales, or $45.0 \%$. According to the results of the Kruskal-Wallis test, however, only three of the 60 scales $(5.0 \%)$ indicated statistically significant differences $(p<0.05)$ as to age among the responses from Millennials, Generation Xers, and Baby Boomers. These were for the words Kahtah on the scale of soft-hard, Vahtah on the scale of soft-hard, and Keetee on the scale of liberal-conservative. Post-hoc MannWhitney U tests indicated that Baby Boomers stood apart from the other two age groups for the word Vahtah on the soft-hard scale, while Millennials were the dissimilar group for the other two instances.

Table 4-1 shows the test results for the three semantic differential scales where statistically significant variation by age was found. Each row represents a different artificial word, while the columns indicate which scale and to what level of significance variation occurred. 
Table 4-1

Significant Results of Statistical Tests for Variation of Means, by Age

\begin{tabular}{|c|c|c|c|c|c|c|c|}
\hline \multirow[b]{3}{*}{ Stimulus } & \multirow[b]{3}{*}{ Scale } & \multicolumn{6}{|c|}{ Post-Hoc Mann-Whitney U Test } \\
\hline & & \multicolumn{3}{|c|}{ Kruskal-Wallis Test } & \multicolumn{3}{|c|}{$\underline{\text { Significance for Groups }}$} \\
\hline & & Chi-Square & $\mathrm{df}$ & Asymp. Sig. & $1 \& 2$ & $2 \& 3$ & $1 \& 3$ \\
\hline Kahtah & soft-hard & 16.396 & 2 & .000 & .004 & .091 & .000 \\
\hline Vahtah & soft-hard & 10.366 & 2 & .006 & .132 & .035 & .001 \\
\hline Keetee & $\begin{array}{l}\text { liberal- } \\
\text { conservative }\end{array}$ & 7.095 & 2 & .029 & .012 & .963 & .002 \\
\hline$p<0.05$ & & & & & & & \\
\hline Group 1 & Millennials & & & & & & \\
\hline Group 2 & Generation Xers & & & & & & \\
\hline Group 3 & Baby Boomers & & & & & & \\
\hline
\end{tabular}

Figure 4-1 plots the means of each age group along the semantic differential scales in which statistically significant variation was found. Here, we can see that the artificial brand name Kahtah is perceived by Baby Boomers to be much more associated with the quality of soft in contrast to Millennials, who consider the word to be more semantically tied to the quality of hard. Similar results are found for the artificial brand name Vahtah. Statistically significant variation was also found for the word Keetee along the scale of liberal-conservative. 
Figure 4-1

Statistically Significant Variation of Means, by Age

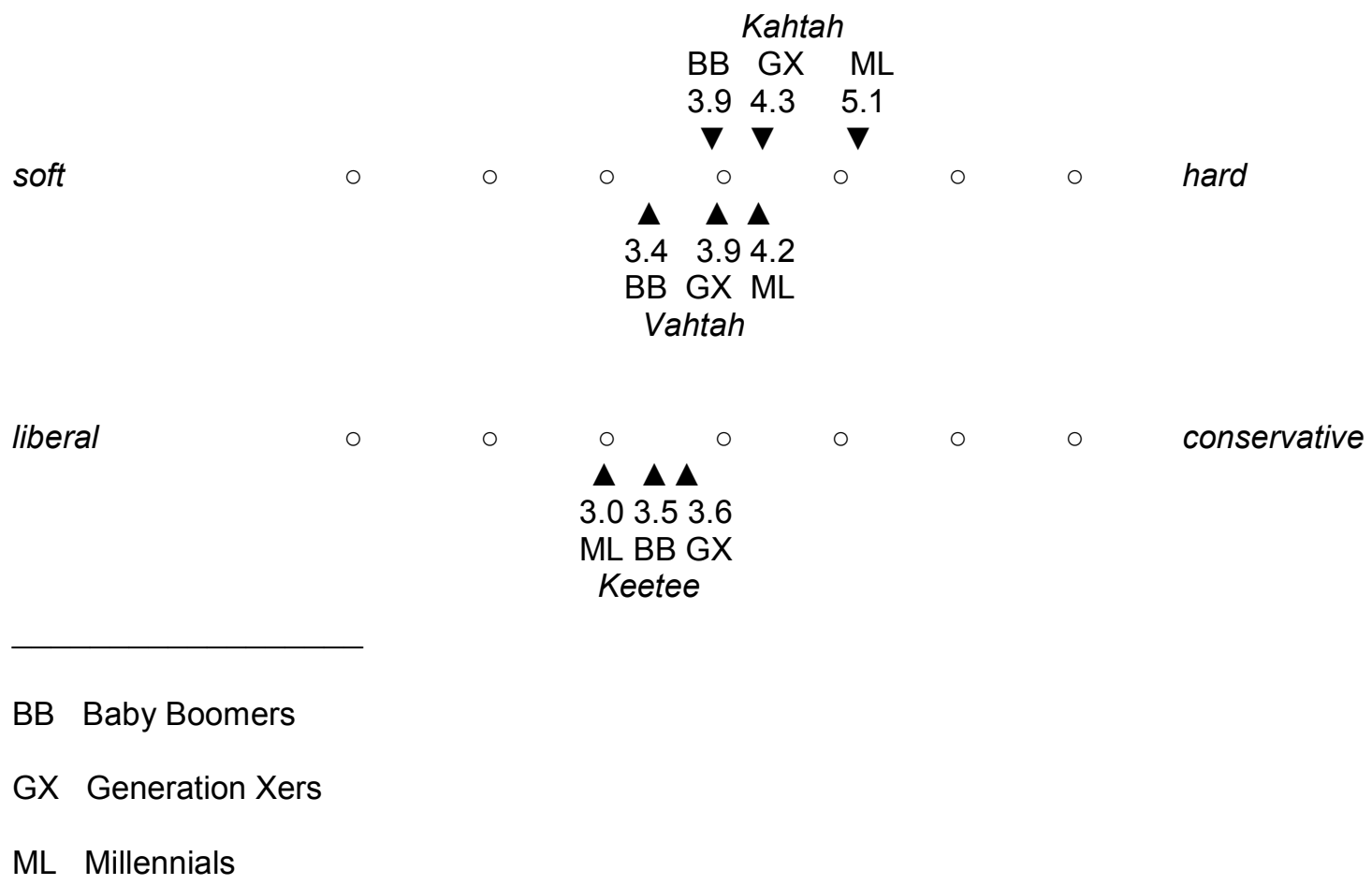

A similar analysis of the quantitative data clustered by age (representing the youngest subjects, the oldest subjects, and the subjects nearest the midpoint of the age range) presented five scales indicating statistically significant differences among the three groups. However, as illustrated in Table 4-2 and Figure 4-2, the significant scales for the age clusters were not the same as the significant scales for the whole population. They were Keetee on the scales of narrow-wide and religious-secular, Nahtah on the scale of slow-fast, Neetee on the scale of narrow-wide, and Veetee on the scale of slow-fast. In this case, the subsequent post-hoc Mann-Whitney U tests did not as clearly define a graduated shift, instead pointing toward the middle age group of Generation $\mathrm{X}$ as the 
segment that was statistically different than the other two. Table 4-2 shows the test results for the five semantic differential scales where statistically significant variation by age was found, while Figure 4-2 plots the means of each age group along those semantic differential scales.

Table 4-2

Significant Results of Statistical Tests for Variation of Means, by Age Clusters

\begin{tabular}{|c|c|c|c|c|c|c|c|}
\hline \multirow[b]{3}{*}{ Stimulus } & \multirow[b]{3}{*}{ Scale } & \multicolumn{6}{|c|}{ Post-Hoc Mann-Whitney U Test } \\
\hline & & \multicolumn{3}{|c|}{ Kruskal-Wallis Test } & \multicolumn{3}{|c|}{ Significance for Groups } \\
\hline & & Chi-Square & df & Asymp. Sig. & $1 \& 2$ & $2 \& 3$ & $1 \& 3$ \\
\hline Keetee & $\begin{array}{l}\text { narrow- } \\
\text { wide }\end{array}$ & 9.416 & 2 & .009 & .005 & .013 & .940 \\
\hline Nahtah & slow-fast & 8.682 & 2 & .013 & .303 & .005 & .038 \\
\hline Neetee & $\begin{array}{l}\text { narrow- } \\
\text { wide }\end{array}$ & 8.507 & 2 & .014 & .008 & .881 & .016 \\
\hline Veetee & slow-fast & 7.592 & 2 & .022 & .674 & .006 & .060 \\
\hline Keetee & $\begin{array}{l}\text { religious- } \\
\text { secular }\end{array}$ & 6.100 & 2 & .047 & .291 & .202 & .011 \\
\hline$p<0.05$ & & & & & & & \\
\hline Group 1 & Millennials & & & & & & \\
\hline Group 2 & Generation Xers & & & & & & \\
\hline Group 3 & Baby Boomers & & & & & & \\
\hline
\end{tabular}


Figure 4-2

Statistically Significant Variation of Means, by Age Clusters

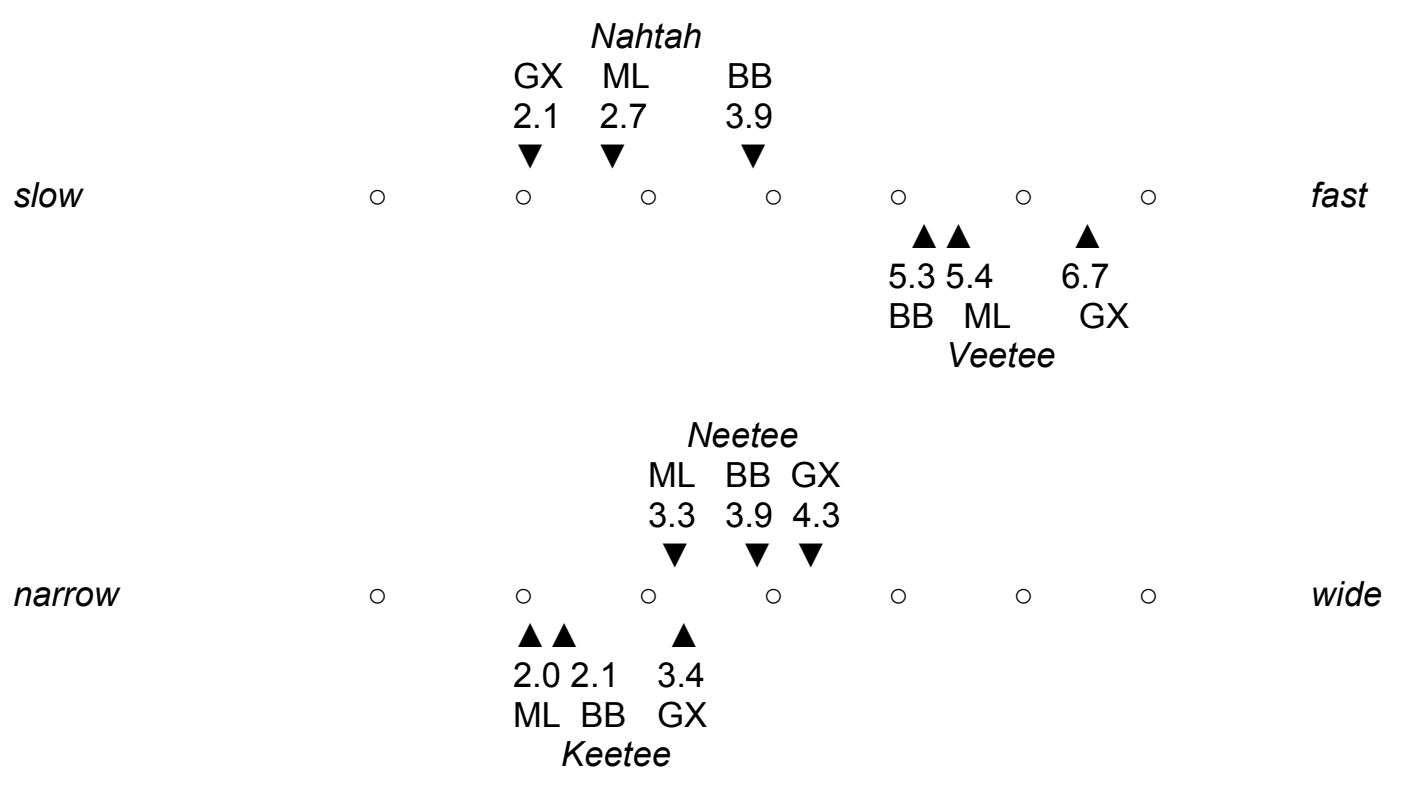

religious

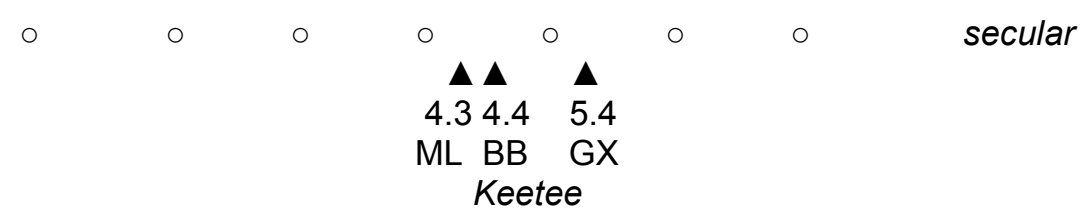

BB Baby Boomers
GX Generation Xers
ML Millennials

4.1.2 Qualitative Data. Figure 4-3 and the tables in Appendix I illustrate the distribution of qualitative responses among a standard taxonomy of product categories (Google, 2014). The graphs represent the three most frequently referenced product categories as a percent of responses grouped by age (e.g., 22.7\% of Baby Boomers said 
the word Keetee represented a product in the category of Animals \& Pet Supplies). A single figure with side-by-side results for all six words appears in color in Appendix J.

Figure 4-3

Three Most Frequently Referenced Product Categories, by Age, Percent of Those Responding

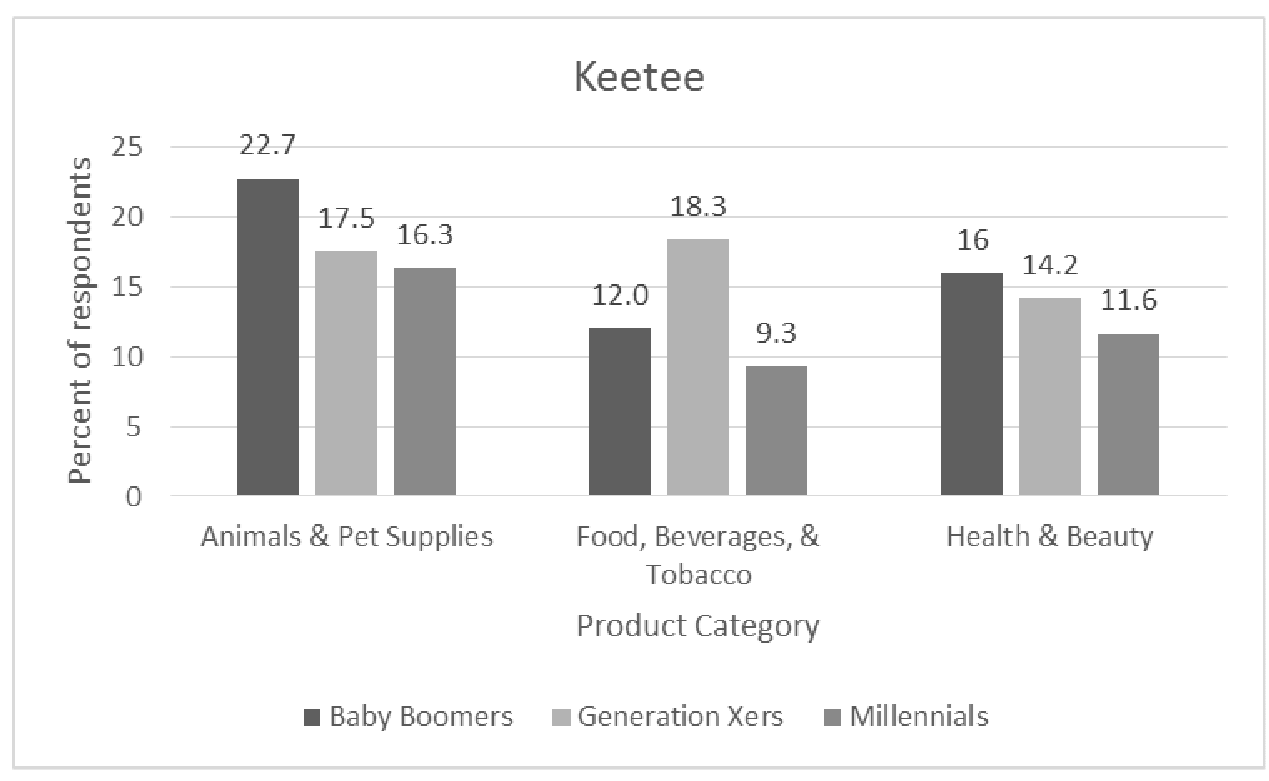

Most frequent references: cat, toy

$n=238$ 


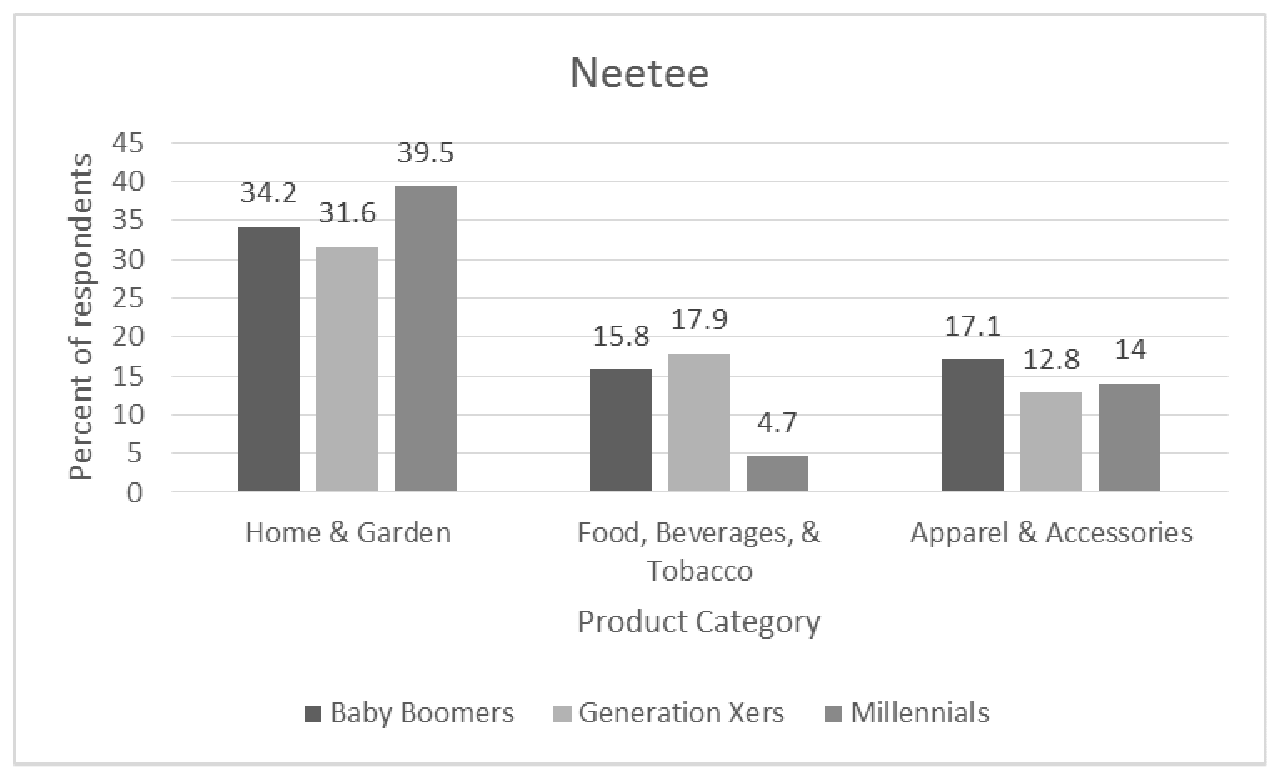

Most frequent references: cleaning, tea, shirt $n=236$

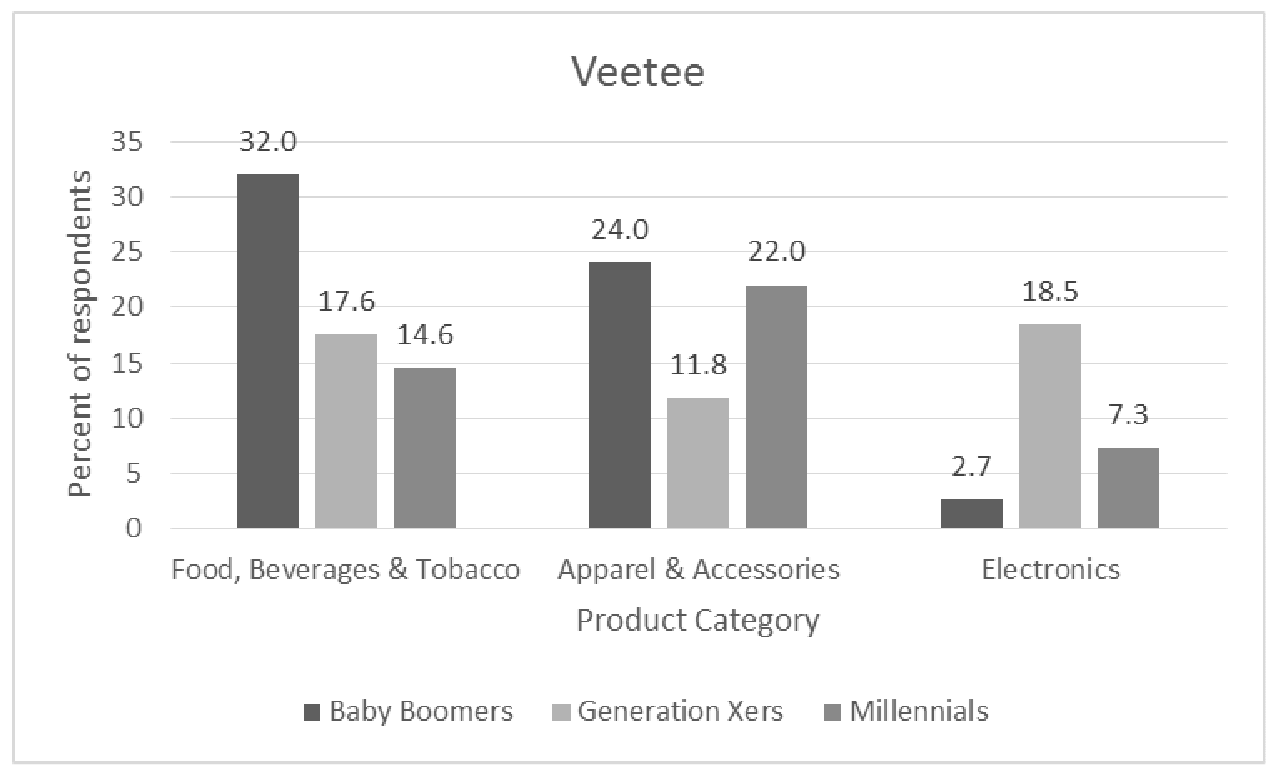

Most frequent references: shirt, drink, car, food, tea, energy $n=235$ 


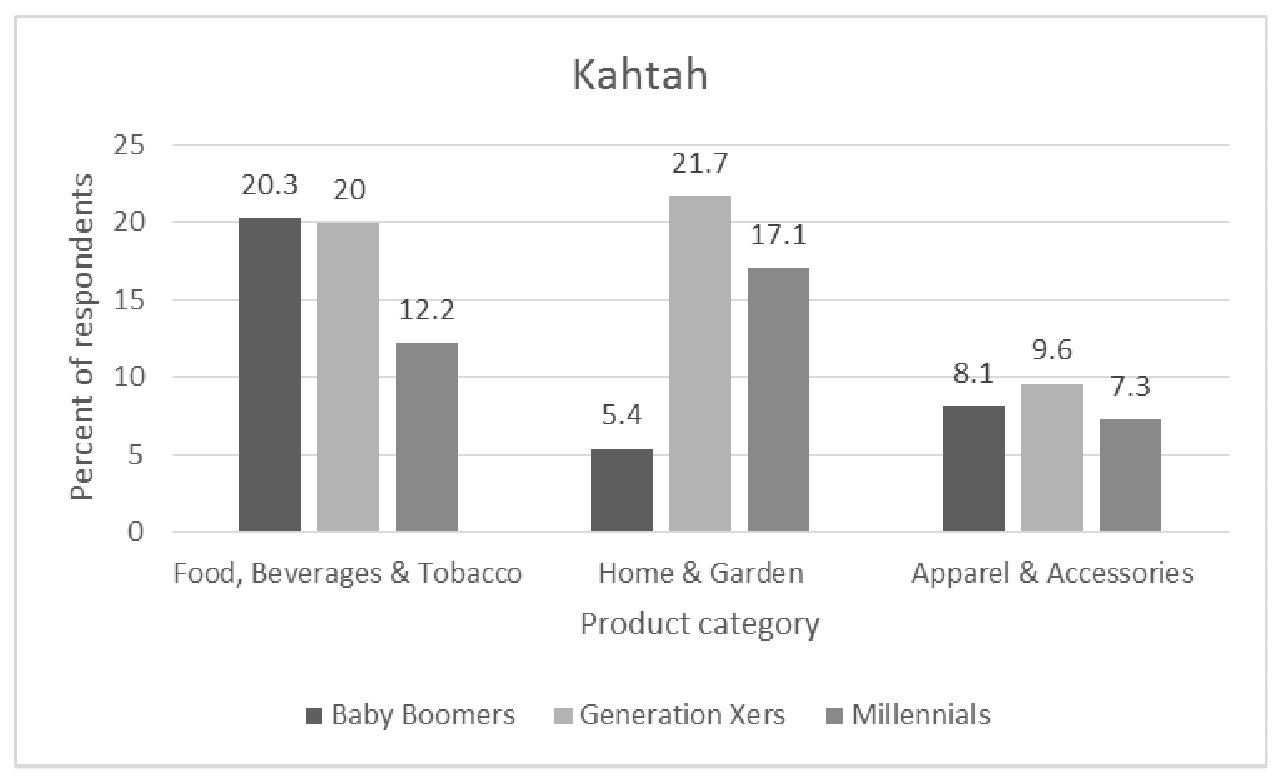

Most frequent references: knife, food

$n=230$

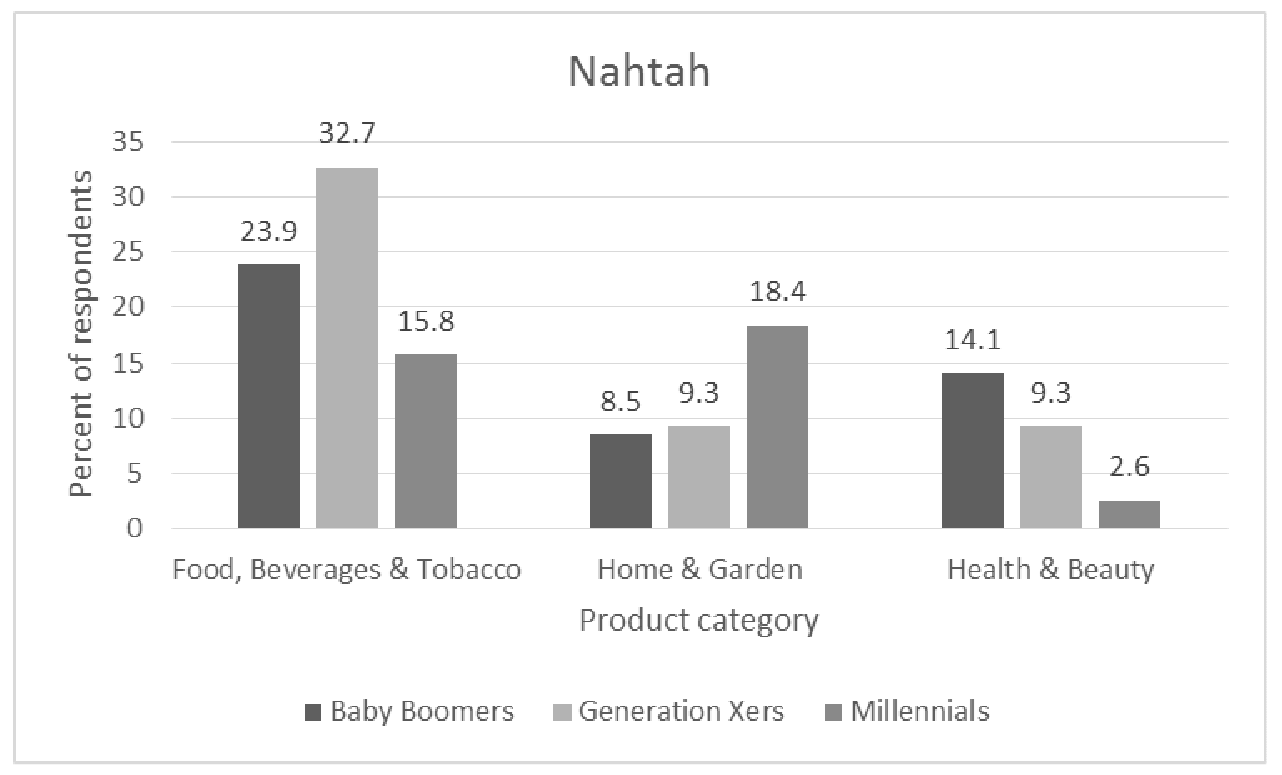

Most frequent reference: food

$n=216$ 


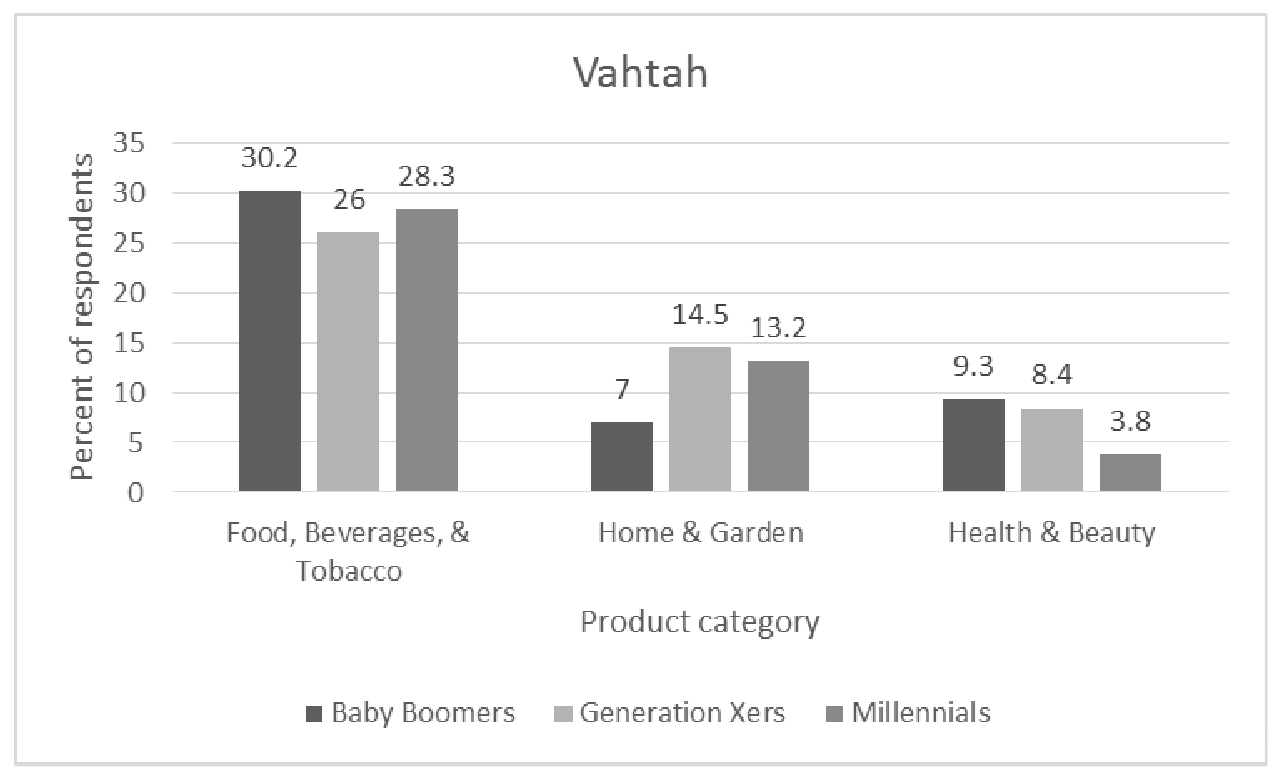

Most frequent references: water, car

$n=270$

\subsection{Gender}

4.2.1 Quantitative Data. Among the means by gender, an arbitrary difference of 0.25 or greater was found on 13 of the 60 scales, or $21.7 \%$. The modes differed in 19 of 60 scales, or $31.7 \%$ of the time. According to the results of the Mann-Whitney U test, however, five of the 60 scales $(8.3 \%)$ presented statistically significant differences $(p<0.05)$ between the responses from males and females. These were for the word Kahtah on the scales of liberal-conservative and soft-hard, and for the word Vahtah on the scales of liberal-conservative, religious-secular, and closed-open.

Table 4-3 shows the test results for the five semantic differential scales where statistically significant variation by gender was found. Each row represents a different 
artificial word, while the columns indicate where (which scale) and to what level of significance variation occurred.

Table 4-3

Significant Results of Statistical Tests for Variation of Means, by Gender

\begin{tabular}{llllll}
\hline Stimulus & Scale & Mann-Whitney U & Wilcoxon W & Z & $\begin{array}{c}\text { Asymp. Sig. } \\
\text { (2-tailed) }\end{array}$ \\
\hline Kahtah & liberal- & 6649.500 & 30085.500 & -2.670 & .008 \\
& conservative & & & & \\
Vahtah & liberal- & 6808.000 & 30244.000 & -2.319 & .020 \\
& conservative & & & & \\
Vahtah & religious- & 6820.000 & 30256.000 & -2.280 & .023 \\
& secular & & & & \\
Vahtah & closed-open & 6901.500 & 9827.500 & -2.108 & .035 \\
& & & & & \\
Kahtah & soft-hard & 6948.000 & 30384.000 & -2.019 & .044
\end{tabular}

Figure 4-4 plots the means of each gender along those semantic differential scales. Here we can see that while the difference may be statistically significant, the effect is small and the means generally surround the midpoints of the scales. 
Figure 4-4

Statistically Significant Variation of Means, by Gender

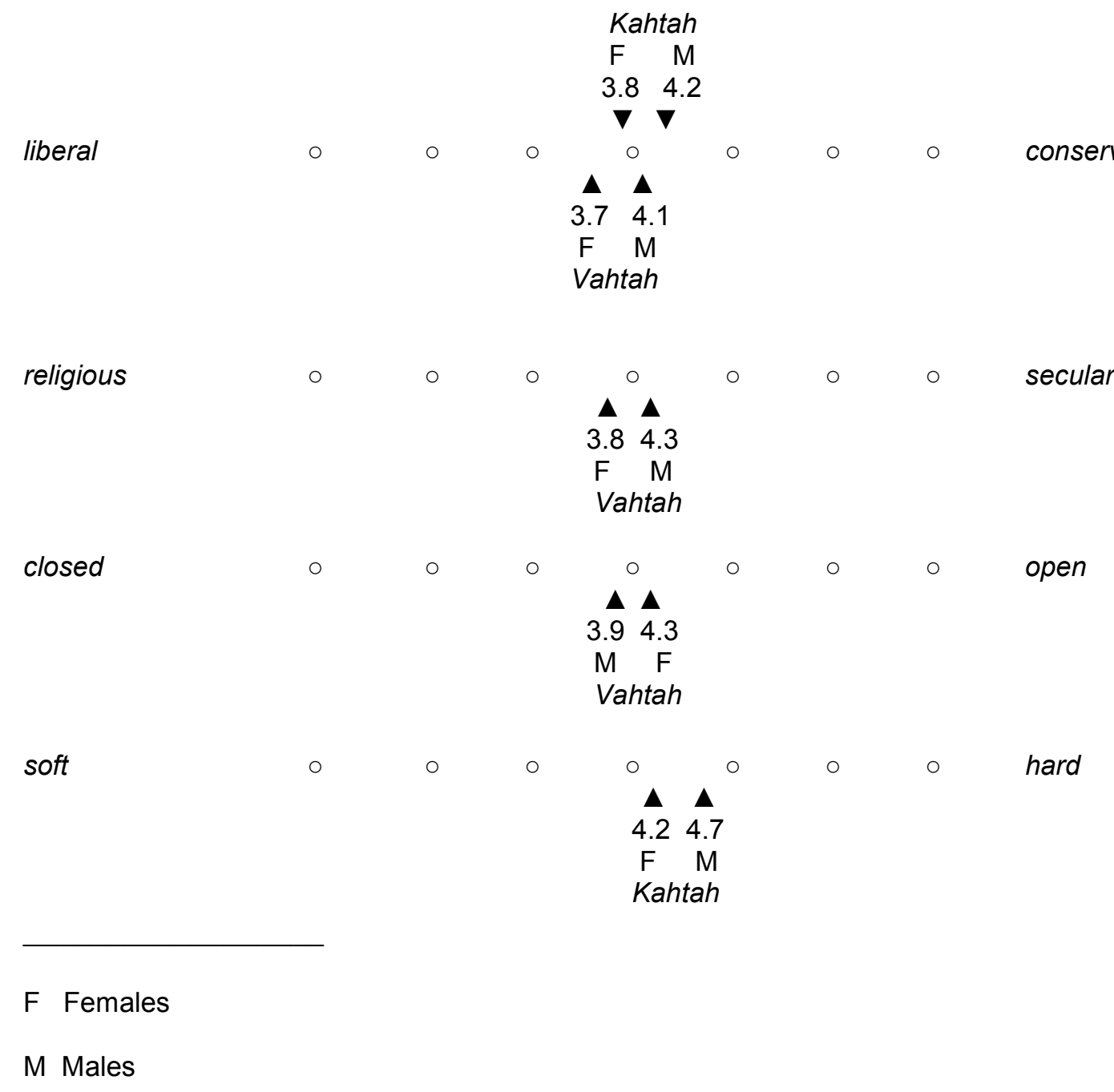


All five of the gender-related instances occurred only among the stimuli with low, back vowels (Kahtah, Vahtah). The age-related instances occurred among the stimuli with either high front vowels or low back vowels (Keetee, Kahtah, Vahtah). None of the instances occurred among the words related to /n/ (Neetee, Nahtah). Table 4-4 plots this distribution of statistically significant results according to semantic differential scale and stimulus. 
Table 4-4

Distribution of Instances of Statistically Significant Variables, by Scale and Stimulus

\begin{tabular}{|c|c|c|c|}
\hline Keetee & Neetee & Kahtah & Vahtah \\
\hline \multicolumn{4}{|l|}{$\begin{array}{l}\text { slow- } \\
\text { fast }\end{array}$} \\
\hline \multicolumn{4}{|l|}{$\begin{array}{l}\text { heavy- } \\
\text { light }\end{array}$} \\
\hline $\begin{array}{l}\text { soft- } \\
\text { hard }\end{array}$ & & $\mathrm{G}, \mathrm{A}$ & $A$ \\
\hline \multicolumn{4}{|l|}{$\begin{array}{l}\text { thin- } \\
\text { thick }\end{array}$} \\
\hline $\begin{array}{l}\text { closed- } \\
\text { open }\end{array}$ & & & G \\
\hline \multicolumn{4}{|l|}{$\begin{array}{l}\text { narrow- } \\
\text { wide }\end{array}$} \\
\hline \multicolumn{4}{|l|}{$\begin{array}{l}\text { energetic- } \\
\text { lazy }\end{array}$} \\
\hline $\begin{array}{l}\text { liberal- } \\
\text { conservative } \quad \mathrm{A}\end{array}$ & & $G$ & $\mathrm{G}$ \\
\hline $\begin{array}{l}\text { religious- } \\
\text { secular }\end{array}$ & & & G \\
\hline $\begin{array}{l}\text { rural- } \\
\text { urban }\end{array}$ & & & \\
\hline
\end{tabular}
A Age
G Gender 
4.2.2 Qualitative Data. Figure 4-5 and the tables in Appendix I illustrate the distribution of qualitative responses among a standard taxonomy of product categories (Google, 2014). The figures represent the percent of responses (e.g., 20.7\% of females said the word Keetee represented a product in the category of Animals \& Pet Supplies).

Figure 4-5

Three Most Frequently Referenced Product Categories, by Gender, Percent of Those Responding

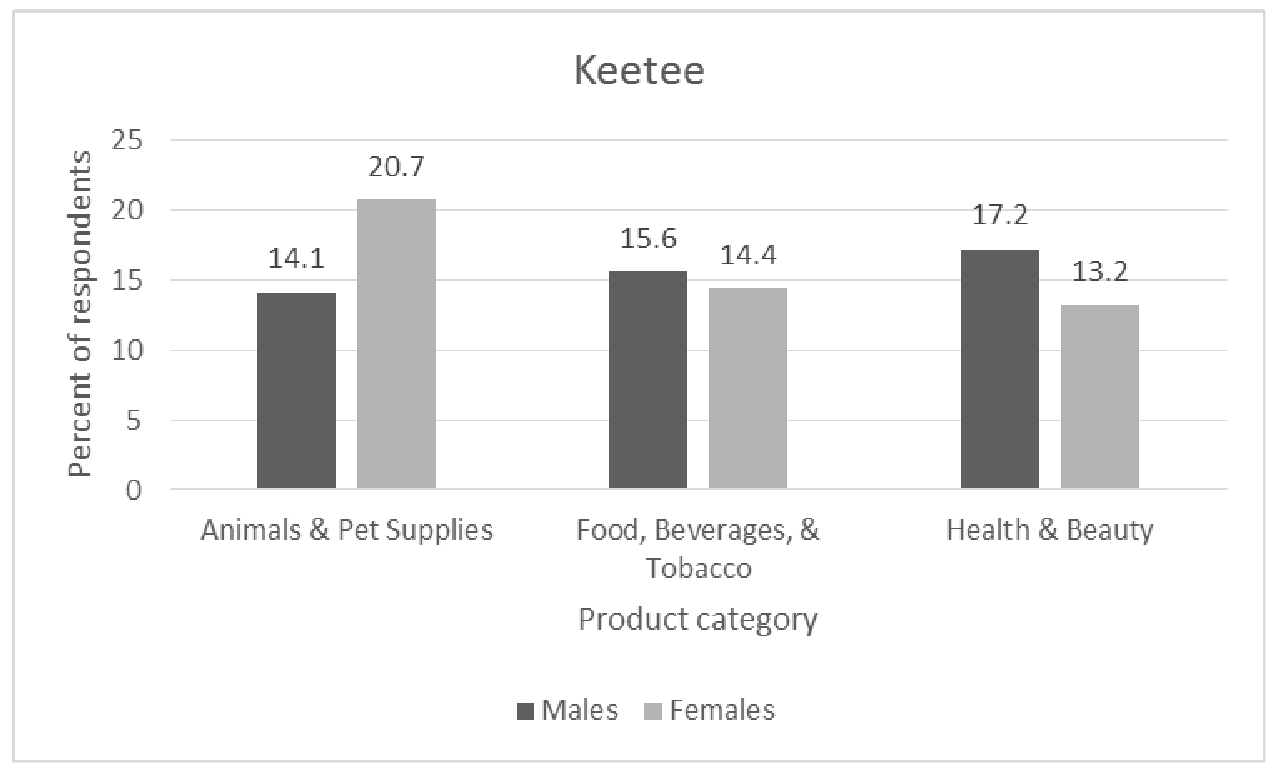

Most frequent references: cat, toy

$n=238$ 


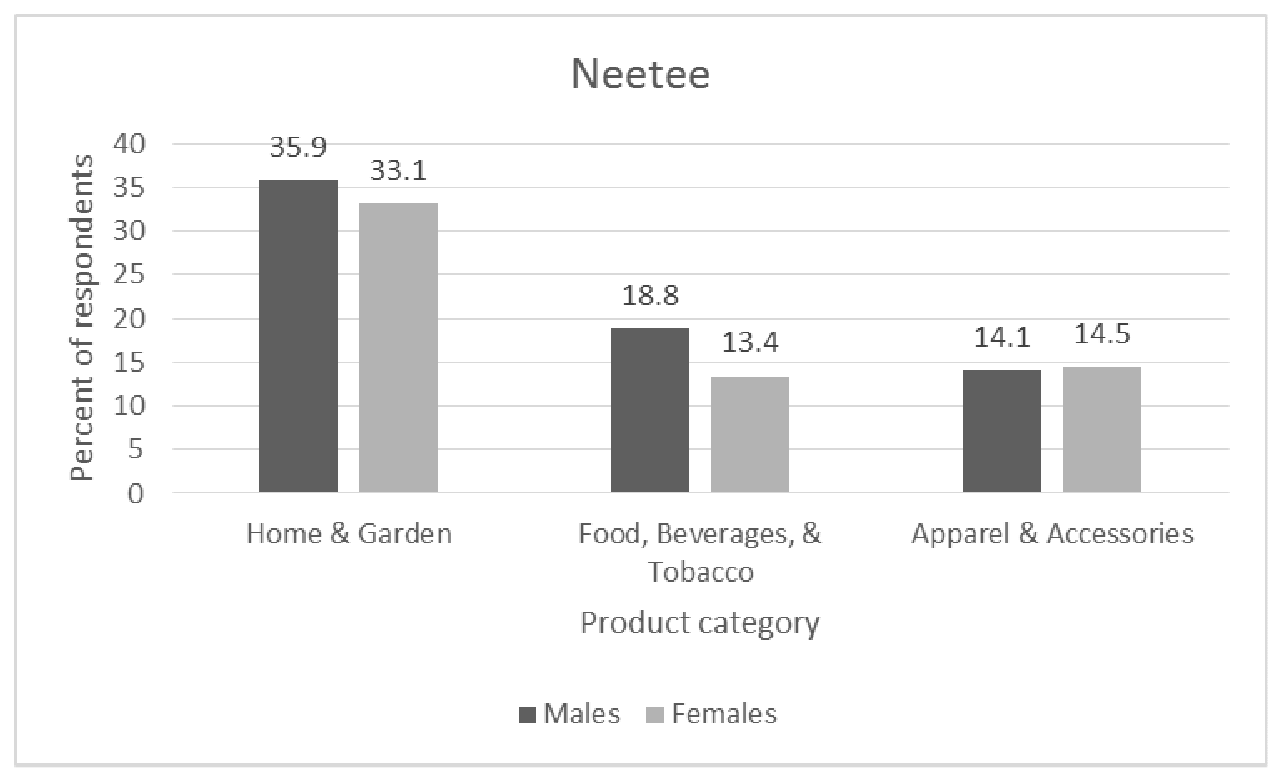

Most frequent references: cleaning, tea, shirt $n=236$

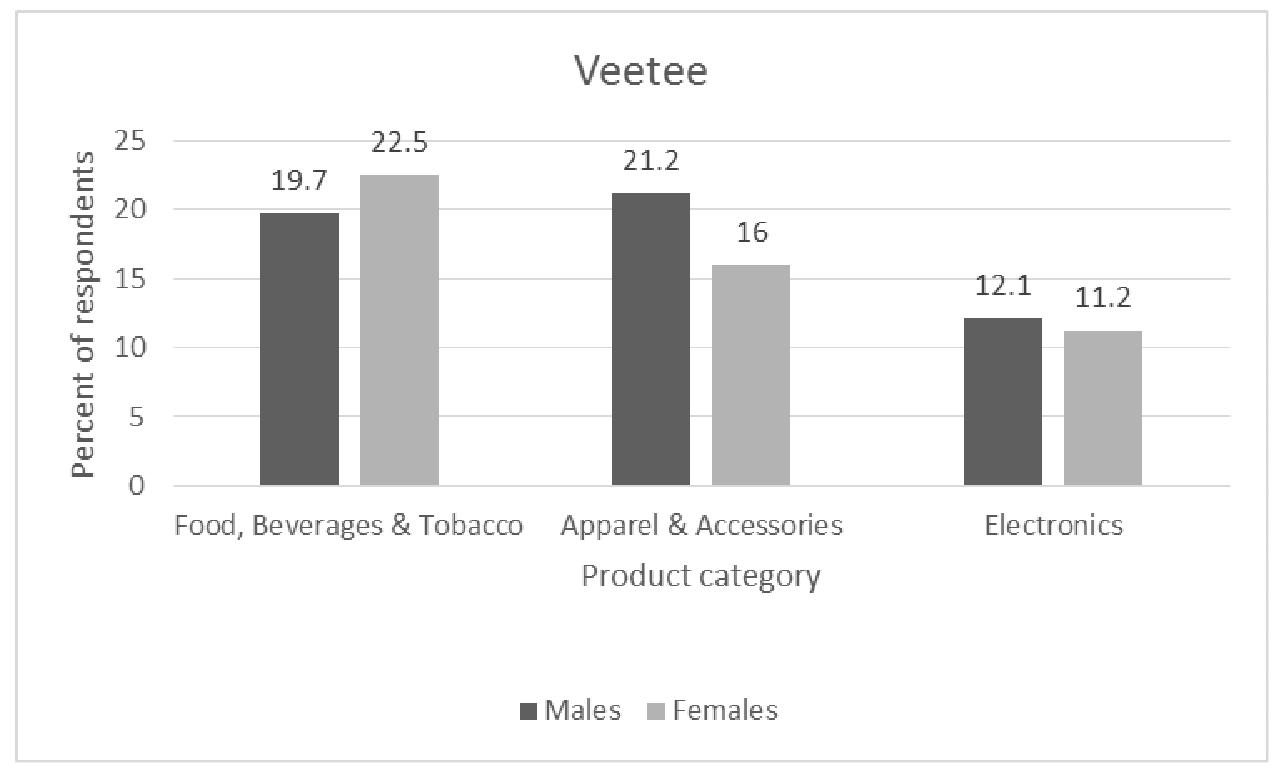

Most frequent references: shirt, drink, cat, food, tea, energy

$n=235$ 


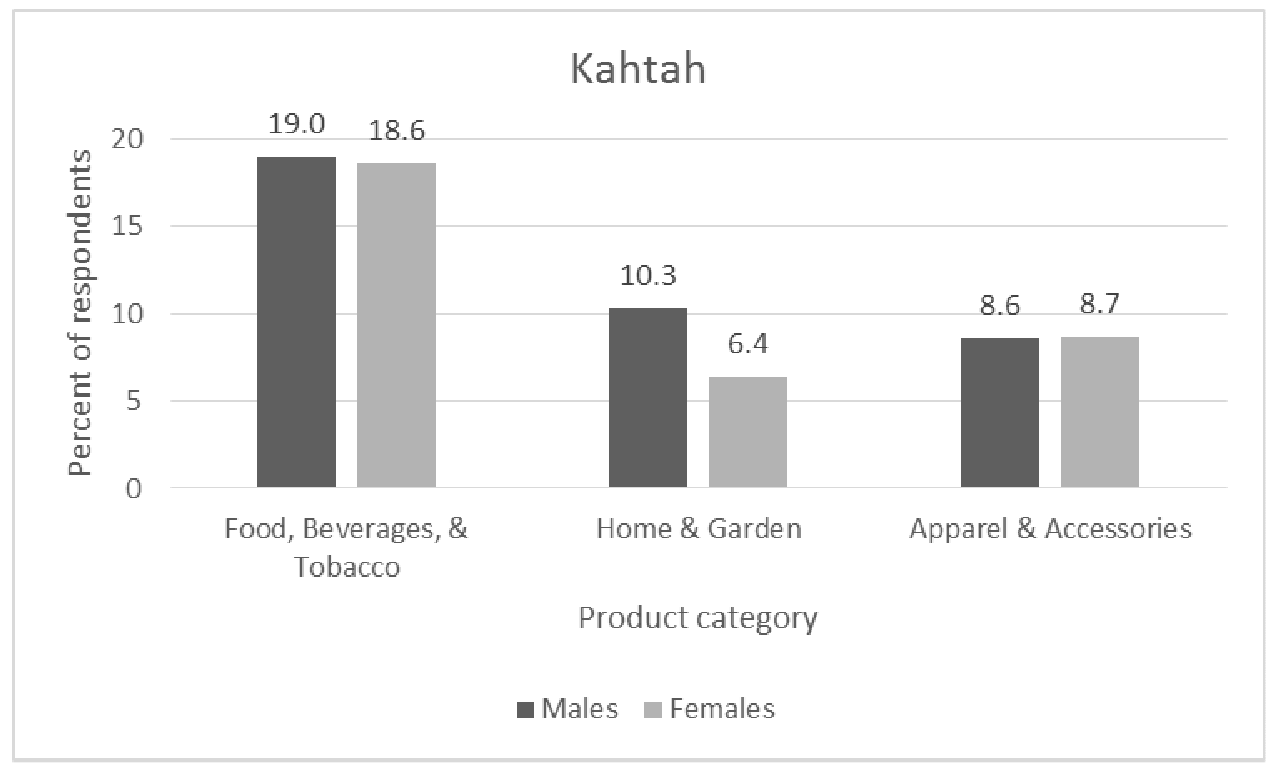

Most frequent references: knife, food

$n=230$

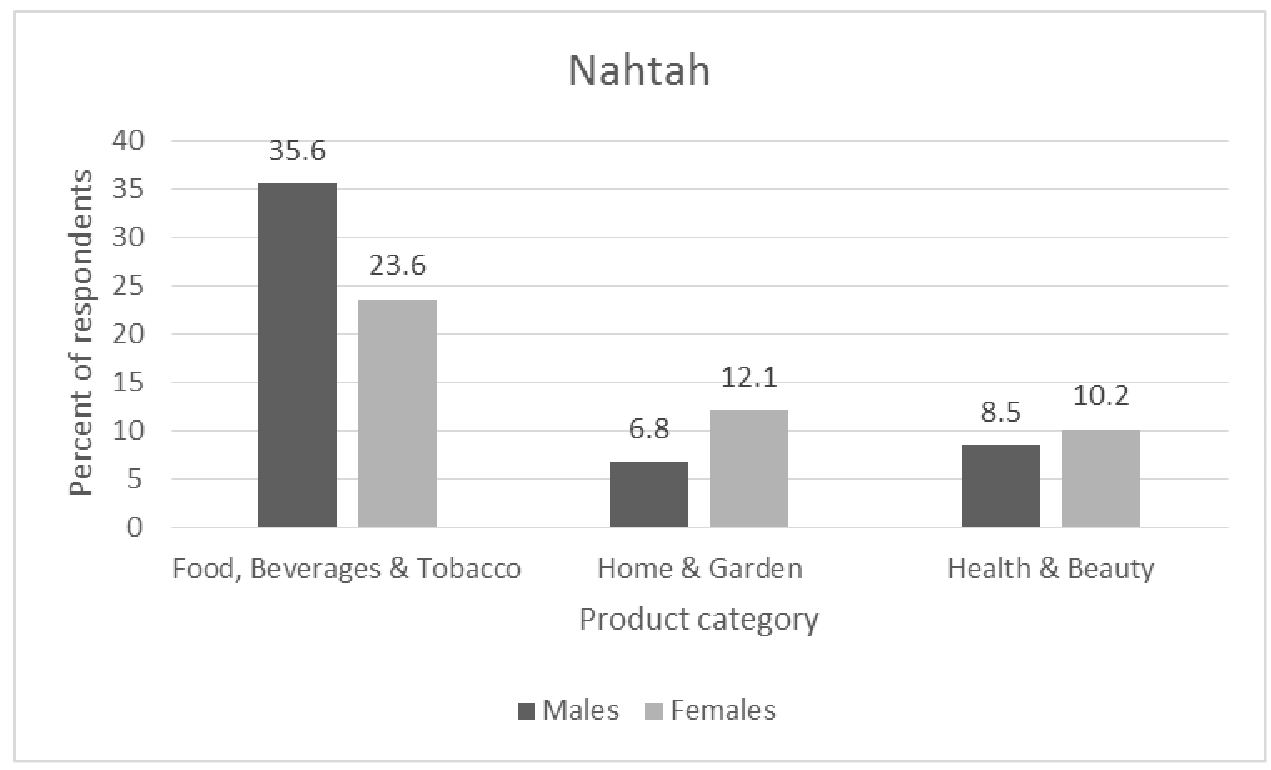

Most frequent reference: food

$n=216$ 


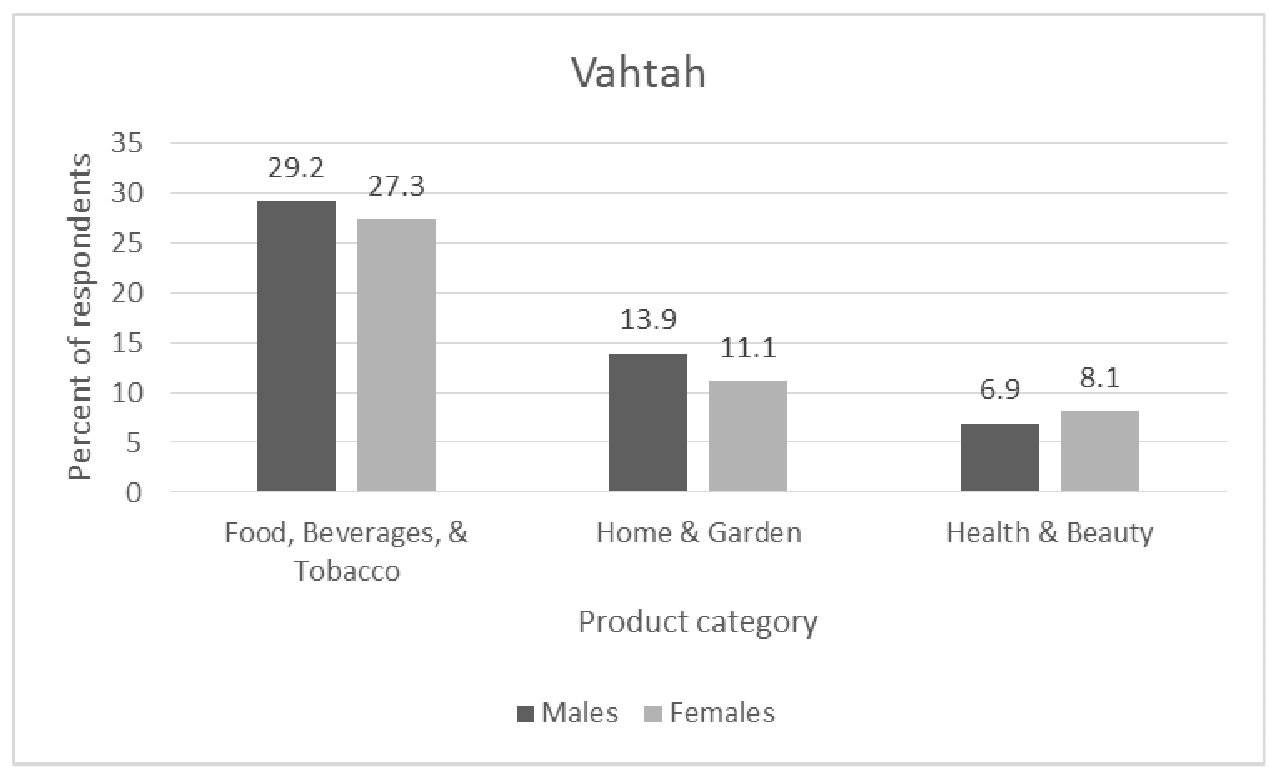

Most frequent references: water, car

$n=270$ 


\section{Chapter 5. Discussion}

In this chapter, I present a discussion of the study's findings, looking specifically at the quantitative, then qualitative results of this survey. I then highlight two trends I found noteworthy and speculate as to their origin. I conclude this chapter with a discussion of potential limitations that may have affected the outcome of this study.

My original research question asked if age and gender were significant factors that co-varied with sound symbolism in American English. My hypotheses were that they would be and that this would be observable as statistically significant variation among age groups and between males and females. A preliminary scan of the means and modes of the quantitative data continued to support this notion. Using a 0.25 -point difference between means as an arbitrary measure of significance implied that while variation according to gender may not have been particularly common, there almost certainly was variation by age - and much of that variation was monotonic. Figures increased or decreased in a graduated fashion from generation to generation, hinting at a potential phonosemantic shift over time.

It was surprising, then, when very little of that variation was found to be statistically significant. In fact, only $8.3 \%$ of the results by gender and $5.0 \%$ of results by age were determined to be statistically significant. While these findings did not support the broad-based hypotheses of this study with regard to expected significant variation by age or gender, the high degree of consensus regarding phonosemantic associations can be taken as evidence for the presence of sound symbolism even if its social conditioning may not operate as predicted. 
In an attempt to tease out a clearer distinction among the generational data, I also examined the significant results of the statistical tests for variation of means by age clusters representing the youngest respondents, the oldest respondents, and the respondents centered between the two in terms of age. Again, only five scales (8.3\%) were statistically significant, but these five scales differed from those of the full data set. Because this was a sample of only 67 respondents, I considered the pool to be too small to generalize and therefore did not proceed with further calculations. Had the smaller sample corroborated the full set, it would have strengthened the latter's significance. Because they differed, however, it weakened the argument that the overall results were more than mere noise.

\subsection{Quantitative Results}

Among the statistically significant results, it is worth reviewing apparent clusters of responses. On the scale of soft-hard, for example, there was significant monotonic variation by age for the artificial words Vahtah and Kahtah from the oldest group of Baby Boomers to Generation Xers to the youngest group of Millennials. Here, the means for Millennials leaned toward the hard end of the scale while Baby Boomers reported more of a connotation of soft. Vahtah and Kahtah share the same vowel, /a/, one that is associated in other studies with the meaning of hard. Assuming no interference by the word's consonants, this pattern suggests that the phoneme /a/ actually may be exhibiting the low back vowel's traditional ties to masculinity especially among males or those who identify with a male role in society. This is consistent with existing research that suggests 
males or those in male roles are more conservative than females or those in female roles in terms of adopting a linguistic variant.

Another cluster of statistically significant results occurred on the liberalconservative scale, an original measure that was not suggested by existing research but included because it represented a strong social divide. Here, in contrast to males, females ranked the phoneme /a/ as being more liberal for the same words Vahtah and Kahtah. For the phoneme $/ \mathrm{i} /$, however, the generational change for the word Keetee, the other statistically significant result on the same liberal-conservative scale, was not a monotonic shift across generations as was seen with the words on the hard-soft scale. Instead, the mean for Millennials was the lowest, or closest to the liberal end of the scale, followed by Baby Boomers, with Generation Xers closer to the conservative end of the scale. The means for all age groups, however, were less than the scale's midpoint of 4.0. This score indicates that all three means referenced a liberal quality that differed only in degree.

The final curiosity among the quantitative results was the reoccurrence of the artificial words Vahtah and Kahtah, which made up all but one of the eight instances of statistically significant measures found in this study for age and gender combined. Again, because they share the phoneme $/ \mathrm{a} /$, it may be possible that change is occurring-perhaps in some interaction between age and gender-whereby /a/ is consistently associated with things that exemplify hard and conservative. The fact that all but one of the artificial words in question shared the phoneme $/ \mathrm{a} /$ and the majority were clustered on the same two scales implies that there is some unifying factor causing this variation.

While the tests of this particular study revealed only these instances of variation, 
different combinations of scales and stimuli could illuminate additional correlations among other phonemes and semantic scales. In other words, we may be seeing evidence that variation by age and gender can and does occur in the sound symbolic system of American English, but the conditions under which it applies are not yet understood. In this case, the phoneme /a/ varies only by age and gender in relation to its semantic associations with soft-hard and liberal-conservative. Other phonemes, however, may react to different associations than those presented here. The question, then, is what are the factors triggering change? Why might the semantic association with /a/ be undergoing change in terms of hard-soft and liberal-conservative, but not in other places where it would seem relevant, such as on other scales on which it often appears opposite /i/ (e.g., slow-fast and heavy-light)?

I considered a number of theories when examining the results of the data analysis. For example, there may be a case for relative strength of association between phoneme and meaning such that a stronger tie may resist variation. Another idea is that the sound symbolic associations of these particular consonants and vowels may have affected each other, either in conflict, concord, or even as a sound cluster producing a third, unique sound-meaning association. Still another reason may be related to regional variation and how this study recruited subjects nationally in an attempt to represent the diversity of the population of speakers of American English. Sound symbolism may be an extensive, complicated, and even hierarchical or dynamic system, and this survey instrument alone simply may not have been able to measure the necessary variables. 


\subsection{Qualitative Results}

An analysis of the qualitative data presented additional clues that may help to answer the question of why sound symbolism does not appear more definitively and universally in these results. After ranking each artificial word, survey participants were asked what they were picturing when answering the question. Unlike the semantic scales that were concerned with only polar-opposite adjectives, the open-ended qualitative responses included a mix of specific nouns (e.g., "a knife") and more generic descriptors (e.g., "something that cuts").

Though not analyzed statistically, the qualitative data depicted many instances of generational differences, but a general lack of notable differences between genders. For example, I observed a clear decline among age groups in how frequently Keetee was thought of as a product within the category of Animal \& Pet Supplies. Sometimes this monotonicity appeared only at the intersection of these variables, such as the number of males who considered the word Keetee to represent some product within the category of Food, Beverages, \& Tobacco. This association showed a distinct decline from $22.2 \%$ of male Baby Boomers to $13.3 \%$ of male Generation Xers to $12.5 \%$ of male Millennials.

When the shift is not monotonic, there often appeared distinct generational blips, the spike or dip where one of the three age groups associates an artificial word with a product category that differs markedly from what the other two age groups report. An example of this could be seen among Generation Xers (males and females). Here, 18.5\% considered the word Veetee to be a product from the category of Electronics in contrast to $2.7 \%$ of Baby Boomers (and, notably, $0 \%$ of male Baby Boomers) and $7.3 \%$ of 
Millennials. Generational blips like these might be explained by a form of sociallyinfluenced variation that caused these phonemes to be interpreted differently by different ages and genders. It is possible that this type of variation is attributable to the passing popularity of certain products, fashions, or fads; the introduction of new technology that subsequently becomes either commonplace or obsolete; or even shifting consumer priorities or preferences. Unlike age grading, these instances reflect a sound-meaning association that sticks with a particular generation.

In colloquial English, for example, there is a fairly recent convention of prefixing words with $e$ - and $i$ - $(/ \mathrm{i} /$ and $/ \mathrm{aI} /)$ to represent or evoke a connection to electronics, computers, and the Internet, as well as the fashionable prestige of Apple brand technology and, in the case if $i$-, a self-centered focus. In these examples, the prefixes may be continuing to carry their sound symbolic associations for Generation Xers and Millennials, the two generations for which it is meaningful. However, its salience may fade over time and no longer be relevant to subsequent generations.

In the same way, it is not difficult to imagine a Baby Boomer connecting the word Veetee to the product category of Food, Beverages, \& Tobacco (with its similarity to "vitamin" and "tea") and a Millennial connecting the word to the product category of Apparel by way of V-neck T-shirt (often referred to simply as a "T") whereas Generation Xers - experiencing both the golden age of television and the dawn of the computer age during their formative years - imagine Veetee to be more associated with VT, an abbreviation for video terminal, or an inversion of the abbreviation for television, both having associations with the product category of Electronics. While the generation in 
question continues to retain the new sound symbolic association, the community at large does not adopt the variation but instead maintains its more general association or even moves on to another semantic association based on new social input.

In this sense, language variation in sound symbolism may operate both by generational shifts, when a community as a whole gradually changes its sound symbolic associations, as well as by generational blips represented by the spikes or dips in sound symbolic associations that continue to track with a particular generation over time. The difference between the two would depend on the durability of the source of the semantic association. A fad that fades or becomes so commonplace that it seems generic would cause only a spike or a dip, while something more enduring would cause a monotonic semantic shift in which the new association replaces the old.

More often than not, it was the Millennials who exhibited this tendency. In both quantitative and qualitative data, Baby Boomers and Generation Xers were often more closely aligned with each other than with Millennials. This, I believe, reflects the individualistic nature of the Millennial generation. As contemporary media continues to evolve toward narrowcasting, or segmentation of communication that provides information or advertising to a particular demographic based on their interests, past behaviors, or even geographic location (Chae \& Flores, 1998), it is not surprising that there is less consensus among Millennials than their predecessors who bonded over less diverse, but a wider, more consistent and ubiquitous broadcast media stream. Although one might argue that sharing is a hallmark of Millennials' relationship to modern media, it is often the case that there are many broadcasters and few listeners, which is a situation 
opposite of the mass media more familiar to Generation Xers and Baby Boomers in which there were many listeners for few broadcasters. This type of isolation among Millennials is reflected here in how Millennials are generally the group that is distinct from the other two generations among the statistically significant quantitative results and the generally low percentages of respondents that agree on product categorization among the qualitative results.

In practical terms, the qualitative results provide evidence that sound symbolic associations affect an individual's perception of even artificial words to the extent that ignoring this association could be detrimental in terms of international or multicultural brand identity or marketing efficacy just as ignoring a word's translation or homophone in another language can have negative consequences. Among many examples are a brand name for a cheese that in French is innocuous but in Farsi describes something rotten and is a common word for penis (Habibinia, 2010) and the apocryphal story of U.S. automaker Chevrolet introducing its Nova model of car into Mexico where the name in Spanish means 'it doesn't go.' A comparable, albeit fictitious, example can be found within the context of this study. Considering the artificial word Neetee to be the brand name of a product, one can see that there is a notably higher association of the word Neetee with a cleaning product within the Home \& Garden category, especially among Millennials, than with the second most-referenced product, namely a type of tea within the Food, Beverages, \& Tobacco category. In this case, $39.5 \%$ of Millennials thought Neetee was a Home \& Garden product while only $4.7 \%$ associated the word with a product in the Food, Beverages, \& Tobacco category. If a company were considering a 
name for a tea to be marketed toward Millennials, it may want to rethink a brand name such as Neetee, a term that its target audience is more likely to consider a cleaner than a beverage. In fact, the company may want to carefully consider any potential brand name that uses the phonemes $/ \mathrm{n} /$ or $/ \mathrm{i} /$.

It is important to note, however, that none of these qualitative data points exceeded $44.4 \%$ (a particularly extreme instance reflecting the proportion of male Baby Boomers who considered Neetee to be a product in the Home \& Garden category). As such, this figure was still less than the majority of the population who provided an answer to that question and, accordingly, an even lower percent of the total population surveyed. This suggests that even where patterns are spotted and even when they are statistically significant, the strength of their effect remains in question. Therefore, when interpreting this data for practical applications, marketers must weigh their options carefully to determine if the effect is strong enough to provide significant return on their investment in segmented marketing based on sound symbolism.

\subsection{Limitations}

Despite the potential to add to research on language variation and sound symbolism in English, this study had potential limitations. First, time and financial considerations restricted the number and diversity of participants. Efforts were made, for example, to ensure a healthy and equal representation of each demographic category combination (e.g., posting a link to the survey on the Facebook page of a magazine geared toward a specific demographic), but I was unable to recruit additional participants 
in certain categories; those categories (e.g., Millennial males) may be under-represented in this study.

Second, I chose to utilize Internet-based testing and to focus on recruiting subjects via web sites situated in the country's largest metropolitan areas as matter of convenience. This may have skewed the results demographically, especially in terms of underrepresentation of rural areas. The use of an online survey instrument also favored participants with access to technology. A self-directed online survey introduced the risk of an uncontrolled and variable testing environment, including, for example, duplicate surveys from the same participant, multiple participants contributing to a single survey, or a large number of incomplete survey attempts. With no financial incentive to participate and the survey software's ability to restrict access to the survey, the risk of duplicate or tainted surveys was low. Participants recruited from Craig's List sites generally tend to skew young and female (Antoun, Zhang, Conrad, \& Schober, 2013), a statistic that also was evidenced in my data, along with a higher response from the Western U.S. compared with Eastern and Central areas, a result of using social media originating primarily among my personal network based in Portland, Oregon.

Presenting the survey in a written format also introduced a risk for the influence of typography (e.g., the letter $n$ is more rounded than the letter $v$ and therefore its visual form may influence participants' responses). Because this has not been a reported issue in either the existing literature or among participants of my pilot study, and because the survey prompts asked participants to consider the sounds of the stimuli, I considered this to have been a very small risk. 
Because the survey repeated the same 10 scales six times, participants may have found the activity to be tedious and failed to provide consistently thoughtful and honest responses. However, similar tests by Osgood and others have used much larger sets of stimuli and scales (Osgood, May \& Miron, 1975) without incident. This questionnaire was much smaller and therefore should not have presented a significant problem. Still, it is interesting to note that of 422 subjects who met all the demographic criteria for this study and attempted to participate in the survey, only 292 (69.2\%) completed all 60 scales. It is unclear if participants simply missed a scale, did not want to answer a scale, or omitted scales out of fatigue or insufficient time.

Finally, there was the potential for conflicting interpretations of the sounds. For example, there was a chance that the sound symbolism of the medial consonant of the artificial words may have interfered with or distracted participants from an interpretation of the targeted phonemes. I tried to account for this by consistently using $/ \mathrm{t} /$ throughout the survey, one of the most common consonants in English as well as one with little influence on adjacent vowels. More importantly, however, may have been the foreign connotations of the artificial words. In an attempt to provide stimuli that were not already existing words in American English, I created artificial words that, while permitted by English phonology, may not have sounded like natural English. Their spelling, chosen to elicit the targeted phonemes, may also have appeared foreign. When asked about this, the pilot study participants agreed that some of the stimuli made them think of foreign or exotic products or attributes. This, therefore, may have been a distraction and/or led the subjects to attribute foreign or exotic qualities to whatever product they had been 
imagining when answering the questions. To address this, I included a short preamble to the survey that incorporated this as motivation for the marketing-oriented survey. Because the words sounded so unusual, I wrote, the marketers wanted to know what associations people already had with these sounds. Then, to better gauge the degree of influence of this foreign quality, I recorded for each artificial word the frequency of such references. This included the words foreign, exotic, references to other countries and cultures, etc. Because the frequency of these mentions never exceeded 14.4\% (see details in Appendix I), I consider this to have had an insignificant effect on the results. 


\section{Chapter 6. Conclusions}

Quantitative analysis of the ranking of artificial brand names on semantic differential scales within the boundaries of this study does not alone provide sufficient evidence to support the broad hypotheses that age or gender correlate with sound symbolism in American English. When combined with qualitative responses, however, the results do provide motivation for further refinement of the survey instrument and its use in order to more clearly identify potential correlations and conditions of those correlations. In particular, what I call generational blips may represent a unique phenomenon socially influenced by both pop culture, fashions, and fads as well as American society's evolution from broadcasting to narrowcasting, a phenomenon in which a generation continues to utilize a sound symbolic association beyond its original environment. The variation between males and females and among generations may be relevant to those studying sound symbolism as well as to marketers wishing to more carefully target their brand messaging. The strength of effect, however, is not large, and therefore its practicality in the marketplace remains in question.

\subsection{Recommendations for Future Research}

Future research should continue to refine the survey instrument and methodology in order to more clearly classify potential variation and its implications. These changes might include:

- compiling a more consistent demographic set, either controlled specifically for equal distribution of demographic variables, including geography, or restricted to a more narrowly defined community; 
- using forced-choice scales, such as a six-point Likert scale, which would not allow for neutral answers;

- incorporating comparative stimuli such as those used in similar sound symbolism research (e.g., Which sounds faster? Veetee or Neetee?);

- creating a two-part question that uses the comparative example above followed by a measure of intensity (e.g., On a scale of 1-5, how fast?);

- addressing a combination of product category and product attribute (e.g., What type of product is Keetee? If Keetee is a , is it a fast or a slow ? How fast/slow is it?);

- measuring strength of effect and providing some sense of what degree is necessary for branding and marketing professionals to consider implementing changes based on these data;

- applying other statistical modeling, including ranges, factor analysis, etc.;

- investigating the effect of pop culture, fashions, and fads on sound symbolism;

- focusing specifically on the phoneme /a/ and the semantic scales of hard-soft and conservative-liberal in order to explore why only /a/ figured in significant correlations;

- performing tests to document the theory of a hierarchy of phonemes relative to their sound symbolic associations and social demographics.

Perhaps most importantly, however, would be the replication of this study that acquires real-time measurement of the same variables. This could serve to confirm the results of qualitative analysis and conclude whether the variation is a form of 
generational shift, age grading, or what I have termed generational blips. This would be especially applicable in instances where Millennials are presented as a generation that is further isolated than the two preceding generations. 


\section{References}

Antoun, C., Zhang, C., Conrad, F. G., \& Schober, M. F. (2013). Comparisons of online recruitment strategies. Retrieved from http://sitemaker.umich.edu/antoun/files/recruiting_poster_ca_cz_v3.1.pdf

Bloomfield, L. (1933). Language. New York: H. Holt \& Company.

Bolinger, D. L. (1940). Word affinities. American Speech, 15(1), 62-73.

Chae, S., \& Flores, D. (1998). Broadcasting versus narrowcasting. Information Economics and Policy (10)1, 41-57.

Chambers, J. K. (2009). Sociolinguistic theory. Malden, MA: Blackwell.

Chambers, J. K., Trudgill, P., \& Schilling-Estes, N. (2004). Language variation and change. Malden, MA: Blackwell.

Childs, G. T. (1994). African ideophones. In L. Hinton, J. Nichols, \& J. Ohala (Eds.), Sound symbolism. Cambridge: Cambridge University Press.

Childs, G. T. (2014). Sound symbolism. In J. R. Taylor (Ed.), The Oxford handbook of the word. Oxford: Oxford University Press.

CNN. (2011). American generations through the years. Retrieved from: http://www.cnn.com/interactive/2011/05/living/infographic.boomer/

Fischer-Jorgensen, E. (1978). On the universal character of phonetic symbolism with special reference to vowels. Studia Linguistica, 32(1-2), 80-90.

Google. (2014). The Google product taxonomy. Retrieved from: https://support.google.com/merchants/answer/1705911?hl=en 
Gordon, M., \& Heath, J. (1998). Sex, sound symbolism, and sociolinguistics. Current Anthropology, 39(4), 421-449.

Greenberg, J. H., \& Jenkins, J. J. (1966/1990). Studies in the psychological correlates of the sound system of American English: III. Descriptive ratings of selected consonants. In K. Denning \& S. Kemmer (Eds.), On language: Selected writings of Joseph H. Greenberg. Stanford, CA: Stanford University Press.

Habibinia, O. (2010, April 26). The French cheese that means "rotten" in Farsi. France, 24. Retrieved from: http://observers.france24.com/content/20100426-frenchcheese-means-rotten-farsi-kiri-genitalia

Harrington, J. (2007). Evidence for a relationship between synchronic variability and diachronic change in the Queen's annual Christmas broadcasts. In J. Cole \& J. Hualde (Eds.), Laboratory phonology, 9 (pp. 125-143). Berlin: Mouton de Gruyter.

Hinton, L., Nichols, J., \& Ohala, J. J. (1994). Sound symbolism. Cambridge: Cambridge University Press.

Imai, M., Kita, S., Nagumo, M., \& Okada, H. (2008). Sound symbolism facilitates early verb learning. Cognition, 109. 54-65.

Jakobson, R., \& Waugh, L. R. (1987). The sound shape of language. Berlin: Mouton de Gruyter.

Jespersen, O. (1922). Language: Its nature, development, and origin. London: George Allen \& Unwin Ltd. 
Kelly, B. F., Leben, W. R., \& Cohen, R. H. (2003). The meanings of consonants. Proceedings from the Twenty-Ninth Meeting of the Berkeley Linguistics Society: General Session and Parasession on Phonetic Sources of Phonological Patterns: Synchronic and Diachronic Explanations. 245-253.

Klink, R. R. (2000). Creating brand names with meaning: The use of sound symbolism. Marketing Letters, 11(1), 5-20.

Klink, R. R. (2003). Creating meaningful brands: The relationship between brand names and brand mark. Marketing Letters, 14(3), 143-157.

Klink, R. R. (2009). Gender differences in new brand name response. Marketing Letters, 20(3), 313-326.

Labov, W. (1990). The interaction of sex and social class in the course of linguistic change. Language Variation and Change, 2(2), 205-254.

Locke, J. (1690, 2013). An essay on human understanding. The Electronics Classics Series. Pennsylvania State University. Retrieved from http://www2.hn.psu.edu/faculty/jmanis/locke/humanund.pdf

Lowrey, T. M., \& Schrum, L. J. (2007). Phonetic symbolism and brand name preference. The Journal of Consumer Research, 34(3), 406-414.

Magnus, M. (1999). A dictionary of English sound. Retrieved from http://www.trismegistos.com/classes.pdf

Magnus, M. (2013). A history of sound symbolism. In K. Allan (Ed.), The Oxford handbook of historical linguistics (pp. 191-208). Oxford: Oxford University Press. 
McKay, S. L. (2012). Principles of teaching English as an international language. In L. Alsagoff, S. L. McKay, G. Hu, \& W. A. Renandya (Eds.), Principles and practices for teaching English as an international language (pp. 28-46). New York: Routledge.

McCrindle, M., \& Wolfinger, E. (2011). The ABC of XYZ: Understanding the global generations. Sydney: UNSW Press.

Meyerhoff, M. (2011). Introducing sociolinguistics. New York: Routledge.

Newman, M. L., Groom, C. J., Handelman, L. D., \& Pennebaker, J. W. (2008). Gender differences in language use: An analysis of 14,000 text samples. Discourse Processes, 45(3), 211-236.

Newman, S. (1933). Further experiments in phonetic symbolism. American Journal of Psychology, 45(1). 53-75.

Newmeyer, F. J. (1993). Iconicity and generative grammar. Language, 68, 756-796.

Nuckolls, J. B. (1999). The case for sound symbolism. Annual Review of Anthropology, 28(1), 225-252.

Ohala, J. (1997). Sound symbolism. Proceedings from the Proceedings of the Fourth Seoul International Conference on Linguistics, Seoul, Korea. Retrieved from http://www.linguistics.berkeley.edu/ ohala/papers/SEOUL4-symbolism.pdf

Osgood, C. E., May, W. H., \& Miron, M. S. (1975). Cross-cultural universals of affective meaning. Urbana, Illinois: University of Illinois Press. 
Osgood, C. E., Suci, G. J., \& Tannenbaum, P. H. (1957/1969). The measurement of meaning. In J. G. Snider \& C. E. Osgood (Eds.), Semantic differential technique: A sourcebook. Chicago: Aldine Publishing Company.

Parise, C. V., \& Pavani, F. (2011). Evidence of sound symbolism in simple vocalizations. Experimentelle Hirnforschung [Experimental brain research]. Expérimentation Cérébrale, 214(3), 373-80.

Pennebaker, J. W., \& Stone, L. D. (2003). Words of wisdom: Language use over the life span. Journal of Personality and Social Psychology, 85(2), 291-301.

Reilly, J., Biun, D., Cowles, H. W., \& Peele, J. E. (2008). Where did words come from? A linking theory of sound symbolism and natural language evolution. Unpublished manuscript, Departments of Neurology and Communicative Disorders, University of Florida, Gainesville, FL. Retrieved from: http://precedings.nature.com/documents/2369/version/1/files/npre200823691.pdf?origin=publication_detail

Sankoff, G., \& Blondeau, H. (2007). Language change across the lifespan:/r/ in Montreal French. Language, 83(3), 580-588.

Sapir, E. (1929). A study in phonetic symbolism. Journal of Experimental Psychology, 12(3), 225-239.

Saussure, F. de (1916/1959). Cours de linguistique générale [Course in general linguistics]. New York: Philosophical Library.

Ultan, R. (1978). Size-sound symbolism. In J. Greenberg (Ed.), Universals of human language, Volume 2: Phonology. Stanford, CT: Stanford University Press. 
Walker, R. (1987). The effects of culture, environment, age, and musical training on choices of visual. Perception and Psychophysics, 42(5), 491-502.

Wright, D. (2012). Scrunch, growze, or chobble?: Investigating regional variation in sound symbolism in the Survey of English Dialects. Leeds Working Papers in Linguistics and Phonetics 17. 


\section{Appendix A. Pilot Study}

In order to determine how best to obtain the most useful data in the most efficient manner, I conducted a pilot study with seven volunteers on May 14, 2014 at a computer lab on the campus of Portland State University. In this section, I describe the pilot study session, its participants, and the specific feedback I received from the focus group discussion. I conclude this section with a list of modifications I made to the survey methodology as a result.

After brief introductions, the volunteers completed the online survey using the computers in the computer lab. The group then re-convened at a nearby restaurant for a focus group discussion over complimentary food and drink. Although the discussion was recorded for reference, participation in the pilot study remained confidential; no results were published and the participants' survey responses as well as the audio recording will be deleted upon completion of this thesis.

\section{Participants}

For the pilot study, I initially sought six volunteers (one male and one female from each of the three age groups). Although I recruited via the local Portland, Oregon Craig's List web site for convenience sake, I used an advertisement that was similar to what I would use later on a national scale. I placed the ad in the "Volunteer" section of the web site, but received only one response who, notably, never communicated further nor attended the focus group. When it became clear that I would not obtain enough volunteers by the date of the focus group if I pursued only this strategy, I placed additional invitations on both my personal Facebook page, in a Facebook group for 
students of Applied Linguistics at Portland State University (specifically seeking their contacts outside of the Applied Linguistics department), as well as on a local theater community listserv in Portland of which I am a member. To my surprise, it was easier to recruit older participants using online methods while the youngest group of Millennialaged subjects was the most difficult. Although I had eight volunteers registered, only seven volunteers attended the pilot study. Table A1 illustrates the distribution of demographics of pilot study participants. All were current residents of Portland, and all but one had responded to the theater listserv invitation (the other was recruited via the post on my personal Facebook page).

Table A-1

Distribution of Demographics among Pilot Study Participants

\begin{tabular}{lccc} 
& & & \\
Gender & Millennials & Generation X-ers & Baby Boomers \\
\hline 3 females & 23 & 47 & 62 \\
4 males & - & 28,37 & 52,60
\end{tabular}

I believe that part of the recruitment challenge was that participants were asked to attend an event at a specific time and place. Because the actual survey would be remotely accessed from participants' homes, offices, public computer terminals, and even smartphones, I believed this would be less of a problem for the actual survey. Still, when discussing motivation to participate, many of the participants expressed skepticism about using Craig's List, suggesting that a trusted referral from a friend or familiar web site would more easily convince them to participate, regardless of reward (see also the 
question below about incentives). One participant also suggested that by using Craig's List sites of the most populous metropolitan areas of the country, the results will reflect an urban and economic bias. This was a valid concern that I subsequently included among the study's limitations. Even if true, however, I expected to still be able to measure variation, if any, among age or gender despite such bias.

\section{Pilot Study Questions}

I outlined a number of questions that I expected my pilot study to answer, the results of which follow.

\section{Are the instructions and questions clearly written? Did participants} understand what they were being asked to do and how to do it? Participants did not express any confusion about how to execute the survey. All participants began with the introductory screen describing the survey scenario and disclosures of safety and privacy, and continued to navigate to the end of the survey without problem. All participants successfully completed the survey. During the focus group, one participant mentioned that she was unsure how some of the scales could apply (i.e., how they are relevant to the given artificial brand name), but that did not prohibit her from completing the survey.

Are all of the participants perceiving the sound of the artificial words in a

similar way? After completing the survey, I asked participants to say aloud the artificial words. Participants reported no confusion as to what sounds were intended to be represented by the artificial words. All were in agreement as to both vowels and consonants. There was some brief discussion about differences in syllable stress, but 
stress was not relevant to this study because it did not alter the pronunciation of the phonemes.

\section{Are there any significant interferences with the artificial words? Were} participants distracted by existing references? None of the participants reported thinking the artificial words were real words in English. Several reported having the impression that some of the artificial words may be of Arabic or Native American origin. One participant said that the artificial word Kahtah was similar to a word used in martial arts training. Because that word is pronounced /'käta/ instead of /'kata/, I believed the similarity to be negligible. However, there was significant discussion around the artificial word Veetee and what ideas of products it brought to mind. They also pointed out that Veetee might be thought of as the initials V.T. While this is a valid point, I thought at the time that it was a small concern given the limited number of combinations of artificial words that can be constructed using any particular set of vowels and consonants. Following a closer analysis of the final data, this association of Veetee with the initials V.T. may contribute to the generational blip I describe in the Discussion chapter of this thesis.

\section{What is the best format of the survey questions? Did participants make} considered choices? Participants did not indicate any prohibitive problems with the question format. However, they offered a number of suggestions, including moving the scale descriptors from underneath to beside the circles on either end of the scales. They also expressed some confusion with the demographic questions regarding where they spent the most time during childhood (i.e., Were these only continuous years or 
cumulative years? Was childhood measured up to age 18 or age 21?). In the same way, there was confusion about how to report number of years at current residence had the participant's time there not been continuous. I considered omitting these questions but opted to retain them because they were only exploratory questions that provided background information and not central to my research questions.

Another participant said the opening page of disclosures was too long and revealed too much about the study prior to completing the survey. I reviewed the text to make edits where possible. However, much of this language was dependent upon the requirements for full disclosure to human subjects and remained unchanged.

A participant suggested that the open-ended questions (in which participants were asked what they were imagining as the products for each artificial word) be grouped at the end; another participant said this would not work as well because he would not be able to recall all six items at the end of the survey. After some discussion, it seemed the majority of participants agreed with the latter position or were indifferent. I also had some concern that if the demographic questions were simply grouped at the end, then some participants might not bother to answer them. Therefore, I maintained their position following each set of 10 scales.

At least one participant suggested re-ordering the six artificial words in order to alternate the sequence of vowel sounds. The existing pattern was based on an early conversational model of presentation (e.g., I imagined an oral interview to include natural discourse, such as "If that was Nahtah, then what about Vahtah?"). Because much of that conversational tone to the questions had been stripped from the current survey 
instrument, I believed this to be a good suggestion and subsequently alternated vowel and consonant sounds for the sake of variety.

None of the participants had any specific feedback about the scales other than to say that if they were unable to choose one or the other descriptor, they intentionally chose the neutral middle circle as their response. It was unanimous that the existing seven-point scale was the right size; it was also unanimous that a two-point—or any forced choicescale was not preferred. They wanted flexibility in how they responded. This led me to retain the existing format of the scales.

How long does the survey take to complete? Everyone completed the survey within 10 to 15 minutes. When asked later about the duration of the survey, no respondents indicated any concerns about the length, especially with the presence of a progress bar indicating how far along they were in the survey. Furthermore, no one indicated any fatigue from answering questions, and no one reported having provided random responses simply to complete the survey. However, there was a suggestion that the progress bar be labeled as such, in order to be as clear as possible, a change that was easy implemented.

Does the technology perform as required? Did participants encounter any problems taking the survey online? There were no reported technological problems in completing the survey or accessing the data. The software performed as expected.

Am I receiving usable data? When analyzing the data, I saw that some of the exported material was not clearly labeled. This was resolved by simply adjusting the 
settings within the Qualtrics survey software. This was only a matter of convenience on my part and did not affect the survey experience or the integrity of the data.

What are the reactions of the participants? All participants were clearly interested in the study, asking numerous questions and providing their own speculations (e.g., they believed that there would be a difference in responses between genders and among age groups). One participant remarked that she thought perhaps she was given too much information about the study upfront. While she mentioned the disclosure screen specifically, I believed part of this came from the wording of the invitation and confirmation e-mails associated with the pilot study specifically. This was background information that future survey participants did not receive.

\section{What are participants' feelings about incentive versus no incentive?}

Participants did not indicate a need for an incentive; instead, they expressed more concern about the invitation coming from a trusted source. Most agreed that while the hook was the topic of the study and the ability to access the results of the study when published, the actual motivation to participate was due to the referral source (e.g., a friend or trusted contact). Conversation also included suggestions for other recruitment sites, including Amazon Mechanical Turk, Metafilter.com, Brainpickings newsletter, Facebook (and Facebook groups), LinkedIn and LinkedIn groups. Ultimately, the Facebook and LinkedIn suggestions were incorporated into my recruitment strategy. 


\section{Recommendations for Modifications}

1. Label the progress bar

2. Edit the disclosure page, advertisement/invitation to be as succinct as possible while still fulfilling the requirements of the Human Subjects Research Review Committee

3. Determine a way to share the results of the study without participants having to contact me, thereby ensuring their continued privacy

4. Explore alternative recruitment possibilities mentioned by pilot study participants, especially those that offer a friendly referral or some endorsement of legitimacy to bolster response rate

5. Review Limitations section of thesis proposal to reflect the aforementioned urban/economic/tech biases

6. Revisit the survey layout to see if scale descriptors could appear on either end instead of below the first and last circles

7. Consider removing the two demographic questions regarding participants current and childhood residency

8. Add missing labels to the underlying data collection fields in the survey software

9. Re-order the sequence of the six words for variety of sounds

10. Before releasing the final survey, purge all pilot study data from the survey collection software and delete audio recording of focus group conversation as well as e-mail communication with participants 


\section{Appendix B. Survey Instruments}

\section{Recruitment Advertisement}

Figure B-1

Image to Accompany Craig's List Advertisement

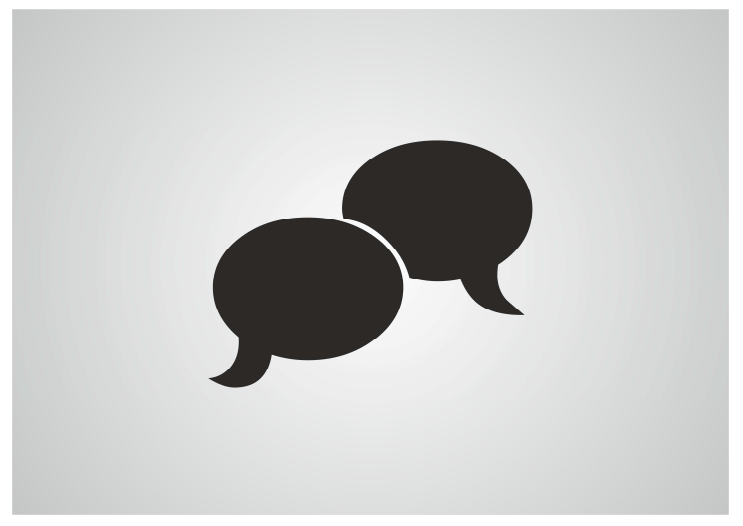

Copyright 2014. Jayanta Behera, www.freeimages.com.

\section{Language Research Study - Online Survey}

I am a graduate student in the Applied Linguistics department of Portland State University in Oregon conducting research into whether age or gender affects how we perceive the meanings of certain sounds in English. I am recruiting volunteers 18 years and older whose first language is American English to participate in an anonymous, 1015 minute online survey asking your opinions about potential brand names for a new product.

The survey is easy to complete and (I like to think) thought-provoking and fun. There is no compensation for your participation, but your input will contribute to a better 
understanding of language variation in English. To take part in this study, click on the following link: https://portlandstate.qualtrics.com//SE/?SID=SV_29bK40V6uygaUL3

Timothy Krause, Graduate Student Department of Applied Linguistics/TESOL

Portland State University, Portland, Oregon

krauset@pdx.edu, 503-516-8351 


\section{Screen 1: Waiver of Signed Consent}

You are being asked to participate in a research study by Prof. G. Tucker Childs, who is the Principal Investigator, and Timothy Krause, a graduate student, from the Department of Applied Linguistics/TESOL at Portland State University in Portland, Oregon. The study is examining differences in meanings associated with certain sounds in the English language. This research is being conducted in order to fulfill a requirement for Timothy's M.A. degree in Applied Linguistics/TESOL.

What will I have to do? If you decide to take part in this study, you will complete an anonymous online questionnaire requiring approximately 10 to 15 minutes of your time. After some preliminary demographic questions, you will be asked to rank six words along 10 scales and then describe the product you think each word represents. Your participation is voluntary.

Are there any risks and what are you doing to protect me? There are very few risks for taking part in this study. There is a small risk that you will feel uncomfortable answering the questions of the questionnaire. However, you are free to skip any questions you feel uncomfortable answering or to exit the survey at any time. Furthermore, your answers are anonymous, and there is no information that links you to the questionnaire.

What will I gain by taking part in this study? By taking part in this study, you will be contributing to the study of language variation and sound symbolism that has the potential to improve our understanding of how individuals perceive the sounds of language. You will also be given a link to a website where you will be able to freely and 
anonymously access the results of the survey in the form of Timothy's thesis when it is released in 2015.

Will I be paid for this study? No, there is no compensation for your participation.

What happens if I decide not to take part in this study? You do not have to take part in this study. Your participation is voluntary, and there is no penalty for choosing not to participate.

What can I do if I have questions? If you have any questions, concerns or complaints at any time about the research study, Prof. Tucker Childs, or his associates will be glad to answer them at (503) 725-4099. If you need to contact someone after business hours or on weekends, please call 503-516-8351 and ask for Timothy Krause. If you have questions regarding your rights as a research participant, you may call the PSU Office for Research Integrity at (503) $725-2227$ or 1(877) $480-4400$. The ORI is the office that supports the PSU Institutional Review Board (IRB). The IRB is a group of people from PSU and the community who provide independent oversight of safety and ethical issues related to research involving human participants. For more information, you may also access the IRB website at https://sites.google.com/a/pdx.edu/research/integrity.

If you agree to participate, please click NEXT to proceed to the survey. If you do not wish to participate, simply exit your browser. Approved by the Portland State University Human Subjects Research Review Committee, Proposal \#143080 


\section{Screen 2: Demographic Questions}

(The first three items were computer-generated for each survey response.)

- Participant number

- Data collection region

- Date survey completed (computer-generated)

(computer-generated)

(computer-generated)

Before we begin, please answer the following demographic questions:

With what gender do you identify?

How old are you?

Is American English your first language?

What other languages do you speak?

Where do you consider your primary childhood residence?

How many years did you live there?

In what state do you currently reside?

How many years have you lived there?

What is the highest level of education that you have completed? (multiple choice)

Male, Female, Other

(open numeric field)

(forced choice)

Yes, No

(open text field)

(computer-generated

dropdown menu of U.S. states)

(open numeric field)

(dropdown of U.S. states)

(open numeric field)

(forced choice)

Less than High School

High School/GED

Some College

2-year College Degree 


\section{4-year College Degree}

Masters Degree

Doctoral Degree

Professional Degree (JD, MD) 


\section{Screen 3: Preamble}

Imagine a marketing company is trying to create a unique brand name for a new product. They have developed six unusual options, some of which are spelled oddly or may not even sound like English words when you pronounce them. Because of this, they are concerned about what you might think when you hear them. The product is still under development, so they can't tell you what it is yet, but they want to know your opinion about the characteristics and types of products that come to mind when you hear these words.

In this survey, you will be asked to rank six different potential brand names according to 10 different scales of opposing characteristics. For example:

If you heard the brand name Leetee, would you imagine the product to be slow or fast or somewhere in between?

slow $0 \quad \circ \quad \circ \quad \circ \quad 0 \quad 0 \quad 0 \quad 0$ fast

For each scale, click on one circle that you feel best reflects the brand name. Work as fast as you can; don't take too long to make any rating. Instead, rate your first impression of how the brand name sounds to you.

This task is, of course, subjective. Some of the ratings will not be very literal. In some cases, you may wonder how a certain scale can apply to the sound you are rating, but we have found that you will be able to make decisions quite easily if you rate quickly on first impressions. Remember, there are no right or wrong answers. We simply want to know your impressions of what these words sound like to you.

When you're ready to begin, please click NEXT. 


\section{Screens 4-9}

(The same 10 scales are repeated for each of the six artificial words, in this format.)

1. Let's suppose that you heard the brand name Keetee. Would you imagine this product to be ....

\begin{tabular}{|c|c|c|c|c|c|c|c|c|}
\hline slow & ० & ○ & o & O & O & ० & ० & fast \\
\hline heavy & 0 & ○ & o & O & O & o & 0 & light \\
\hline soft & ० & ○ & o & o & ० & O & O & hard \\
\hline thin & o & o & 0 & o & o & o & O & thick \\
\hline closed & ० & ○ & o & ○ & o & o & O & open \\
\hline narrow & 0 & ○ & o & O & O & O & ० & wide \\
\hline energetic & & ○ & o & o & 0 & o & o & lazy \\
\hline liberal & o & o & o & o & 0 & 0 & o & conservative \\
\hline religious & ○ & $\circ$ & ○ & ○ & O & O & ○ & secular \\
\hline rural & 0 & 0 & 0 & 0 & 0 & 0 & 0 & urban \\
\hline
\end{tabular}

When you were imagining a product named Keetee, what were you picturing? (openended answer) 


\section{Screen 10: Exit}

Thank you for participating in this study.

If you are interested in learning more about the outcome of this study, you will be able to view the results of this study sometime in June 2015 via this link: http://tinyurl.com/SoundSymbolismThesis.

If you have any questions, concerns or complaints at any time about the research study, Prof. Tucker Childs, or his associates will be glad to answer them at (503) 7254099. If you need to contact someone after business hours or on weekends, please call 503-516-8351 and ask for Timothy Krause. If you have questions regarding your rights as a research participant, you may call the PSU Office for Research Integrity at (503) 725 2227 or $1(877) 480-4400$. The ORI is the office that supports the PSU Institutional Review Board (IRB). The IRB is a group of people from PSU and the community who provide independent oversight of safety and ethical issues related to research involving human participants. For more information, you may also access the IRB website at https://sites.google.com/a/pdx.edu/research/integrity. 


\section{Appendix C. Survey Distribution}

I posted a call for participants on the Internet sites described below. The post included a link to the survey as well as a request for readers to share the post on their own networks. Whenever I observed that someone shared the link, I also "liked" their post and often commented on it in order to raise its popularity and, therefore, its visibility. I also personally asked a variety of contacts on Facebook, representing a variety of demographics, to share the link, which many did.

\section{Facebook}

- My personal page

- PSU Linguistics Survivors Support Group page

- One-week ad specifically targeting 18 - to 23 -year-old males in the U.S. who speak American English

- Various interest groups related to language

- Various pages representing products or media targeted toward demographics that had low representation among survey participants (e.g., Millennial males)

\section{LinkedIn}

- My personal account

- Language-related research groups

- Marketing-related research groups

Craig's List (in the Volunteers section; repeated once n each city)

- New York City

- Los Angeles 
- Chicago

- Houston

- Minneapolis

- Seattle

- Phoenix

- Boston

\section{Other Sites}

- Social Psychology Network website - Wesleyan University

- Psychological Research on the Net - Hanover College

- Reddit - Participant Recruitment Page

\section{Direct E-mail}

- Professors Kimberley Brown and Nike Arnold, Portland State University, who said they would share it with their students

- Members of the pilot study focus group 


\section{Appendix D. Letter of Exemption from Portland State University Human Subjects Research Review Committee}

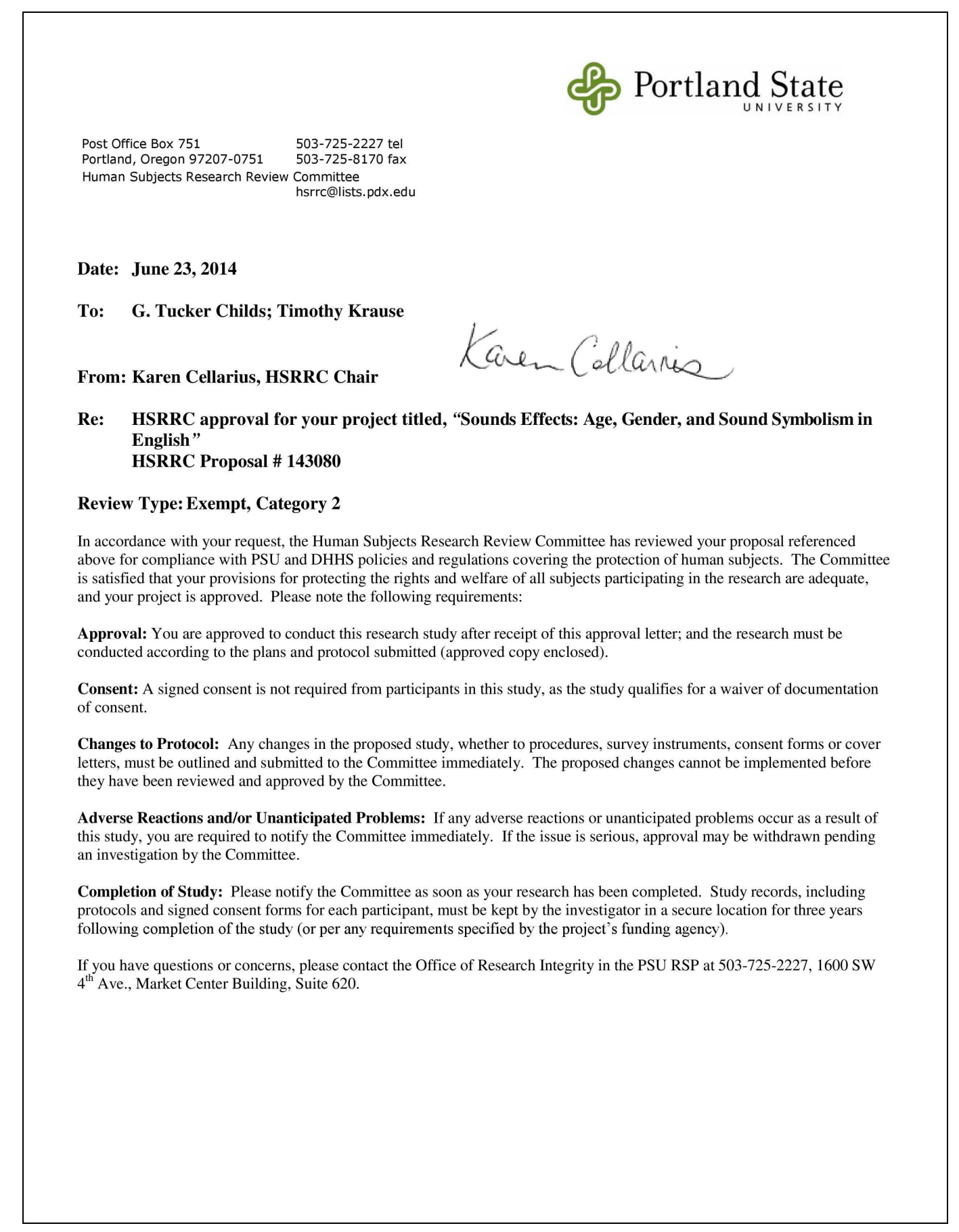


Appendix E. Means, Modes, and Medians, by Age

Table E-1

Means, Modes, and Medians for the Artificial Word Keetee, by Age

\begin{tabular}{|c|c|c|c|c|c|c|c|c|c|c|c|}
\hline \multirow[b]{2}{*}{ Measure } & \multicolumn{11}{|c|}{ Keetee } \\
\hline & Age Groups & $\begin{array}{c}\text { slow- } \\
\text { fast }\end{array}$ & $\begin{array}{c}\text { heavy- } \\
\text { light }\end{array}$ & $\begin{array}{l}\text { soft- } \\
\text { hard }\end{array}$ & $\begin{array}{l}\text { thin- } \\
\text { thick }\end{array}$ & $\begin{array}{c}\text { closed- } \\
\text { open }\end{array}$ & $\begin{array}{l}\text { narrow- } \\
\text { wide }\end{array}$ & $\begin{array}{c}\text { energetic- } \\
\text { lazy }\end{array}$ & $\begin{array}{l}\text { liberal- } \\
\text { conserv }\end{array}$ & $\begin{array}{l}\text { religious- } \\
\text { secular }\end{array}$ & $\begin{array}{l}\text { rural- } \\
\text { urban }\end{array}$ \\
\hline \multicolumn{12}{|l|}{ Counts } \\
\hline & Millennials & 54 & 54 & 54 & 54 & 54 & 54 & 54 & 54 & 54 & 54 \\
\hline & Generation Xers & 143 & 143 & 143 & 143 & 143 & 143 & 143 & 143 & 143 & 143 \\
\hline & Baby Boomers & 95 & 95 & 95 & 95 & 95 & 95 & 95 & 95 & 95 & 95 \\
\hline & Totals & 292 & 292 & 292 & 292 & 292 & 292 & 292 & 292 & 292 & 292 \\
\hline \multicolumn{12}{|l|}{ Means } \\
\hline & Millennials & 4.65 & 4.70 & 3.56 & 3.22 & 4.04 & 3.20 & 2.93 & 2.96 & 4.85 & 4.70 \\
\hline & Generation Xers & 4.33 & 4.99 & 3.97 & 3.31 & 4.23 & 3.11 & 2.86 & 3.55 & 5.05 & 4.69 \\
\hline & Baby Boomers & 4.36 & 5.07 & 3.94 & 3.32 & 4.58 & 3.52 & 2.98 & 3.51 & 4.78 & 4.77 \\
\hline & Variation between $\mathrm{ML}$ and $\mathrm{GX}$ & 0.32 & -0.28 & -0.41 & -0.09 & -0.19 & 0.09 & 0.07 & -0.58 & -0.20 & 0.02 \\
\hline & Variation between GX and BB & -0.03 & -0.09 & 0.03 & -0.01 & -0.35 & -0.40 & -0.12 & 0.04 & 0.27 & -0.08 \\
\hline & Variation between $\mathrm{ML}$ and $\mathrm{BB}$ & 0.29 & -0.37 & -0.38 & -0.09 & -0.54 & -0.31 & -0.05 & -0.54 & 0.07 & -0.06 \\
\hline
\end{tabular}

Medians

\begin{tabular}{|c|c|c|c|c|c|c|c|c|c|}
\hline Millennials & 5 & 5 & 3 & 3 & 4 & 3 & 3 & 3 & 5 \\
\hline Generation Xers & 4 & 5 & 4 & 3 & 4 & 3 & 2 & 4 & 5 \\
\hline Baby Boomers & 4 & 5 & 4 & 3 & 4 & 3 & 3 & 4 & 4 \\
\hline Variation between $\mathrm{ML}$ and $\mathrm{GX}$ & 1 & 0 & -1 & 0 & 0 & 0 & 1 & -1 & 0 \\
\hline Variation between $\mathrm{GX}$ and $\mathrm{BB}$ & 0 & 0 & 0 & 0 & 0 & 0 & -1 & 0 & 1 \\
\hline Variation between $\mathrm{ML}$ and $\mathrm{BB}$ & 1 & 0 & -1 & 0 & 0 & 0 & 0 & -1 & 1 \\
\hline
\end{tabular}

Modes

\begin{tabular}{|c|c|c|c|c|c|c|c|c|c|}
\hline Millennials & 5 & 6 & 2 & 2 & 4 & 2 & 2 & 4 & 4 \\
\hline Generation Xers & 4 & 5 & 5 & 2 & 4 & 3 & 2 & 4 & 4 \\
\hline Baby Boomers & 4 & 6 & 5 & 2 & 4 & 2 & 2 & 4 & 4 \\
\hline Variation between $\mathrm{ML}$ and $\mathrm{GX}$ & 1 & 1 & -3 & 0 & 0 & -1 & 0 & 0 & 0 \\
\hline Variation between GX and BB & 0 & -1 & 0 & 0 & 0 & 1 & 0 & 0 & 0 \\
\hline Variation between $\mathrm{ML}$ and $\mathrm{BB}$ & 1 & 0 & -3 & 0 & 0 & 0 & 0 & 0 & 0 \\
\hline
\end{tabular}

Note: On the slow-fast scale, $1=$ slowest and $7=$ fastest.

$\begin{array}{ll}\text { BB } & \text { Baby Boomers } \\ \text { GX } & \text { Generation Xers } \\ \text { ML } & \text { Millennials }\end{array}$


SOUND EFFECTS: AGE, GENDER, AND SOUND SYMBOLISM

Table E-2

Means, Modes, and Medians for the Artificial Word Vahtah, by Age

\begin{tabular}{|c|c|c|c|c|c|c|c|c|c|c|c|}
\hline \multirow[b]{2}{*}{ Measure } & \multicolumn{11}{|c|}{ Vahtah } \\
\hline & Age Groups & $\begin{array}{c}\text { slow- } \\
\text { fast }\end{array}$ & $\begin{array}{c}\text { heavy- } \\
\text { light }\end{array}$ & $\begin{array}{l}\text { soft- } \\
\text { hard }\end{array}$ & $\begin{array}{l}\text { thin- } \\
\text { thick }\end{array}$ & $\begin{array}{c}\text { closed- } \\
\text { open }\end{array}$ & $\begin{array}{c}\text { narrow- } \\
\text { wide }\end{array}$ & $\begin{array}{c}\text { energetic- } \\
\text { lazy }\end{array}$ & $\begin{array}{l}\text { liberal- } \\
\text { conserv }\end{array}$ & $\begin{array}{l}\text { religious- } \\
\text { secular }\end{array}$ & $\begin{array}{l}\text { rural- } \\
\text { urban }\end{array}$ \\
\hline \multicolumn{12}{|l|}{ Counts } \\
\hline & Millennials & 54 & 54 & 54 & 54 & 54 & 54 & 54 & 54 & 54 & 54 \\
\hline & Generation Xers & 143 & 143 & 143 & 143 & 143 & 143 & 143 & 143 & 143 & 143 \\
\hline & Baby Boomers & 95 & 95 & 95 & 95 & 95 & 95 & 95 & 95 & 95 & 95 \\
\hline & Totals & 292 & 292 & 292 & 292 & 292 & 292 & 292 & 292 & 292 & 292 \\
\hline \multicolumn{12}{|l|}{ Means } \\
\hline & Millennials & 3.815 & 3.185 & 4.241 & 5.093 & 4.037 & 5.093 & 4.130 & 3.796 & 4.056 & 4.000 \\
\hline & Generation Xers & 3.531 & 3.434 & 3.867 & 4.490 & 4.385 & 4.895 & 4.273 & 3.720 & 3.930 & 4.161 \\
\hline & Baby Boomers & 3.463 & 3.421 & 3.421 & 4.726 & 4.074 & 4.821 & 4.358 & 3.789 & 3.905 & 4.242 \\
\hline & Variation between $\mathrm{ML}$ and $\mathrm{GX}$ & 0.283 & -0.248 & 0.374 & 0.603 & -0.348 & 0.197 & -0.143 & 0.076 & 0.125 & -0.161 \\
\hline & Variation between GX and BB & 0.068 & 0.013 & 0.446 & -0.237 & 0.311 & 0.074 & -0.085 & -0.069 & 0.025 & -0.081 \\
\hline & Variation between $\mathrm{ML}$ and $\mathrm{BB}$ & 0.352 & -0.236 & 0.820 & 0.366 & -0.037 & 0.272 & -0.228 & 0.007 & 0.150 & -0.242 \\
\hline
\end{tabular}

Medians

\begin{tabular}{|c|c|c|c|c|c|c|c|c|c|}
\hline Millennials & 4 & 3 & 5 & 5 & 4 & 5 & 4 & 4 & 4 \\
\hline Generation Xers & 3 & 3 & 4 & 5 & 4 & 5 & 4 & 4 & 4 \\
\hline Baby Boomers & 3 & 3 & 3 & 5 & 4 & 5 & 5 & 4 & 4 \\
\hline Variation between $\mathrm{ML}$ and $\mathrm{GX}$ & 1 & 0 & 1 & 0 & 0 & 0 & 0 & 0 & 0 \\
\hline Variation between GX and BB & 0 & 0 & 1 & 0 & 0 & 0 & -1 & 0 & 0 \\
\hline Variation between $\mathrm{ML}$ and $\mathrm{BB}$ & 1 & 0 & 2 & 0 & 0 & 0 & -1 & 0 & 0 \\
\hline
\end{tabular}

Modes

\begin{tabular}{|c|c|c|c|c|c|c|c|c|c|}
\hline Millennials & 4 & 2 & 5 & 5 & 4 & 4 & 5 & 4 & 4 \\
\hline Generation Xers & 2 & 2 & 4 & 4 & 4 & 4 & 5 & 4 & 4 \\
\hline Baby Boomers & 2 & 3 & 4 & 5 & 4 & 4 & 5 & 4 & 4 \\
\hline Variation between $\mathrm{ML}$ and $\mathrm{GX}$ & 2 & 0 & 1 & 1 & 0 & 0 & 0 & 0 & 0 \\
\hline Variation between GX and BB & 0 & -1 & 0 & -1 & 0 & 0 & 0 & 0 & 0 \\
\hline Variation between $\mathrm{ML}$ and $\mathrm{BB}$ & 2 & -1 & 1 & 0 & 0 & 0 & 0 & 0 & 0 \\
\hline
\end{tabular}

Note: On the slow-fast scale, $1=$ slowest and $7=$ fastest.

$\begin{array}{ll}\text { BB } & \text { Baby Boomers } \\ \text { GX } & \text { Generation Xers } \\ \text { ML } & \text { Millennials }\end{array}$




\section{Table E-3}

Means, Modes, and Medians for the Artificial Word Neetee, by Age

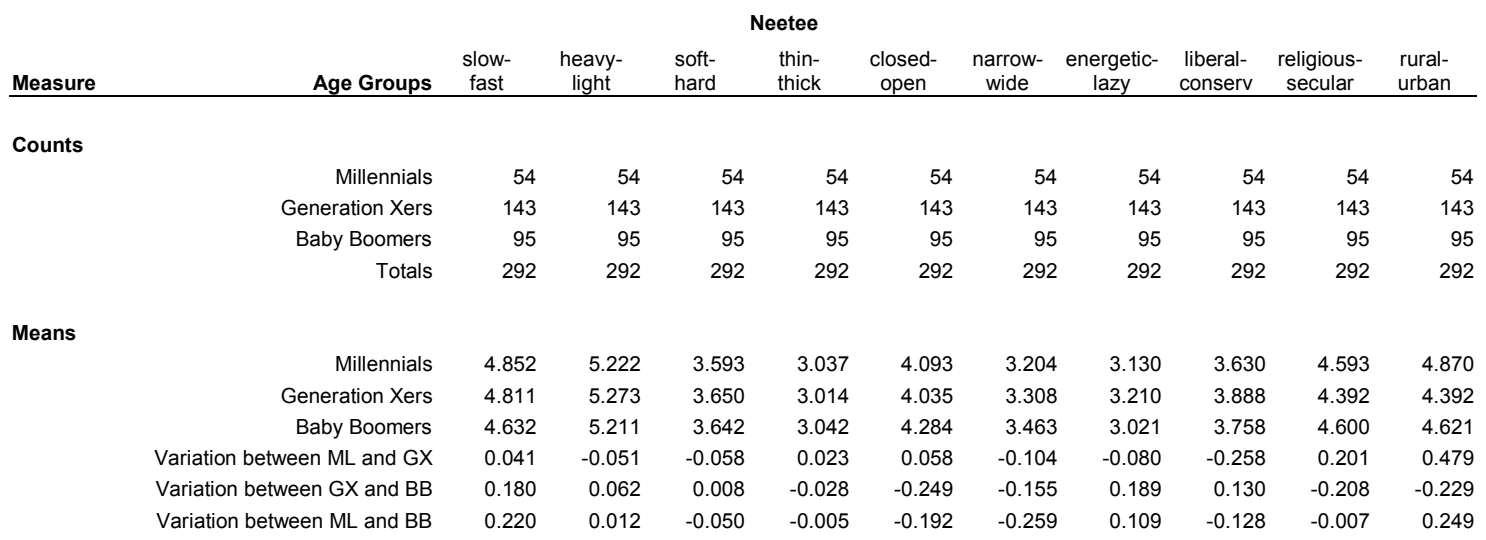

Medians

\begin{tabular}{|c|c|c|c|c|c|c|c|c|c|}
\hline Millennials & 5 & 5 & 4 & 3 & 4 & 3 & 3 & 4 & 4 \\
\hline Generation Xers & 5 & 5 & 4 & 3 & 4 & 3 & 3 & 4 & 4 \\
\hline Baby Boomers & 4 & 5 & 4 & 3 & 4 & 4 & 3 & 4 & 4 \\
\hline Variation between $\mathrm{ML}$ and $\mathrm{GX}$ & 0 & 0 & 0 & 0 & 0 & 0 & 0 & 0 & 0 \\
\hline Variation between GX and BB & 1 & 0 & 0 & 0 & 0 & -1 & 0 & 0 & 0 \\
\hline Variation between $\mathrm{ML}$ and $\mathrm{BB}$ & 1 & 0 & 0 & 0 & 0 & -1 & 0 & 0 & 0 \\
\hline
\end{tabular}

Modes

\begin{tabular}{|c|c|c|c|c|c|c|c|c|c|}
\hline Millennials & 5 & 5 & 5 & 3 & 4 & 4 & 2 & 4 & 4 \\
\hline Generation Xers & 5 & 6 & 4 & 2 & 4 & 4 & 4 & 4 & 4 \\
\hline Baby Boomers & 4 & 6 & 4 & 3 & 4 & 4 & 4 & 4 & 4 \\
\hline Variation between $\mathrm{ML}$ and $\mathrm{GX}$ & 0 & -1 & 1 & 1 & 0 & 0 & -2 & 0 & 0 \\
\hline Variation between GX and BB & 1 & 0 & 0 & -1 & 0 & 0 & 0 & 0 & 0 \\
\hline Variation between $\mathrm{ML}$ and $\mathrm{BB}$ & 1 & -1 & 1 & 0 & 0 & 0 & -2 & 0 & 0 \\
\hline
\end{tabular}

Note: On the slow-fast scale, $1=$ slowest and $7=$ fastest

$\begin{array}{ll}\text { BB } & \text { Baby Boomers } \\ \text { GX } & \text { Generation Xers } \\ \text { ML } & \text { Millennials }\end{array}$


Table E-4

Means, Modes, and Medians for the Artificial Word Kahtah, by Age

\begin{tabular}{|c|c|c|c|c|c|c|c|c|c|c|c|}
\hline \multirow[b]{2}{*}{ Measure } & \multicolumn{11}{|c|}{ Kahtah } \\
\hline & Age Groups & $\begin{array}{c}\text { slow- } \\
\text { fast }\end{array}$ & $\begin{array}{c}\text { heavy- } \\
\text { light }\end{array}$ & $\begin{array}{l}\text { soft- } \\
\text { hard }\end{array}$ & $\begin{array}{l}\text { thin- } \\
\text { thick }\end{array}$ & $\begin{array}{c}\text { closed- } \\
\text { open }\end{array}$ & $\begin{array}{l}\text { narrow- } \\
\text { wide }\end{array}$ & $\begin{array}{c}\text { energetic- } \\
\text { lazy }\end{array}$ & $\begin{array}{l}\text { liberal- } \\
\text { conserv }\end{array}$ & $\begin{array}{l}\text { religious- } \\
\text { secular }\end{array}$ & $\begin{array}{l}\text { rural- } \\
\text { urban }\end{array}$ \\
\hline \multicolumn{12}{|l|}{ Counts } \\
\hline & Millennials & 54 & 54 & 54 & 54 & 54 & 54 & 54 & 54 & 54 & 54 \\
\hline & Generation Xers & 143 & 143 & 143 & 143 & 143 & 143 & 143 & 143 & 143 & 143 \\
\hline & Baby Boomers & 95 & 95 & 95 & 95 & 95 & 95 & 95 & 95 & 95 & 95 \\
\hline & Totals & 292 & 292 & 292 & 292 & 292 & 292 & 292 & 292 & 292 & 292 \\
\hline \multicolumn{12}{|l|}{ Means } \\
\hline & Millennials & 4.093 & 3.556 & 5.074 & 4.185 & 3.741 & 4.037 & 3.833 & 3.870 & 4.296 & 3.611 \\
\hline & Generation Xers & 3.993 & 3.790 & 4.294 & 4.238 & 4.014 & 4.406 & 3.734 & 3.979 & 4.098 & 4.105 \\
\hline & Baby Boomers & 3.853 & 3.863 & 3.947 & 4.674 & 4.042 & 4.726 & 4.200 & 3.884 & 3.937 & 3.958 \\
\hline & Variation between ML and GX & 0.100 & -0.235 & 0.780 & -0.053 & -0.273 & -0.369 & 0.099 & -0.109 & 0.198 & -0.494 \\
\hline & Variation between GX and BB & 0.140 & -0.073 & 0.346 & -0.436 & -0.028 & -0.321 & -0.466 & 0.095 & 0.161 & 0.147 \\
\hline & Variation between $\mathrm{ML}$ and $\mathrm{BB}$ & 0.240 & -0.308 & 1.127 & -0.488 & -0.301 & -0.689 & -0.367 & -0.014 & 0.359 & -0.347 \\
\hline
\end{tabular}

Medians

\begin{tabular}{|c|c|c|c|c|c|c|c|c|c|}
\hline Millennials & 4 & 3 & 5.5 & 4 & 4 & 4 & 4 & 4 & 4 \\
\hline Generation Xers & 4 & 4 & 5 & 4 & 4 & 4 & 4 & 4 & 4 \\
\hline Baby Boomers & 4 & 4 & 4 & 5 & 4 & 5 & 4 & 4 & 4 \\
\hline Variation between $\mathrm{ML}$ and $\mathrm{GX}$ & 0 & -1 & 0.5 & 0 & 0 & 0 & 0 & 0 & 0 \\
\hline Variation between $\mathrm{GX}$ and $\mathrm{BB}$ & 0 & 0 & 1 & -1 & 0 & -1 & 0 & 0 & 0 \\
\hline Variation between $\mathrm{ML}$ and $\mathrm{BB}$ & 0 & -1 & 1.5 & -1 & 0 & -1 & 0 & 0 & 0 \\
\hline
\end{tabular}

Modes

\begin{tabular}{|c|c|c|c|c|c|c|c|c|c|}
\hline Millennials & 3 & 3 & 6 & 4 & 4 & 5 & 4 & 4 & 4 \\
\hline Generation Xers & 3 & 3 & 5 & 4 & 4 & 4 & 4 & 4 & 4 \\
\hline Baby Boomers & 3 & 3 & 3 & 4 & 4 & 4 & 4 & 4 & 4 \\
\hline Variation between $\mathrm{ML}$ and $\mathrm{GX}$ & 0 & 0 & 1 & 0 & 0 & 1 & 0 & 0 & 0 \\
\hline Variation between $\mathrm{GX}$ and $\mathrm{BB}$ & 0 & 0 & 2 & 0 & 0 & 0 & 0 & 0 & 0 \\
\hline Variation between $\mathrm{ML}$ and $\mathrm{BB}$ & 0 & 0 & 3 & 0 & 0 & 1 & 0 & 0 & 0 \\
\hline
\end{tabular}

Note: On the slow-fast scale, $1=$ slowest and 7 = fastest.

$\begin{array}{ll}\text { BB } & \text { Baby Boomers } \\ \text { GX } & \text { Generation Xers } \\ \text { ML } & \text { Millennials }\end{array}$


Table E-5

Means, Modes, and Medians for the Artificial Word Veetee, by Age

\begin{tabular}{|c|c|c|c|c|c|c|c|c|c|c|c|}
\hline \multirow[b]{2}{*}{ Measure } & \multicolumn{11}{|c|}{ Veetee } \\
\hline & Age Groups & $\begin{array}{c}\text { slow- } \\
\text { fast }\end{array}$ & $\begin{array}{c}\text { heavy- } \\
\text { light }\end{array}$ & $\begin{array}{l}\text { soft- } \\
\text { hard }\end{array}$ & $\begin{array}{l}\text { thin- } \\
\text { thick }\end{array}$ & $\begin{array}{c}\text { closed- } \\
\text { open }\end{array}$ & $\begin{array}{l}\text { narrow- } \\
\text { wide }\end{array}$ & $\begin{array}{c}\text { energetic- } \\
\text { lazy }\end{array}$ & $\begin{array}{c}\text { liberal- } \\
\text { conserv }\end{array}$ & $\begin{array}{c}\text { religious- } \\
\text { secular }\end{array}$ & $\begin{array}{l}\text { rural- } \\
\text { urban }\end{array}$ \\
\hline \multicolumn{12}{|l|}{ Counts } \\
\hline & Millennials & 54 & 54 & 54 & 54 & 54 & 54 & 54 & 54 & 54 & 54 \\
\hline & Generation Xers & 143 & 143 & 143 & 143 & 143 & 143 & 143 & 143 & 143 & 143 \\
\hline & Baby Boomers & 95 & 95 & 95 & 95 & 95 & 95 & 95 & 95 & 95 & 95 \\
\hline & Totals & 292 & 292 & 292 & 292 & 292 & 292 & 292 & 292 & 292 & 292 \\
\hline \multicolumn{12}{|l|}{ Means } \\
\hline & Millennials & 5.222 & 5.444 & 4.296 & 3.074 & 3.963 & 3.481 & 3.130 & 3.722 & 4.667 & 4.870 \\
\hline & Generation Xers & 5.154 & 5.084 & 4.259 & 3.105 & 4.147 & 3.266 & 2.846 & 3.524 & 4.622 & 4.944 \\
\hline & Baby Boomers & 5.179 & 5.337 & 3.979 & 2.979 & 4.305 & 3.021 & 2.758 & 3.442 & 4.842 & 4.821 \\
\hline & Variation between $\mathrm{ML}$ and $\mathrm{GX}$ & 0.068 & 0.361 & 0.038 & -0.031 & -0.184 & 0.216 & 0.283 & 0.198 & 0.044 & -0.074 \\
\hline & Variation between GX and BB & -0.025 & -0.253 & 0.280 & 0.126 & -0.158 & 0.245 & 0.088 & 0.082 & -0.220 & 0.123 \\
\hline & Variation between $\mathrm{ML}$ and $\mathrm{BB}$ & 0.043 & 0.108 & 0.317 & 0.095 & -0.342 & 0.460 & 0.372 & 0.280 & -0.175 & 0.049 \\
\hline
\end{tabular}

Medians

\begin{tabular}{|c|c|c|c|c|c|c|c|c|c|}
\hline Millennials & 5 & 6 & 4 & 3 & 4 & 4 & 3 & 4 & 4 \\
\hline Generation Xers & 5 & 5 & 4 & 3 & 4 & 3 & 3 & 4 & 4 \\
\hline Baby Boomers & 5 & 5 & 4 & 3 & 4 & 3 & 3 & 4 & 4 \\
\hline Variation between $\mathrm{ML}$ and $\mathrm{GX}$ & 0 & 1 & 0 & 0 & 0 & 1 & 0 & 0 & 0 \\
\hline Variation between GX and BB & 0 & 0 & 0 & 0 & 0 & 0 & 0 & 0 & 0 \\
\hline Variation between $\mathrm{ML}$ and $\mathrm{BB}$ & 0 & 1 & 0 & 0 & 0 & 1 & 0 & 0 & 0 \\
\hline
\end{tabular}

Modes

\begin{tabular}{|c|c|c|c|c|c|c|c|c|c|}
\hline Millennials & 7 & 5 & 6 & 2 & 4 & 4 & 4 & 4 & 4 \\
\hline Generation Xers & 7 & 6 & 4 & 3 & 4 & 4 & 2 & 4 & 4 \\
\hline Baby Boomers & 4 & 6 & 4 & 2 & 4 & 4 & 2 & 4 & 4 \\
\hline Variation between $\mathrm{ML}$ and $\mathrm{GX}$ & 0 & -1 & 2 & -1 & 0 & 0 & 2 & 0 & 0 \\
\hline Variation between $\mathrm{GX}$ and $\mathrm{BB}$ & 3 & 0 & 0 & 1 & 0 & 0 & 0 & 0 & 0 \\
\hline Variation between $\mathrm{ML}$ and $\mathrm{BB}$ & 3 & -1 & 2 & 0 & 0 & 0 & 2 & 0 & 0 \\
\hline
\end{tabular}

Note: On the slow-fast scale, $1=$ slowest and $7=$ fastest.

$\begin{array}{ll}\text { BB } & \text { Baby Boomers } \\ \text { GX } & \text { Generation Xers } \\ \text { ML } & \text { Millennials }\end{array}$




\section{Table E-6}

Means, Modes, and Medians for the Artificial Word Nahtah, by Age

\begin{tabular}{|c|c|c|c|c|c|c|c|c|c|c|c|}
\hline Measure & Age Groups & $\begin{array}{c}\text { slow- } \\
\text { fast }\end{array}$ & $\begin{array}{c}\text { heavy- } \\
\text { light }\end{array}$ & $\begin{array}{l}\text { soft- } \\
\text { hard }\end{array}$ & $\begin{array}{l}\text { ahtah } \\
\text { thin- } \\
\text { thick }\end{array}$ & $\begin{array}{l}\text { closed- } \\
\text { open }\end{array}$ & $\begin{array}{l}\text { narrow- } \\
\text { wide }\end{array}$ & $\begin{array}{c}\text { energetic- } \\
\text { lazy }\end{array}$ & $\begin{array}{l}\text { liberal- } \\
\text { conserv }\end{array}$ & $\begin{array}{l}\text { religious- } \\
\text { secular }\end{array}$ & $\begin{array}{l}\text { rural- } \\
\text { urban }\end{array}$ \\
\hline \multicolumn{12}{|l|}{ Counts } \\
\hline & Millennials & 54 & 54 & 54 & 54 & 54 & 54 & 54 & 54 & 54 & 54 \\
\hline & Generation Xers & 143 & 143 & 143 & 143 & 143 & 143 & 143 & 143 & 143 & 143 \\
\hline & Baby Boomers & 95 & 95 & 95 & 95 & 95 & 95 & 95 & 95 & 95 & 95 \\
\hline & Totals & 292 & 292 & 292 & 292 & 292 & 292 & 292 & 292 & 292 & 292 \\
\hline \multicolumn{12}{|l|}{ Means } \\
\hline & Millennials & 3.167 & 3.444 & 3.593 & 4.944 & 4.111 & 4.944 & 4.796 & 4.130 & 4.222 & 3.463 \\
\hline & Generation Xers & 3.007 & 3.748 & 3.329 & 4.573 & 4.140 & 4.510 & 4.685 & 4.161 & 4.168 & 3.720 \\
\hline & Baby Boomers & 3.358 & 3.537 & 3.695 & 4.726 & 3.726 & 4.474 & 4.526 & 3.989 & 4.147 & 3.968 \\
\hline & Variation between ML and GX & 0.160 & -0.304 & 0.264 & 0.371 & -0.029 & 0.434 & 0.111 & -0.031 & 0.054 & -0.257 \\
\hline & Variation between GX and BB & -0.351 & 0.211 & -0.366 & -0.153 & 0.414 & 0.037 & 0.159 & 0.171 & 0.020 & -0.248 \\
\hline & Variation between $\mathrm{ML}$ and $\mathrm{BB}$ & -0.191 & -0.092 & -0.102 & 0.218 & 0.385 & 0.471 & 0.270 & 0.140 & 0.075 & -0.505 \\
\hline
\end{tabular}

Medians

\begin{tabular}{|c|c|c|c|c|c|c|c|c|c|}
\hline Millennials & 3 & 3 & 4 & 5 & 4 & 5 & 5 & 4 & 4 \\
\hline Generation Xers & 3 & 4 & 3 & 5 & 4 & 5 & 5 & 4 & 4 \\
\hline Baby Boomers & 3 & 4 & 4 & 5 & 4 & 4 & 5 & 4 & 4 \\
\hline Variation between $\mathrm{ML}$ and $\mathrm{GX}$ & 0 & -1 & 1 & 0 & 0 & 0 & 0 & 0 & 0 \\
\hline Variation between $\mathrm{GX}$ and $\mathrm{BB}$ & 0 & 0 & -1 & 0 & 0 & 1 & 0 & 0 & 0 \\
\hline Variation between $\mathrm{ML}$ and $\mathrm{BB}$ & 0 & -1 & 0 & 0 & 0 & 1 & 0 & 0 & 0 \\
\hline
\end{tabular}

Modes

\begin{tabular}{|c|c|c|c|c|c|c|c|c|c|}
\hline Millennials & 3 & 3 & 2 & 5 & 4 & 5 & 5 & 4 & 4 \\
\hline Generation Xers & 3 & 4 & 3 & 4 & 4 & 4 & 4 & 4 & 4 \\
\hline Baby Boomers & 4 & 4 & 4 & 4 & 4 & 4 & 4 & 4 & 4 \\
\hline Variation between $\mathrm{ML}$ and $\mathrm{GX}$ & 0 & -1 & -1 & 1 & 0 & 1 & 1 & 0 & 0 \\
\hline Variation between GX and BB & -1 & 0 & -1 & 0 & 0 & 0 & 0 & 0 & 0 \\
\hline Variation between $\mathrm{ML}$ and $\mathrm{BB}$ & -1 & -1 & -2 & 1 & 0 & 1 & 1 & 0 & 0 \\
\hline
\end{tabular}

Note: On the slow-fast scale, $1=$ slowest and $7=$ fastest.

$\begin{array}{ll}\text { BB } & \text { Baby Boomers } \\ \text { GX } & \text { Generation Xers } \\ \text { ML } & \text { Millennials }\end{array}$




\section{Appendix F. Means, Modes, and Medians, by Gender}

Table F-1

Means, Modes, and Medians for the Artificial Word Keetee, by Gender

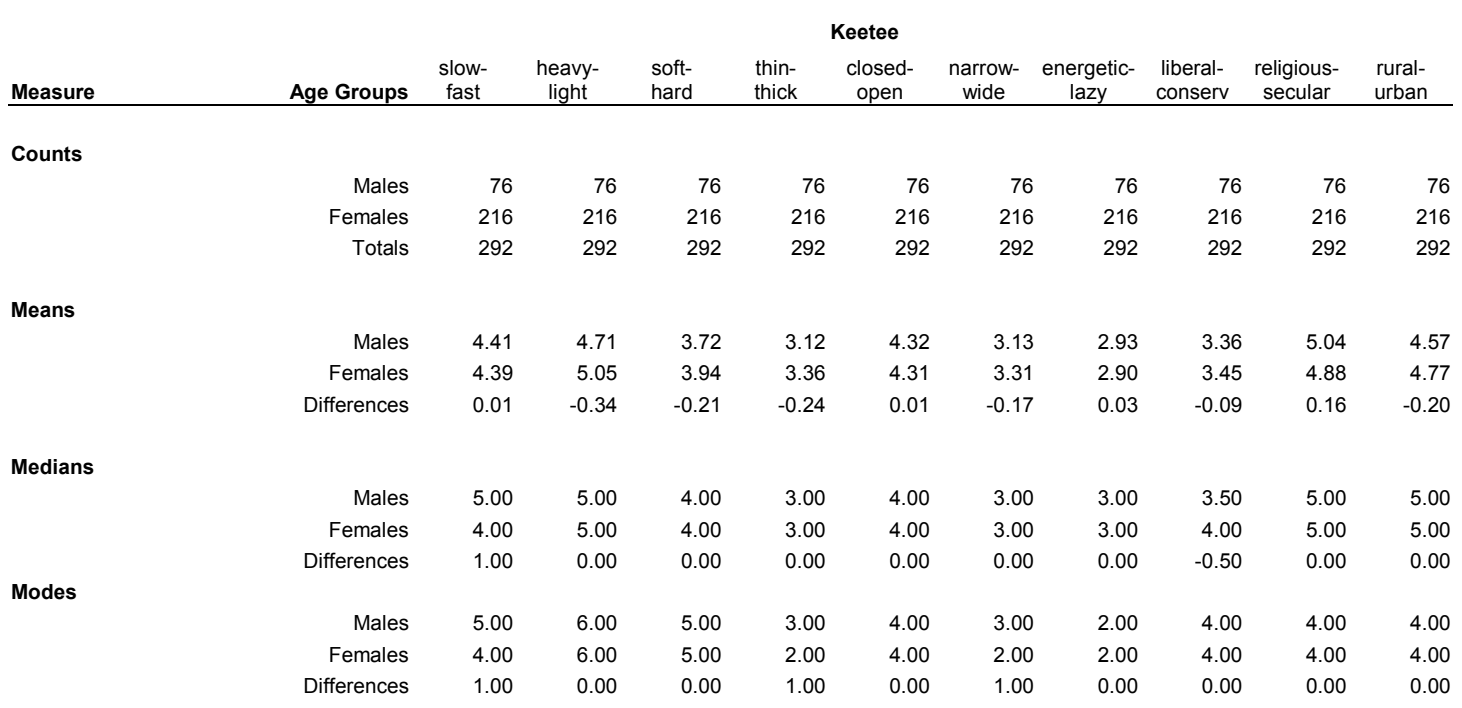

Note: On the slow-fast scale, $1=$ slowest and $7=$ fastest.

Table F-2

Means, Modes, and Medians for the Artificial Word Vahtah, by Gender

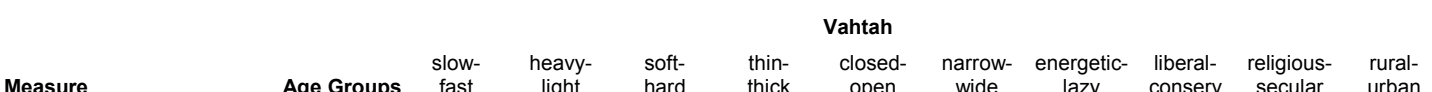

\begin{tabular}{|c|c|c|c|c|c|c|c|c|c|c|c|}
\hline Measure & Age Groups & $\begin{array}{c}\text { slow- } \\
\text { fast }\end{array}$ & $\begin{array}{c}\text { heavy- } \\
\text { light }\end{array}$ & $\begin{array}{l}\text { soft- } \\
\text { hard }\end{array}$ & $\begin{array}{l}\text { thin- } \\
\text { thick }\end{array}$ & $\begin{array}{c}\text { closed- } \\
\text { open }\end{array}$ & $\begin{array}{c}\text { narrow- } \\
\text { wide }\end{array}$ & $\begin{array}{c}\text { energetic- } \\
\text { lazy }\end{array}$ & $\begin{array}{l}\text { liberal- } \\
\text { conserv }\end{array}$ & $\begin{array}{c}\text { religious- } \\
\text { secular }\end{array}$ & $\begin{array}{l}\text { rural- } \\
\text { urban }\end{array}$ \\
\hline \multicolumn{12}{|l|}{ Counts } \\
\hline & Males & 76 & 76 & 76 & 76 & 76 & 76 & 76 & 76 & 76 & 76 \\
\hline & Females & 216 & 216 & 216 & 216 & 216 & 216 & 216 & 216 & 216 & 216 \\
\hline & Totals & 292 & 292 & 292 & 292 & 292 & 292 & 292 & 292 & 292 & 292 \\
\hline & Females & 3.56 & 3.42 & 3.75 & 4.66 & 4.32 & 4.94 & 4.33 & 3.65 & 3.84 & 4.16 \\
\hline & Differences & 0.02 & -0.13 & 0.18 & 0.06 & -0.40 & -0.11 & -0.23 & 0.40 & 0.41 & -0.02 \\
\hline \multicolumn{12}{|l|}{ Medians } \\
\hline & Males & 3.50 & 3.00 & 4.00 & 5.00 & 4.00 & 5.00 & 4.00 & 4.00 & 4.00 & 4.00 \\
\hline & Females & 3.00 & 3.00 & 4.00 & 5.00 & 4.00 & 5.00 & 5.00 & 4.00 & 4.00 & 4.00 \\
\hline & Females & 2.00 & 2.00 & 4.00 & 6.00 & 4.00 & 5.00 & 5.00 & 4.00 & 4.00 & 4.00 \\
\hline & Differences & 0.00 & 0.00 & 0.00 & -2.00 & 0.00 & -1.00 & -1.00 & 0.00 & 0.00 & 0.00 \\
\hline
\end{tabular}

Note: On the slow-fast scale, $1=$ slowest and $7=$ fastest. 
SOUND EFFECTS: AGE, GENDER, AND SOUND SYMBOLISM

Table F-3

Means, Modes, and Medians for the Artificial Word Neetee, by Gender

\begin{tabular}{|c|c|c|c|c|c|c|c|c|c|c|c|}
\hline \multirow[b]{2}{*}{ Measure } & \multirow[b]{2}{*}{ Age Groups } & \multicolumn{7}{|c|}{ Neetee } & \multirow[b]{2}{*}{$\begin{array}{l}\text { liberal- } \\
\text { conserv }\end{array}$} & \multirow[b]{2}{*}{$\begin{array}{l}\text { religious- } \\
\text { secular }\end{array}$} & \multirow[b]{2}{*}{$\begin{array}{l}\text { rural- } \\
\text { urban }\end{array}$} \\
\hline & & $\begin{array}{c}\text { slow- } \\
\text { fast }\end{array}$ & $\begin{array}{c}\text { heavy- } \\
\text { light }\end{array}$ & $\begin{array}{l}\text { soft- } \\
\text { hard }\end{array}$ & $\begin{array}{l}\text { thin- } \\
\text { thick }\end{array}$ & $\begin{array}{c}\text { closed- } \\
\text { open }\end{array}$ & $\begin{array}{l}\text { narrow- } \\
\text { wide }\end{array}$ & $\begin{array}{c}\text { energetic- } \\
\text { lazy }\end{array}$ & & & \\
\hline & Males & 76 & 76 & 76 & 76 & 76 & 76 & 76 & 76 & 76 & 76 \\
\hline & Females & 216 & 216 & 216 & 216 & 216 & 216 & 216 & 216 & 216 & 216 \\
\hline & Totals & 292 & 292 & 292 & 292 & 292 & 292 & 292 & 292 & 292 & 292 \\
\hline \multicolumn{12}{|l|}{ Means } \\
\hline & Males & 4.80 & 5.38 & 3.41 & 2.93 & 4.14 & 3.43 & 3.26 & 3.87 & 4.55 & 4.58 \\
\hline & Females & 4.75 & 5.19 & 3.72 & 3.06 & 4.12 & 3.31 & 3.09 & 3.77 & 4.48 & 4.55 \\
\hline & Differences & 0.06 & 0.19 & -0.31 & -0.13 & 0.02 & 0.13 & 0.18 & 0.10 & 0.08 & 0.03 \\
\hline \multicolumn{12}{|l|}{ Medians } \\
\hline & Males & 5.00 & 5.00 & 4.00 & 3.00 & 4.00 & 4.00 & 4.00 & 4.00 & 4.00 & 4.00 \\
\hline & Females & 4.00 & 6.00 & 4.00 & 2.00 & 4.00 & 4.00 & 4.00 & 4.00 & 4.00 & 4.00 \\
\hline & Differences & 1.00 & -1.00 & 0.00 & 1.00 & 0.00 & 0.00 & 0.00 & 0.00 & 0.00 & 0.00 \\
\hline
\end{tabular}

Note: On the slow-fast scale, $1=$ slowest and $7=$ fastest.

Table F-4

Means, Modes, and Medians for the Artificial Word Kahtah, by Gender

\begin{tabular}{|c|c|c|c|c|c|c|c|c|c|c|c|}
\hline Measure & Age Groups & $\begin{array}{c}\text { slow- } \\
\text { fast }\end{array}$ & $\begin{array}{c}\text { heavy- } \\
\text { light }\end{array}$ & $\begin{array}{l}\text { soft- } \\
\text { hard }\end{array}$ & $\begin{array}{l}\text { thin- } \\
\text { thick }\end{array}$ & $\begin{array}{l}\text { Kahtah } \\
\text { closed- } \\
\text { open } \\
\end{array}$ & $\begin{array}{l}\text { narrow- } \\
\text { wide }\end{array}$ & $\begin{array}{c}\text { energetic- } \\
\text { lazy }\end{array}$ & $\begin{array}{l}\text { liberal- } \\
\text { conserv }\end{array}$ & $\begin{array}{l}\text { religious- } \\
\text { secular }\end{array}$ & $\begin{array}{l}\text { rural- } \\
\text { urban }\end{array}$ \\
\hline & Males & 76 & 76 & 76 & 76 & 76 & 76 & 76 & 76 & 76 & 76 \\
\hline & Females & 216 & 216 & 216 & 216 & 216 & 216 & 216 & 216 & 216 & 216 \\
\hline & Totals & 292 & 292 & 292 & 292 & 292 & 292 & 292 & 292 & 292 & 292 \\
\hline \multicolumn{12}{|l|}{ Means } \\
\hline & Males & 4.12 & 3.64 & 4.66 & 4.16 & 3.76 & 4.38 & 3.79 & 4.20 & 3.97 & 3.79 \\
\hline & Females & 3.91 & 3.81 & 4.21 & 4.44 & 4.05 & 4.46 & 3.94 & 3.83 & 4.12 & 4.03 \\
\hline & Differences & 0.21 & -0.17 & 0.45 & -0.29 & -0.28 & -0.08 & -0.15 & 0.36 & -0.15 & -0.24 \\
\hline \multicolumn{12}{|l|}{ Medians } \\
\hline & Males & 3.00 & 3.00 & 5.00 & 4.00 & 4.00 & 5.00 & 4.00 & 4.00 & 4.00 & 4.00 \\
\hline & Females & 4.00 & 3.00 & 5.00 & 4.00 & 4.00 & 4.00 & 4.00 & 4.00 & 4.00 & 4.00 \\
\hline & Differences & -1.00 & 0.00 & 0.00 & 0.00 & 0.00 & 1.00 & 0.00 & 0.00 & 0.00 & 0.00 \\
\hline
\end{tabular}

Note: On the slow-fast scale, $1=$ slowest and $7=$ fastest. 
SOUND EFFECTS: AGE, GENDER, AND SOUND SYMBOLISM

Table F-5

Means, Modes, and Medians for the Artificial Word Veetee, by Gender

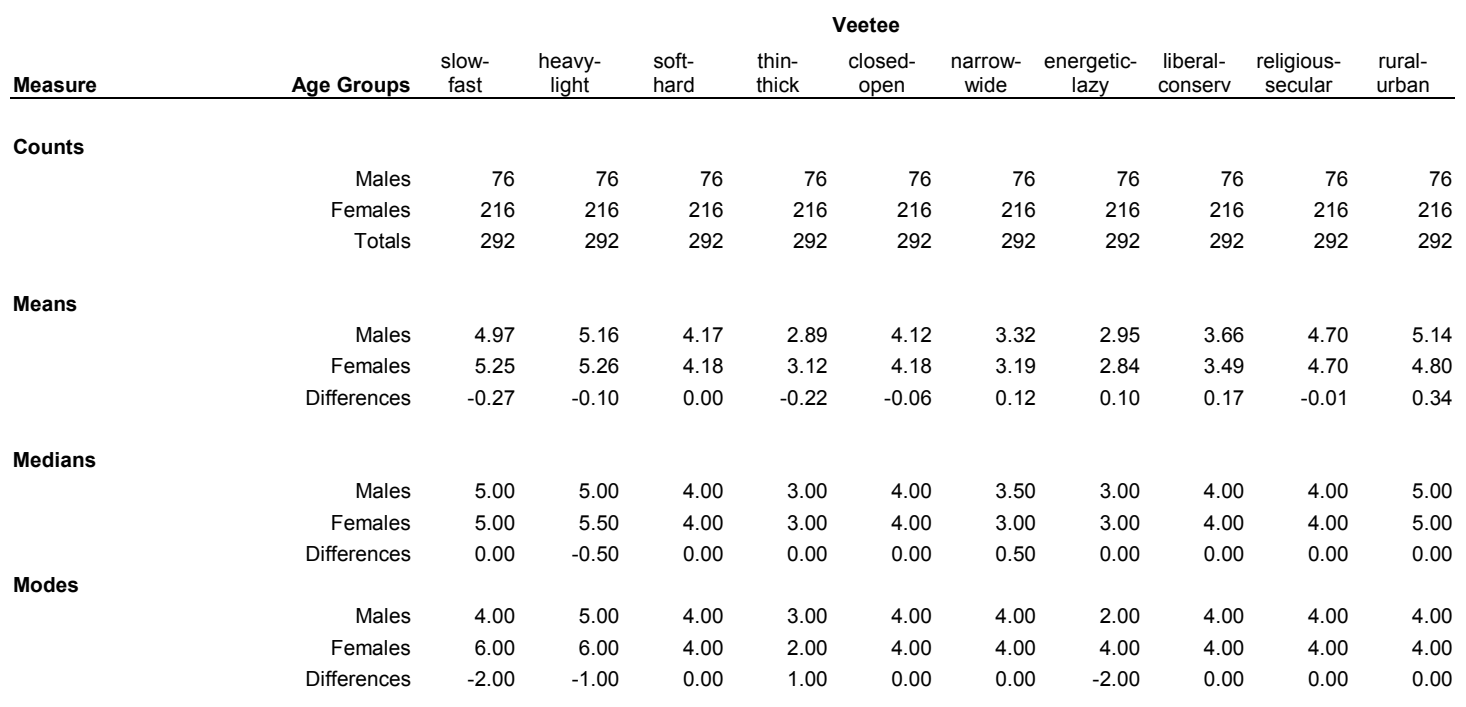

Note: On the slow-fast scale, $1=$ slowest and $7=$ fastest.

Table F-6

Means, Modes, and Medians for the Artificial Word Nahtah, by Gender

\begin{tabular}{|c|c|c|c|c|c|c|c|c|c|c|c|}
\hline Measure & Age Groups & $\begin{array}{c}\text { slow- } \\
\text { fast }\end{array}$ & $\begin{array}{c}\text { heavy- } \\
\text { light }\end{array}$ & $\begin{array}{l}\text { soft- } \\
\text { hard }\end{array}$ & $\begin{array}{l}\text { thin- } \\
\text { thick }\end{array}$ & $\begin{array}{l}\text { Nahtah } \\
\text { closed- } \\
\text { open } \\
\end{array}$ & $\begin{array}{l}\text { narrow- } \\
\text { wide }\end{array}$ & $\begin{array}{c}\text { energetic- } \\
\text { lazy }\end{array}$ & $\begin{array}{l}\text { liberal- } \\
\text { conserv }\end{array}$ & $\begin{array}{l}\text { religious- } \\
\text { secular }\end{array}$ & $\begin{array}{l}\text { rural- } \\
\text { urban }\end{array}$ \\
\hline & Males & 76 & 76 & 76 & 76 & 76 & 76 & 76 & 76 & 76 & 76 \\
\hline & Females & 216 & 216 & 216 & 216 & 216 & 216 & 216 & 216 & 216 & 216 \\
\hline & Totals & 292 & 292 & 292 & 292 & 292 & 292 & 292 & 292 & 292 & 292 \\
\hline \multicolumn{12}{|l|}{ Means } \\
\hline & Males & 2.99 & 3.78 & 3.25 & 4.68 & 3.78 & 4.67 & 4.57 & 4.28 & 4.29 & 3.93 \\
\hline & Females & 3.21 & 3.57 & 3.58 & 4.69 & 4.08 & 4.55 & 4.69 & 4.04 & 4.13 & 3.69 \\
\hline & Differences & -0.22 & 0.21 & -0.33 & -0.01 & -0.30 & 0.12 & -0.12 & 0.24 & 0.16 & 0.24 \\
\hline \multicolumn{12}{|l|}{ Medians } \\
\hline & Males & 2.00 & 3.00 & 2.00 & 4.00 & 4.00 & 4.00 & 5.00 & 4.00 & 4.00 & 4.00 \\
\hline & Females & 3.00 & 4.00 & 4.00 & 4.00 & 4.00 & 4.00 & 4.00 & 4.00 & 4.00 & 4.00 \\
\hline & Differences & -1.00 & -1.00 & -2.00 & 0.00 & 0.00 & 0.00 & 1.00 & 0.00 & 0.00 & 0.00 \\
\hline
\end{tabular}

Note: On the slow-fast scale, $1=$ slowest and $7=$ fastest. 
Appendix G. Results of Kruskal-Wallis Test, for Age

Table G-1

Results of Kruskal-Wallis Test, for Age

\begin{tabular}{|c|c|c|c|}
\hline \multicolumn{4}{|c|}{ Test Statistics } \\
\hline & Chi-Square & df & Asymp. Sig. \\
\hline Kahtah - Soft-Hard & 16.396 & 2 & .000 \\
\hline Vahtah - Soft-Hard & 10.366 & 2 & .006 \\
\hline Keetee - Liberal-Conservative & 7.095 & 2 & .029 \\
\hline Kahtah - Energetic-Lazy & 5.548 & 2 & .062 \\
\hline Kahtah - Thin-Thick & 5.430 & 2 & .066 \\
\hline Nahtah - Narrow-Wide & 5.345 & 2 & .069 \\
\hline Kahtah - Rural-Urban & 5.306 & 2 & .070 \\
\hline Vahtah - Thin-Thick & 5.128 & 2 & .077 \\
\hline Kahtah - Narrow-Wide & 4.896 & 2 & .086 \\
\hline Neetee - Rural-Urban & 4.771 & 2 & .092 \\
\hline Nahtah - Closed-Open & 4.660 & 2 & .097 \\
\hline Veetee - Narrow-Wide & 4.641 & 2 & .098 \\
\hline Nahtah - Rural-Urban & 4.623 & 2 & .099 \\
\hline Keetee - Narrow-Wide & 4.438 & 2 & .109 \\
\hline Keetee - Closed-Open & 3.848 & 2 & .146 \\
\hline Nahtah - Slow-Fast & 3.522 & 2 & .172 \\
\hline Nahtah - Soft-Hard & 3.333 & 2 & .189 \\
\hline Vahtah - Closed-Open & 2.794 & 2 & .247 \\
\hline Nahtah - Thin-Thick & 2.749 & 2 & .253 \\
\hline Veetee - Heavy-Light & 2.586 & 2 & .274 \\
\hline Keetee - Slow-Fast & 2.550 & 2 & .279 \\
\hline Keetee - Soft-Hard & 2.362 & 2 & .307 \\
\hline Neetee - Closed-Open & 2.226 & 2 & .329 \\
\hline Kahtah - Religious-Secular & 2.068 & 2 & .356 \\
\hline Veetee - Soft-Hard & 2.067 & 2 & .356 \\
\hline Nahtah - Heavy-Light & 2.042 & 2 & .360 \\
\hline Keetee- Religious-Secular & 1.966 & 2 & .374 \\
\hline Neetee - Slow-Fast & 1.841 & 2 & .398 \\
\hline Nahtah - Energetic-Lazy & 1.818 & 2 & .403 \\
\hline Kahtah - Closed-Open & 1.742 & 2 & .418 \\
\hline Vahtah - Slow-Fast & 1.728 & 2 & .422 \\
\hline
\end{tabular}




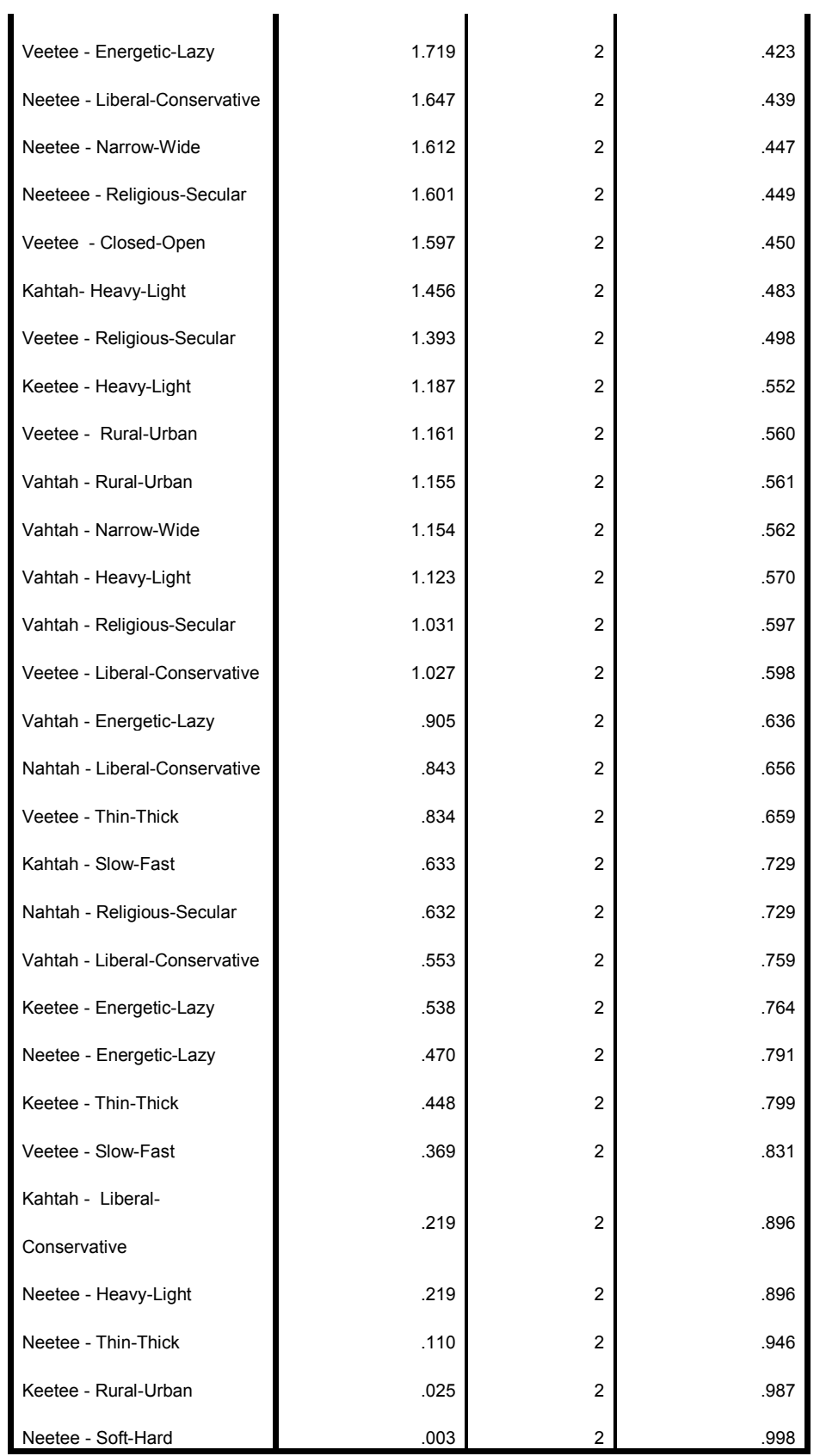


SOUND EFFECTS: AGE, GENDER, AND SOUND SYMBOLISM

Appendix H. Results of Mann-Whitney U Test, for Gender

Table H-1

Results of Kruskal-Wallis Test, for Gender

\begin{tabular}{|c|c|c|c|c|}
\hline & Mann-Whitney U & Wilcoxon W & z & Asymp. Sig. (2-tailed) \\
\hline Kahtah - Liberal-Conservative & 6649.500 & 30085.500 & -2.670 & .008 \\
\hline Vahtah - Liberal-Conservative & 6808.000 & 30244.000 & -2.319 & .020 \\
\hline Vahtah - Religious-Secular & 6820.000 & 30256.000 & -2.280 & .023 \\
\hline Vahtah - Closed-Open & 6901.500 & 9827.500 & -2.108 & .035 \\
\hline Kahtah - Soft-Hard & 6948.000 & 30384.000 & -2.019 & .044 \\
\hline Veetee - Rural-Urban & 7037.500 & 30473.500 & -1.923 & .054 \\
\hline Kahtah - Closed-Open & 7189.500 & 10115.500 & -1.656 & .098 \\
\hline Keetee - Heavy-Light & 7187.000 & 10113.000 & -1.650 & .099 \\
\hline Nahtah - Soft-Hard & 7199.500 & 10125.500 & -1.622 & .105 \\
\hline Veetee - Slow-Fast & 7237.000 & 10163.000 & -1.573 & .116 \\
\hline Nahtah - Liberal-Conservative & 7297.500 & 30733.500 & -1.567 & .117 \\
\hline Neetee - Soft-Hard & 7300.500 & 10226.500 & -1.461 & .144 \\
\hline Nahtah - Closed-Open & 7431.000 & 10357.000 & -1.263 & .207 \\
\hline Vahtah - Energetic-Lazy & 7435.000 & 10361.000 & -1.248 & .212 \\
\hline Nahtah - Rural-Urban & 7503.000 & 30939.000 & -1.187 & .235 \\
\hline Kahtah - Religious-Secular & 7504.000 & 10430.000 & -1.177 & .239 \\
\hline Kahtah - Heavy-Light & 7496.000 & 10422.000 & -1.144 & .253 \\
\hline Neetee - Heavy-Light & 7507.500 & 30943.500 & -1.137 & .256 \\
\hline Nahtah - Religious-Secular & 7553.000 & 30989.000 & -1.129 & .259 \\
\hline Keetee - Rural-Urban & 7532.000 & 10458.000 & -1.090 & .276 \\
\hline Kahtah - Rural-Urban & 7575.000 & 10501.000 & -1.053 & .292 \\
\hline Nahtah - Slow-Fast & 7570.500 & 10496.500 & -1.029 & .303 \\
\hline Vahtah - Heavy-Light & 7597.500 & 10523.500 & -.982 & .326 \\
\hline Keetee - Soft-Hard & 7609.000 & 10535.000 & -.961 & .337 \\
\hline Keetee - Thin-Thick & 7621.000 & 10547.000 & -.948 & .343 \\
\hline Veetee - Thin-Thick & 7669.500 & 10595.500 & -.869 & .385 \\
\hline Keetee- Narrow-Wide & 7703.000 & 10629.000 & -.815 & .415 \\
\hline Vahtah- Soft-Hard & 7702.500 & 31138.500 & -.812 & .417 \\
\hline Veetee - Liberal-Conservative & 7753.000 & 31189.000 & -.776 & .438 \\
\hline Kahtah - Thin-Thick & 7739.000 & 10665.000 & -.760 & .447 \\
\hline
\end{tabular}




\begin{tabular}{|c|c|c|c|c|}
\hline Keetee - Religious-Secular & 7749.000 & 31185.000 & -.759 & .448 \\
\hline Kahtah - Slow-Fast & 7743.500 & 31179.500 & -.746 & .456 \\
\hline Vahtah - Narrow-Wide & 7760.000 & 10686.000 & -.728 & .467 \\
\hline $\begin{array}{l}\text { Keetee - Liberal- } \\
\text { Conservative }\end{array}$ & 7801.000 & 10727.000 & -.675 & .499 \\
\hline Veetee - Narrow-Wide & 7797.500 & 31233.500 & -.667 & .504 \\
\hline Veetee - Heavy-Light & 7810.000 & 10736.000 & -.644 & .519 \\
\hline Neetee - Thin-Thick & 7825.000 & 10751.000 & -.620 & .535 \\
\hline Nahtah - Energetic-Lazy & 7847.000 & 10773.000 & -.584 & .559 \\
\hline Kahtah - Energetic-Lazy & 7849.000 & 10775.000 & -.579 & .563 \\
\hline Veetee - Energetic-Lazy & 7851.000 & 31287.000 & -.578 & .564 \\
\hline Neetee - Energetic-Lazy & 7859.500 & 31295.500 & -.565 & .572 \\
\hline Keetee - Energetic-Lazy & 7858.500 & 31294.500 & -.565 & .572 \\
\hline Neetee - Narrow-Wide & 7876.500 & 31312.500 & -.539 & .590 \\
\hline Keetee - Slow-Fast & 7893.500 & 31329.500 & -.515 & .607 \\
\hline Neetee- Slow-Fast & 7919.000 & 31355.000 & -.470 & .638 \\
\hline Nahtah - Heavy-Light & 7921.500 & 31357.500 & -.460 & .646 \\
\hline Veetee - Closed-Open & 7960.000 & 10886.000 & -.406 & .684 \\
\hline Vahtah - Thin-Thick & 8020.500 & 31456.500 & -.303 & .762 \\
\hline Neetee - Liberal-Conservative & 8040.500 & 31476.500 & -.289 & .773 \\
\hline Nahtah - Narrow-Wide & 8043.000 & 31479.000 & -.268 & .789 \\
\hline Vahtah - Rural-Urban & 8051.000 & 10977.000 & -.256 & .798 \\
\hline Neetee - Closed-Wide & 8070.500 & 10996.500 & -.226 & .821 \\
\hline Neetee - Rural-Urban & 8088.000 & 31524.000 & -.199 & .842 \\
\hline Vahtah - Slow-Fast & 8084.500 & 31520.500 & -.199 & .842 \\
\hline Keetee - Closed-Open & 8092.500 & 11018.500 & -.188 & .851 \\
\hline Neetee - Religious-Secular & 8103.000 & 31539.000 & -.183 & .855 \\
\hline Veetee - Soft-Hard & 8159.500 & 11085.500 & -.078 & .938 \\
\hline Veetee - Religious-Secular & 8186.000 & 31622.000 & -.038 & .970 \\
\hline Kahtah - Narrow-Wide & 8207.000 & 31643.000 & -.002 & .999 \\
\hline Nahtah - Thin-Thick & 8208.000 & 11134.000 & .000 & 1.000 \\
\hline
\end{tabular}


SOUND EFFECTS: AGE, GENDER, AND SOUND SYMBOLISM

\section{Appendix I. Results of Category Coding of Qualitative Data}

Table I-1

Results of Category Coding of Qualitative Data for the Artificial Word Keetee

\begin{tabular}{|c|c|c|c|c|c|c|c|c|c|c|c|c|}
\hline KEETEE & & 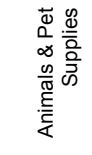 & 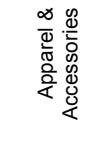 & 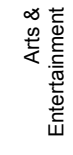 & 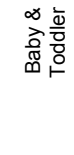 & 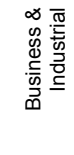 & 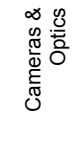 & 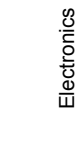 & 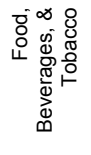 & 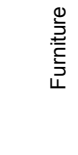 & 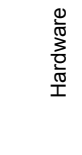 & 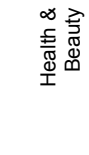 \\
\hline Number of responses & 238 & 45 & 20 & 3 & 2 & 2 & 0 & 18 & 35 & 0 & 2 & 34 \\
\hline Percent of responses & & $18.91 \%$ & $8.40 \%$ & $1.26 \%$ & $0.84 \%$ & $0.84 \%$ & $0.00 \%$ & $7.56 \%$ & $14.71 \%$ & $0.00 \%$ & $0.84 \%$ & $14.29 \%$ \\
\hline Females & 174 & $20.69 \%$ & $9.77 \%$ & $0.57 \%$ & $0.57 \%$ & $1.15 \%$ & $0.00 \%$ & $9.20 \%$ & $14.37 \%$ & $0.00 \%$ & $1.15 \%$ & $13.22 \%$ \\
\hline Males & 64 & $14.06 \%$ & $4.69 \%$ & $3.13 \%$ & $1.56 \%$ & $0.00 \%$ & $0.00 \%$ & $3.13 \%$ & $15.63 \%$ & $0.00 \%$ & $0.00 \%$ & $17.19 \%$ \\
\hline Baby Boomers & 75 & $22.67 \%$ & $8.00 \%$ & $0.00 \%$ & $2.67 \%$ & $0.00 \%$ & $0.00 \%$ & $4.00 \%$ & $12.00 \%$ & $0.00 \%$ & $0.00 \%$ & $16.00 \%$ \\
\hline Generation Xers & 120 & $17.50 \%$ & $7.50 \%$ & $1.67 \%$ & $0.00 \%$ & $0.00 \%$ & $0.00 \%$ & $8.33 \%$ & $18.33 \%$ & $0.00 \%$ & $0.83 \%$ & $14.17 \%$ \\
\hline Millennials & 43 & $16.28 \%$ & $11.63 \%$ & $2.33 \%$ & $0.00 \%$ & $4.65 \%$ & $0.00 \%$ & $11.63 \%$ & $9.30 \%$ & $0.00 \%$ & $2.33 \%$ & $11.63 \%$ \\
\hline Baby Boomer females & 57 & $26.32 \%$ & $10.53 \%$ & $0.00 \%$ & $1.75 \%$ & $0.00 \%$ & $0.00 \%$ & $5.26 \%$ & $8.77 \%$ & $0.00 \%$ & $0.00 \%$ & $14.04 \%$ \\
\hline Baby Boomer males & 18 & $11.11 \%$ & $0.00 \%$ & $0.00 \%$ & $5.56 \%$ & $0.00 \%$ & $0.00 \%$ & $0.00 \%$ & $22.22 \%$ & $0.00 \%$ & $0.00 \%$ & $22.22 \%$ \\
\hline Generation $X$ females & 90 & $20.00 \%$ & $6.67 \%$ & $1.11 \%$ & $0.00 \%$ & $0.00 \%$ & $0.00 \%$ & $10.00 \%$ & $20.00 \%$ & $0.00 \%$ & $1.11 \%$ & $13.33 \%$ \\
\hline Generation $\mathrm{X}$ males & 30 & $10.00 \%$ & $10.00 \%$ & $3.33 \%$ & $0.00 \%$ & $0.00 \%$ & $0.00 \%$ & $3.33 \%$ & $13.33 \%$ & $0.00 \%$ & $0.00 \%$ & $16.67 \%$ \\
\hline Millennial females & 27 & $11.11 \%$ & $18.52 \%$ & $0.00 \%$ & $0.00 \%$ & $7.41 \%$ & $0.00 \%$ & $14.81 \%$ & $7.41 \%$ & $0.00 \%$ & $3.70 \%$ & $11.11 \%$ \\
\hline Millennial males & 16 & $13.33 \%$ & $0.00 \%$ & $3.33 \%$ & $0.00 \%$ & $0.00 \%$ & $0.00 \%$ & $3.33 \%$ & $6.67 \%$ & $0.00 \%$ & $0.00 \%$ & 6.67 \\
\hline
\end{tabular}

\begin{tabular}{|c|c|c|c|c|c|c|c|c|c|c|c|c|}
\hline KEETEE & \begin{tabular}{ll}
$\infty$ & \multicolumn{1}{c}{} \\
$\stackrel{0}{0}$ \\
है \\
유
\end{tabular} & 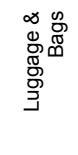 & 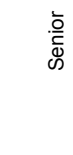 & $\begin{array}{l}\frac{\pi}{\bar{\alpha}} \\
\frac{\mathbb{d}}{2}\end{array}$ & 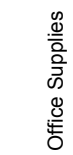 & 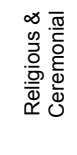 & 造 & 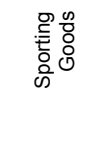 & 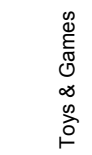 & 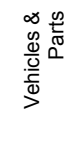 & 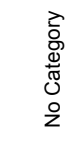 & 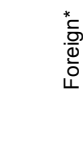 \\
\hline Number of responses & 24 & 0 & 1 & 0 & 0 & 0 & 10 & 18 & 18 & 10 & 12 & 15 \\
\hline Percent of responses & $10.08 \%$ & $0.00 \%$ & $0.42 \%$ & $0.00 \%$ & $0.00 \%$ & $0.00 \%$ & $4.20 \%$ & $7.56 \%$ & $7.56 \%$ & $4.20 \%$ & $5.04 \%$ & $6.30 \%$ \\
\hline Females & $9.77 \%$ & $0.00 \%$ & $0.57 \%$ & $0.00 \%$ & $0.00 \%$ & $0.00 \%$ & $4.02 \%$ & $8.05 \%$ & $6.32 \%$ & $3.45 \%$ & $1.72 \%$ & $7.47 \%$ \\
\hline Males & 0.10938 & $0.00 \%$ & $0.00 \%$ & $0.00 \%$ & $0.00 \%$ & $0.00 \%$ & $4.69 \%$ & $6.25 \%$ & $10.94 \%$ & $6.25 \%$ & $4.69 \%$ & $3.13 \%$ \\
\hline Baby Boomers & $8.00 \%$ & $0.00 \%$ & $1.33 \%$ & $0.00 \%$ & $0.00 \%$ & $0.00 \%$ & $1.33 \%$ & $5.33 \%$ & $5.33 \%$ & $5.33 \%$ & $5.33 \%$ & $9.33 \%$ \\
\hline Generation Xers & $10.83 \%$ & $0.00 \%$ & $0.00 \%$ & $0.00 \%$ & $0.00 \%$ & $0.00 \%$ & $5.00 \%$ & $8.33 \%$ & $10.83 \%$ & $4.17 \%$ & $4.17 \%$ & $5.83 \%$ \\
\hline Millennials & $11.63 \%$ & $0.00 \%$ & $0.00 \%$ & $0.00 \%$ & $0.00 \%$ & $0.00 \%$ & $6.98 \%$ & $9.30 \%$ & $2.33 \%$ & $2.33 \%$ & $6.98 \%$ & $2.33 \%$ \\
\hline Baby Boomer females & $7.02 \%$ & $0.00 \%$ & $1.75 \%$ & $0.00 \%$ & $0.00 \%$ & $0.00 \%$ & $1.75 \%$ & $7.02 \%$ & $3.51 \%$ & $5.26 \%$ & $7.02 \%$ & $8.77 \%$ \\
\hline Baby Boomer males & $11.11 \%$ & $0.00 \%$ & $0.00 \%$ & $0.00 \%$ & $0.00 \%$ & $0.00 \%$ & $0.00 \%$ & $0.00 \%$ & $11.11 \%$ & $5.56 \%$ & $0.00 \%$ & $11.11 \%$ \\
\hline Generation X females & $10.00 \%$ & $0.00 \%$ & $0.00 \%$ & $0.00 \%$ & $0.00 \%$ & $0.00 \%$ & $4.44 \%$ & $7.78 \%$ & $10.00 \%$ & $3.33 \%$ & $4.44 \%$ & $7.78 \%$ \\
\hline Generation $\mathrm{X}$ males & $13.33 \%$ & $0.00 \%$ & $0.00 \%$ & $0.00 \%$ & $0.00 \%$ & $0.00 \%$ & $6.67 \%$ & $10.00 \%$ & $13.33 \%$ & $6.67 \%$ & $3.33 \%$ & $0.00 \%$ \\
\hline Millennial females & $14.81 \%$ & $0.00 \%$ & $0.00 \%$ & $0.00 \%$ & $0.00 \%$ & $0.00 \%$ & $7.41 \%$ & $11.11 \%$ & $0.00 \%$ & $0.00 \%$ & $3.70 \%$ & $3.70 \%$ \\
\hline Millennial males & $3.33 \%$ & $0.00 \%$ & $0.00 \%$ & $0.00 \%$ & $0.00 \%$ & $0.00 \%$ & $3.33 \%$ & $3.33 \%$ & $3.33 \%$ & $3.33 \%$ & $6.67 \%$ & $0.00 \%$ \\
\hline
\end{tabular}

*"Foreign" was not a category on the standard product taxonomy

but includes any mention of the words foreign, exotic, names of other countries or languages, etc. 
SOUND EFFECTS: AGE, GENDER, AND SOUND SYMBOLISM

Table I-2

Results of Category Coding of Qualitative Data for the Artificial Word Vahtah

\begin{tabular}{|c|c|c|c|c|c|c|c|c|c|c|c|c|}
\hline VAHTAH & & 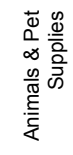 & 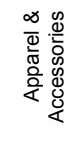 & 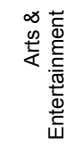 & 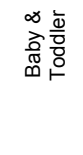 & 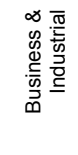 & 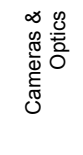 & $\begin{array}{l}\frac{0}{0} \\
\frac{0}{0} \\
\frac{0}{0} \\
\frac{0}{W}\end{array}$ & 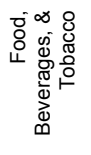 & 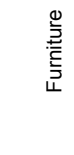 & $\begin{array}{l}\frac{0}{\frac{10}{\pi}} \\
\frac{3}{0} \\
\frac{0}{10} \\
\frac{10}{1}\end{array}$ & 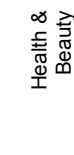 \\
\hline Number of responses & 270 & 4 & 12 & 7 & 1 & 3 & 0 & 5 & 75 & 5 & 1 & 21 \\
\hline Percent of responses & & $1.48 \%$ & $4.44 \%$ & $2.59 \%$ & $0.37 \%$ & $1.11 \%$ & $0.00 \%$ & $1.85 \%$ & $27.78 \%$ & $1.85 \%$ & $0.37 \%$ & $7.78 \%$ \\
\hline Females & 198 & $1.52 \%$ & $6.06 \%$ & $3.03 \%$ & $0.51 \%$ & $0.51 \%$ & $0.00 \%$ & $2.02 \%$ & $27.27 \%$ & $1.01 \%$ & $0.51 \%$ & $8.08 \%$ \\
\hline Males & 72 & $1.39 \%$ & $0.00 \%$ & $1.39 \%$ & $0.00 \%$ & $2.78 \%$ & $0.00 \%$ & $1.39 \%$ & $29.17 \%$ & $4.17 \%$ & $0.00 \%$ & $6.94 \%$ \\
\hline Baby Boomers & 86 & $0.0 \%$ & $7.0 \%$ & $4.7 \%$ & $0.0 \%$ & $0.0 \%$ & $0.0 \%$ & $0.0 \%$ & $30.2 \%$ & $1.2 \%$ & $0.0 \%$ & $9.3 \%$ \\
\hline Generation Xers & 131 & $3.1 \%$ & $3.1 \%$ & $0.8 \%$ & $0.8 \%$ & $1.5 \%$ & $0.0 \%$ & $3.1 \%$ & $26.0 \%$ & $1.5 \%$ & $0.0 \%$ & $8.4 \%$ \\
\hline Millennials & 53 & $0.0 \%$ & $3.8 \%$ & $3.8 \%$ & $0.0 \%$ & $1.9 \%$ & $0.0 \%$ & $1.9 \%$ & $28.3 \%$ & $3.8 \%$ & $1.9 \%$ & $3.8 \%$ \\
\hline Baby Boomer females & 65 & $0.0 \%$ & $9.2 \%$ & $4.6 \%$ & $0.0 \%$ & $0.0 \%$ & $0.0 \%$ & $0.0 \%$ & $27.7 \%$ & $1.5 \%$ & $0.0 \%$ & $12.3 \%$ \\
\hline Baby Boomer males & 21 & $0.0 \%$ & $0.0 \%$ & $4.8 \%$ & $0.0 \%$ & $0.0 \%$ & $0.0 \%$ & $0.0 \%$ & $38.1 \%$ & $0.0 \%$ & $0.0 \%$ & $0.0 \%$ \\
\hline Generation $\mathrm{X}$ females & 98 & $3.1 \%$ & $4.1 \%$ & $1.0 \%$ & $1.0 \%$ & $0.0 \%$ & $0.0 \%$ & $3.1 \%$ & $26.5 \%$ & $1.0 \%$ & $0.0 \%$ & $6.1 \%$ \\
\hline Generation $\mathrm{X}$ males & 33 & $3.0 \%$ & $0.0 \%$ & $0.0 \%$ & $0.0 \%$ & $6.1 \%$ & $0.0 \%$ & $3.0 \%$ & $24.2 \%$ & $3.0 \%$ & $0.0 \%$ & $15.2 \%$ \\
\hline Millennial females & 35 & $0.0 \%$ & $5.7 \%$ & $5.7 \%$ & $0.0 \%$ & $2.9 \%$ & $0.0 \%$ & $2.9 \%$ & $28.6 \%$ & $0.0 \%$ & $2.9 \%$ & 5. \\
\hline Millennial males & 18 & $0.0 \%$ & $0.0 \%$ & $0.0 \%$ & $0.0 \%$ & $0.0 \%$ & $0.0 \%$ & $0.0 \%$ & $27.8 \%$ & $11.1 \%$ & $0.0 \%$ & 0.0 \\
\hline
\end{tabular}

\begin{tabular}{|c|c|c|c|c|c|c|c|c|c|c|c|c|}
\hline VAHTAH & 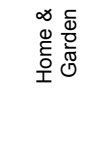 & 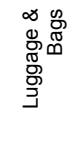 & $\begin{array}{l}\frac{\bar{o}}{\bar{T}} \\
\stackrel{\bar{D}}{ }\end{array}$ & $\begin{array}{l}\frac{\pi}{\pi} \\
\sum^{\frac{\pi}{2}}\end{array}$ & 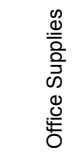 & 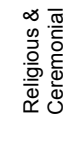 & 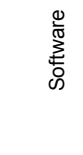 & 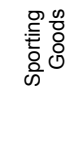 & 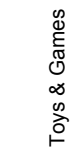 & 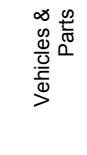 & 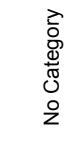 & 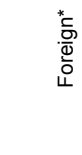 \\
\hline Number of responses & 32 & 0 & 1 & 0 & 1 & 9 & 3 & 16 & 3 & 19 & 23 & 39 \\
\hline Percent of responses & $11.85 \%$ & $0.00 \%$ & $0.37 \%$ & $0.00 \%$ & $0.37 \%$ & $3.33 \%$ & $1.11 \%$ & $5.93 \%$ & $1.11 \%$ & $7.04 \%$ & $8.52 \%$ & $14.44 \%$ \\
\hline Females & $11.11 \%$ & $0.00 \%$ & $0.51 \%$ & $0.00 \%$ & $0.51 \%$ & $3.54 \%$ & $0.00 \%$ & $6.06 \%$ & $1.52 \%$ & $5.05 \%$ & $8.59 \%$ & $14.65 \%$ \\
\hline Males & $13.89 \%$ & $0.00 \%$ & $0.00 \%$ & $0.00 \%$ & $0.00 \%$ & $2.78 \%$ & $4.17 \%$ & $5.56 \%$ & $0.00 \%$ & $12.50 \%$ & $8.33 \%$ & $13.89 \%$ \\
\hline Baby Boomers & $7.0 \%$ & $0.0 \%$ & $0.0 \%$ & $0.0 \%$ & $1.2 \%$ & $4.7 \%$ & $1.2 \%$ & $5.8 \%$ & $0.0 \%$ & $3.5 \%$ & $10.5 \%$ & $15.1 \%$ \\
\hline Generation Xers & $14.5 \%$ & $0.0 \%$ & $0.8 \%$ & $0.0 \%$ & $0.0 \%$ & $3.1 \%$ & $1.5 \%$ & $4.6 \%$ & $2.3 \%$ & $9.2 \%$ & $6.1 \%$ & $16.0 \%$ \\
\hline Millennials & $13.2 \%$ & $0.0 \%$ & $0.0 \%$ & $0.0 \%$ & $0.0 \%$ & $1.9 \%$ & $0.0 \%$ & $9.4 \%$ & $0.0 \%$ & $7.5 \%$ & $11.3 \%$ & $9.4 \%$ \\
\hline Baby Boomer females & $6.2 \%$ & $0.0 \%$ & $0.0 \%$ & $0.0 \%$ & $1.5 \%$ & $6.2 \%$ & $0.0 \%$ & $6.2 \%$ & $0.0 \%$ & $1.5 \%$ & $12.3 \%$ & $15.4 \%$ \\
\hline Baby Boomer males & $9.5 \%$ & $0.0 \%$ & $0.0 \%$ & $0.0 \%$ & $0.0 \%$ & $0.0 \%$ & $4.8 \%$ & $4.8 \%$ & $0.0 \%$ & $9.5 \%$ & $4.8 \%$ & $14.3 \%$ \\
\hline Generation $\mathrm{X}$ females & $13.3 \%$ & $0.0 \%$ & $1.0 \%$ & $0.0 \%$ & $0.0 \%$ & $3.1 \%$ & $0.0 \%$ & $5.1 \%$ & $3.1 \%$ & $7.1 \%$ & $7.1 \%$ & $17.3 \%$ \\
\hline Generation $\mathrm{X}$ males & $18.2 \%$ & $0.0 \%$ & $0.0 \%$ & $0.0 \%$ & $0.0 \%$ & $3.0 \%$ & $6.1 \%$ & $3.0 \%$ & $0.0 \%$ & $15.2 \%$ & $3.0 \%$ & $12.1 \%$ \\
\hline Millennial females & $14.3 \%$ & $0.0 \%$ & $0.0 \%$ & $0.0 \%$ & $0.0 \%$ & $0.0 \%$ & $0.0 \%$ & $8.6 \%$ & $0.0 \%$ & $5.7 \%$ & $5.7 \%$ & $5.7 \%$ \\
\hline Millennial males & $11.1 \%$ & $0.0 \%$ & $0.0 \%$ & $0.0 \%$ & $0.0 \%$ & $5.6 \%$ & $0.0 \%$ & $11.1 \%$ & $0.0 \%$ & $11.1 \%$ & $22.2 \%$ & $16.7 \%$ \\
\hline
\end{tabular}

*"Foreign" was not a category on the standard product taxonomy

but includes any mention of the words foreign, exotic, names of other countries or languages, etc. 
SOUND EFFECTS: AGE, GENDER, AND SOUND SYMBOLISM

Table I-3

Results of Category Coding of Qualitative Data for the Artificial Word Neetee

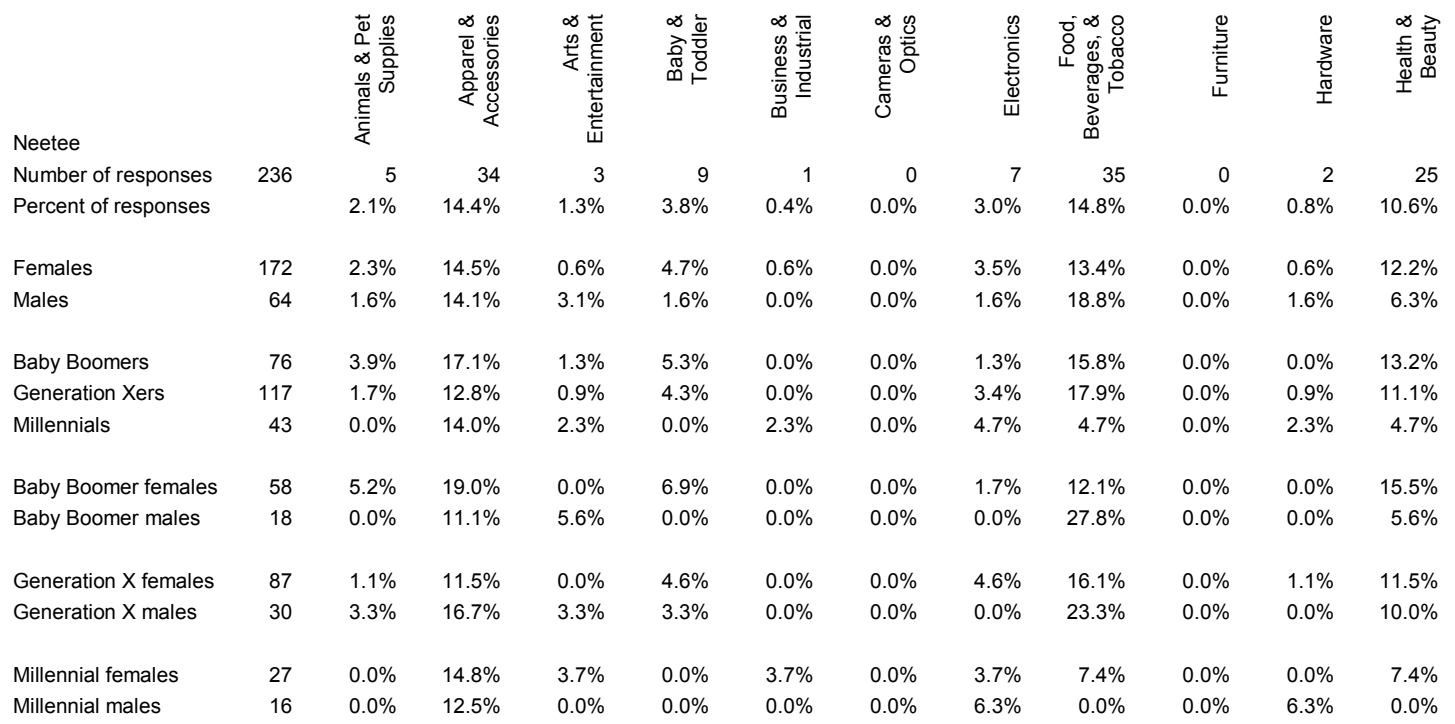

\begin{tabular}{|c|c|c|c|c|c|c|c|c|c|c|c|c|}
\hline Neetee & 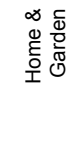 & 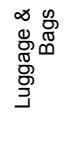 & 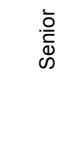 & $\begin{array}{l}\frac{\pi}{0} \\
\frac{0}{2}\end{array}$ & 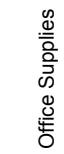 & 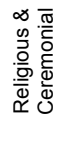 & 离 & 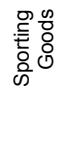 & 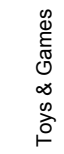 & 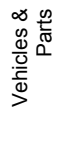 & 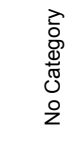 & 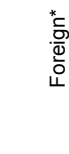 \\
\hline Number of responses & 80 & 0 & 2 & 0 & 4 & 0 & 2 & 5 & 6 & 3 & 17 & 8 \\
\hline Percent of responses & $33.9 \%$ & $0.0 \%$ & $0.8 \%$ & $0.0 \%$ & $1.7 \%$ & $0.0 \%$ & $0.8 \%$ & $2.1 \%$ & $2.5 \%$ & $1.3 \%$ & $7.2 \%$ & $3.4 \%$ \\
\hline Females & $33.1 \%$ & $0.0 \%$ & $1.2 \%$ & $0.0 \%$ & $2.3 \%$ & $0.0 \%$ & $0.6 \%$ & $1.7 \%$ & $2.9 \%$ & $1.2 \%$ & $7.0 \%$ & $2.3 \%$ \\
\hline Males & $35.9 \%$ & $0.0 \%$ & $0.0 \%$ & $0.0 \%$ & $0.0 \%$ & $0.0 \%$ & $1.6 \%$ & $3.1 \%$ & $1.6 \%$ & $1.6 \%$ & $7.8 \%$ & $6.3 \%$ \\
\hline Baby Boomers & $34.2 \%$ & $0.0 \%$ & $0.0 \%$ & $0.0 \%$ & $0.0 \%$ & $0.0 \%$ & $1.3 \%$ & $1.3 \%$ & $1.3 \%$ & $0.0 \%$ & $2.6 \%$ & $2.6 \%$ \\
\hline Generation Xers & $31.6 \%$ & $0.0 \%$ & $1.7 \%$ & $0.0 \%$ & $2.6 \%$ & $0.0 \%$ & $0.9 \%$ & $2.6 \%$ & $2.6 \%$ & $0.9 \%$ & $8.5 \%$ & $4.3 \%$ \\
\hline Millennials & $39.5 \%$ & $0.0 \%$ & $0.0 \%$ & $0.0 \%$ & $2.3 \%$ & $0.0 \%$ & $0.0 \%$ & $2.3 \%$ & $4.7 \%$ & $4.7 \%$ & $11.6 \%$ & $2.3 \%$ \\
\hline Baby Boomer females & $31.0 \%$ & $0.0 \%$ & $0.0 \%$ & $0.0 \%$ & $0.0 \%$ & $0.0 \%$ & $0.0 \%$ & $1.7 \%$ & $1.7 \%$ & $0.0 \%$ & $3.4 \%$ & $0.0 \%$ \\
\hline Baby Boomer males & $44.4 \%$ & $0.0 \%$ & $0.0 \%$ & $0.0 \%$ & $0.0 \%$ & $0.0 \%$ & $5.6 \%$ & $0.0 \%$ & $0.0 \%$ & $0.0 \%$ & $0.0 \%$ & $11.1 \%$ \\
\hline Generation $\mathrm{X}$ females & $33.3 \%$ & $0.0 \%$ & $2.3 \%$ & $0.0 \%$ & $3.4 \%$ & $0.0 \%$ & $1.1 \%$ & $2.3 \%$ & $3.4 \%$ & $1.1 \%$ & $6.9 \%$ & $4.6 \%$ \\
\hline Generation $\mathrm{X}$ males & $26.7 \%$ & $0.0 \%$ & $0.0 \%$ & $0.0 \%$ & $0.0 \%$ & $0.0 \%$ & $0.0 \%$ & $3.3 \%$ & $0.0 \%$ & $0.0 \%$ & $13.3 \%$ & $3.3 \%$ \\
\hline Millennial females & $37.0 \%$ & $0.0 \%$ & $0.0 \%$ & $0.0 \%$ & $3.7 \%$ & $0.0 \%$ & $0.0 \%$ & $0.0 \%$ & $3.7 \%$ & $3.7 \%$ & $14.8 \%$ & $0.0 \%$ \\
\hline Millennial males & $43.8 \%$ & $0.0 \%$ & $0.0 \%$ & $0.0 \%$ & $0.0 \%$ & $0.0 \%$ & $0.0 \%$ & $6.3 \%$ & $6.3 \%$ & $6.3 \%$ & $6.3 \%$ & $6.3 \%$ \\
\hline
\end{tabular}

*"Foreign" was not a category on the standard product taxonomy

but includes any mention of the words foreign, exotic, names of other countries or languages, etc. 
SOUND EFFECTS: AGE, GENDER, AND SOUND SYMBOLISM

Table I-4

Results of Category Coding of Qualitative Data for the Artificial Word Kahtah

\begin{tabular}{|c|c|c|c|c|c|c|c|c|c|c|c|c|}
\hline Kahtah & & 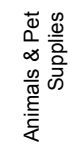 & 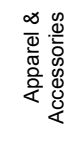 & 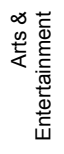 & 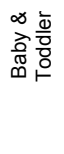 & 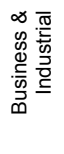 & 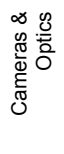 & 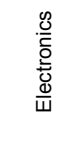 & 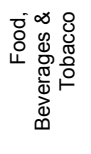 & 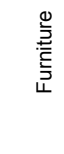 & $\begin{array}{l}\frac{0}{\frac{0}{\pi}} \\
\frac{3}{3} \\
\frac{0}{\pi} \\
\frac{\pi}{1}\end{array}$ & 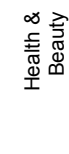 \\
\hline Number of responses & 230 & 14 & 20 & 8 & 1 & 2 & 0 & 2 & 43 & 2 & 9 & 11 \\
\hline Percent of responses & & $6.1 \%$ & $8.7 \%$ & $3.5 \%$ & $0.4 \%$ & $0.9 \%$ & $0.0 \%$ & $0.9 \%$ & $18.7 \%$ & $0.9 \%$ & $3.9 \%$ & $4.8 \%$ \\
\hline Baby Boomers & 74 & $10.8 \%$ & $8.1 \%$ & $4.1 \%$ & $0.0 \%$ & $1.4 \%$ & $0.0 \%$ & $1.4 \%$ & $20.3 \%$ & $0.0 \%$ & $2.7 \%$ & $6.8 \%$ \\
\hline Generation Xers & 115 & $5.2 \%$ & $9.6 \%$ & $2.6 \%$ & $0.9 \%$ & $0.0 \%$ & $0.0 \%$ & $0.0 \%$ & $20.0 \%$ & $0.9 \%$ & $3.5 \%$ & $4.3 \%$ \\
\hline Millennials & 41 & $0.0 \%$ & $7.3 \%$ & $4.9 \%$ & $0.0 \%$ & $2.4 \%$ & $0.0 \%$ & $2.4 \%$ & $12.2 \%$ & $2.4 \%$ & $7.3 \%$ & $2.4 \%$ \\
\hline Generation $\mathrm{X}$ males & 31 & $6.5 \%$ & $3.2 \%$ & $6.5 \%$ & $0.0 \%$ & $0.0 \%$ & $0.0 \%$ & $0.0 \%$ & $25.8 \%$ & $0.0 \%$ & $0.0 \%$ & $0.0 \%$ \\
\hline Millennial females & 26 & $0.0 \%$ & $3.8 \%$ & $7.7 \%$ & $0.0 \%$ & $3.8 \%$ & $0.0 \%$ & $3.8 \%$ & $11.5 \%$ & $3.8 \%$ & $0.0 \%$ & $3.8 \%$ \\
\hline Millennial males & 15 & $0.0 \%$ & $13.3 \%$ & $0.0 \%$ & $0.0 \%$ & $0.0 \%$ & $0.0 \%$ & $0.0 \%$ & $13.3 \%$ & $0.0 \%$ & $20.0 \%$ & $0.0 \%$ \\
\hline
\end{tabular}

\begin{tabular}{|c|c|c|c|c|c|c|c|c|c|c|c|c|}
\hline Kahtah & 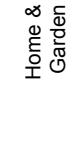 & 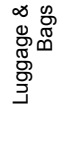 & $\begin{array}{l}\frac{\overline{0}}{\bar{E}} \\
\stackrel{\infty}{\infty}\end{array}$ & $\frac{\frac{\pi}{\pi}}{\frac{0}{2}}$ & 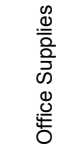 & 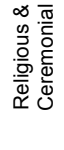 & 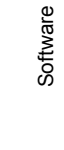 & 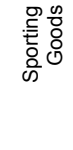 & 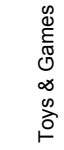 & 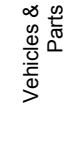 & 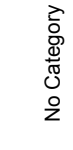 & \\
\hline Number of responses & 36 & 0 & 1 & 0 & 1 & 3 & 1 & 17 & 5 & 13 & 24 & 27 \\
\hline Percent of responses & $15.7 \%$ & $0.0 \%$ & $0.4 \%$ & $0.0 \%$ & $0.4 \%$ & $1.3 \%$ & $0.4 \%$ & $7.4 \%$ & $2.2 \%$ & $5.7 \%$ & $10.4 \%$ & $11.7 \%$ \\
\hline Females & $17.4 \%$ & $0.0 \%$ & $0.6 \%$ & $0.0 \%$ & $0.0 \%$ & $1.2 \%$ & $0.0 \%$ & $6.4 \%$ & $2.3 \%$ & $4.1 \%$ & $11.6 \%$ & $11.0 \%$ \\
\hline Males & $10.3 \%$ & $0.0 \%$ & $0.0 \%$ & $0.0 \%$ & $1.7 \%$ & $1.7 \%$ & $1.7 \%$ & $10.3 \%$ & $1.7 \%$ & $10.3 \%$ & $6.9 \%$ & $13.8 \%$ \\
\hline Baby Boomers & $5.4 \%$ & $0.0 \%$ & $1.4 \%$ & $0.0 \%$ & $0.0 \%$ & $4.1 \%$ & $0.0 \%$ & $2.7 \%$ & $2.7 \%$ & $6.8 \%$ & $12.2 \%$ & $14.9 \%$ \\
\hline Generation Xers & $21.7 \%$ & $0.0 \%$ & $0.0 \%$ & $0.0 \%$ & $0.9 \%$ & $0.0 \%$ & $0.9 \%$ & $8.7 \%$ & $0.9 \%$ & $6.1 \%$ & $7.8 \%$ & $10.4 \%$ \\
\hline Millennials & $17.1 \%$ & $0.0 \%$ & $0.0 \%$ & $0.0 \%$ & $0.0 \%$ & $0.0 \%$ & $0.0 \%$ & $12.2 \%$ & $4.9 \%$ & $2.4 \%$ & $14.6 \%$ & $9.8 \%$ \\
\hline Baby Boomer females & $4.8 \%$ & $0.0 \%$ & $1.6 \%$ & $0.0 \%$ & $0.0 \%$ & $3.2 \%$ & $0.0 \%$ & $3.2 \%$ & $3.2 \%$ & $6.5 \%$ & $14.5 \%$ & $12.9 \%$ \\
\hline Baby Boomer males & $8.3 \%$ & $0.0 \%$ & $0.0 \%$ & $0.0 \%$ & $0.0 \%$ & $8.3 \%$ & $0.0 \%$ & $0.0 \%$ & $0.0 \%$ & $8.3 \%$ & $0.0 \%$ & $25.0 \%$ \\
\hline Generation $\mathrm{X}$ females & $25.0 \%$ & $0.0 \%$ & $0.0 \%$ & $0.0 \%$ & $0.0 \%$ & $0.0 \%$ & $0.0 \%$ & $7.1 \%$ & $1.2 \%$ & $3.6 \%$ & $7.1 \%$ & $9.5 \%$ \\
\hline Generation X males & $12.9 \%$ & $0.0 \%$ & $0.0 \%$ & $0.0 \%$ & $3.2 \%$ & $0.0 \%$ & $3.2 \%$ & $12.9 \%$ & $0.0 \%$ & $12.9 \%$ & $9.7 \%$ & $12.9 \%$ \\
\hline Millennial females & $23.1 \%$ & $0.0 \%$ & $0.0 \%$ & $0.0 \%$ & $0.0 \%$ & $0.0 \%$ & $0.0 \%$ & $11.5 \%$ & $3.8 \%$ & $0.0 \%$ & $19.2 \%$ & $11.5 \%$ \\
\hline Millennial males & $6.7 \%$ & $0.0 \%$ & $0.0 \%$ & $0.0 \%$ & $0.0 \%$ & $0.0 \%$ & $0.0 \%$ & $13.3 \%$ & $6.7 \%$ & $6.7 \%$ & $6.7 \%$ & $6.7 \%$ \\
\hline
\end{tabular}

*"Foreign" was not a category on the standard product taxonomy

but includes any mention of the words foreign, exotic, names of other countries or languages, etc. 
SOUND EFFECTS: AGE, GENDER, AND SOUND SYMBOLISM

Table I-5

Results of Category Coding of Qualitative Data for the Artificial Word Veetee

\begin{tabular}{|c|c|c|c|c|c|c|c|c|c|c|c|c|}
\hline Veetee & & 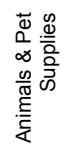 & 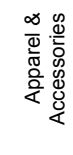 & 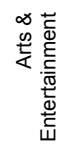 & 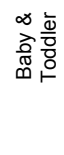 & 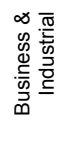 & 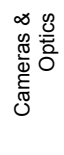 & 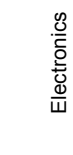 & 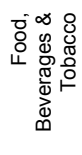 & 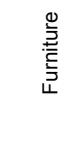 & $\begin{array}{l}0 \\
\frac{0}{\pi} \\
\frac{3}{0} \\
\frac{\pi}{10} \\
\frac{1}{1}\end{array}$ & 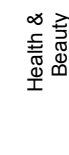 \\
\hline Number of responses & 235 & 4 & 41 & 2 & 3 & 0 & 0 & 27 & 51 & 1 & 2 & 24 \\
\hline Percent of responses & & $1.7 \%$ & $17.4 \%$ & $0.9 \%$ & $1.3 \%$ & $0.0 \%$ & $0.0 \%$ & $11.5 \%$ & $21.7 \%$ & $0.4 \%$ & $0.9 \%$ & $10.2 \%$ \\
\hline Baby Boomers & 75 & $4.0 \%$ & $24.0 \%$ & $0.0 \%$ & $1.3 \%$ & $0.0 \%$ & $0.0 \%$ & $2.7 \%$ & $32.0 \%$ & $0.0 \%$ & $0.0 \%$ & $9.3 \%$ \\
\hline Generation Xers & 119 & $0.8 \%$ & $11.8 \%$ & $1.7 \%$ & $0.8 \%$ & $0.0 \%$ & $0.0 \%$ & $18.5 \%$ & $17.6 \%$ & $0.0 \%$ & $1.7 \%$ & $11.8 \%$ \\
\hline Millennials & 41 & $0.0 \%$ & $22.0 \%$ & $0.0 \%$ & $2.4 \%$ & $0.0 \%$ & $0.0 \%$ & $7.3 \%$ & $14.6 \%$ & $2.4 \%$ & $0.0 \%$ & $7.3 \%$ \\
\hline Generation $\mathrm{X}$ males & 32 & $0.0 \%$ & $18.8 \%$ & $3.1 \%$ & $3.1 \%$ & $0.0 \%$ & $0.0 \%$ & $21.9 \%$ & $21.9 \%$ & $0.0 \%$ & $3.1 \%$ & $6.3 \%$ \\
\hline Millennial females & 26 & $0.0 \%$ & $19.2 \%$ & $0.0 \%$ & $3.8 \%$ & $0.0 \%$ & $0.0 \%$ & $7.7 \%$ & $15.4 \%$ & $3.8 \%$ & $0.0 \%$ & $3.8 \%$ \\
\hline Millennial males & 15 & $0.0 \%$ & $26.7 \%$ & $0.0 \%$ & $0.0 \%$ & $0.0 \%$ & $0.0 \%$ & $6.7 \%$ & $13.3 \%$ & $0.0 \%$ & $0.0 \%$ & $13.3 \%$ \\
\hline
\end{tabular}

\begin{tabular}{|c|c|c|c|c|c|c|c|c|c|c|c|c|}
\hline Veetee & $\begin{array}{l}\infty ~ \\
\Phi \\
\stackrel{0}{0} \\
\text { 윰 } \\
\text { 이 }\end{array}$ & 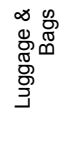 & 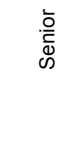 & $\begin{array}{l}\frac{\pi}{\sigma} \\
\frac{0}{2}\end{array}$ & 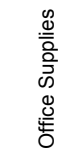 & 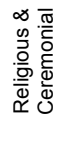 & 离 & 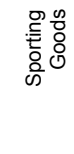 & 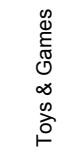 & 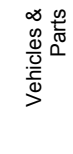 & 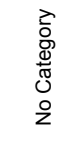 & 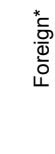 \\
\hline Number of responses & 16 & 0 & 0 & 0 & 2 & 0 & 2 & 16 & 8 & 27 & 12 & 10 \\
\hline Percent of responses & $6.8 \%$ & $0.0 \%$ & $0.0 \%$ & $0.0 \%$ & $0.9 \%$ & $0.0 \%$ & $0.9 \%$ & $6.8 \%$ & $3.4 \%$ & $11.5 \%$ & $5.1 \%$ & $4.3 \%$ \\
\hline Females & $4.7 \%$ & $0.0 \%$ & $0.0 \%$ & $0.0 \%$ & $1.2 \%$ & $0.0 \%$ & $0.0 \%$ & $7.7 \%$ & $3.6 \%$ & $11.8 \%$ & $5.3 \%$ & $4.1 \%$ \\
\hline Males & $12.1 \%$ & $0.0 \%$ & $0.0 \%$ & $0.0 \%$ & $0.0 \%$ & $0.0 \%$ & $3.0 \%$ & $4.5 \%$ & $3.0 \%$ & $10.6 \%$ & $4.5 \%$ & $4.5 \%$ \\
\hline Baby Boomers & $6.7 \%$ & $0.0 \%$ & $0.0 \%$ & $0.0 \%$ & $0.0 \%$ & $0.0 \%$ & $0.0 \%$ & $4.0 \%$ & $2.7 \%$ & $9.3 \%$ & $1.3 \%$ & $2.7 \%$ \\
\hline Generation Xers & $6.7 \%$ & $0.0 \%$ & $0.0 \%$ & $0.0 \%$ & $1.7 \%$ & $0.0 \%$ & $1.7 \%$ & $6.7 \%$ & $4.2 \%$ & $12.6 \%$ & $6.7 \%$ & $5.0 \%$ \\
\hline Millennials & $7.3 \%$ & $0.0 \%$ & $0.0 \%$ & $0.0 \%$ & $0.0 \%$ & $0.0 \%$ & $0.0 \%$ & $12.2 \%$ & $2.4 \%$ & $12.2 \%$ & $7.3 \%$ & $4.9 \%$ \\
\hline Baby Boomer females & $3.6 \%$ & $0.0 \%$ & $0.0 \%$ & $0.0 \%$ & $0.0 \%$ & $0.0 \%$ & $0.0 \%$ & $3.6 \%$ & $3.6 \%$ & $8.9 \%$ & $1.8 \%$ & $1.8 \%$ \\
\hline Baby Boomer males & $15.8 \%$ & $0.0 \%$ & $0.0 \%$ & $0.0 \%$ & $0.0 \%$ & $0.0 \%$ & $0.0 \%$ & $5.3 \%$ & $0.0 \%$ & $10.5 \%$ & $0.0 \%$ & $5.3 \%$ \\
\hline Generation $\mathrm{X}$ females & $3.4 \%$ & $0.0 \%$ & $0.0 \%$ & $0.0 \%$ & $2.3 \%$ & $0.0 \%$ & $0.0 \%$ & $9.2 \%$ & $4.6 \%$ & $13.8 \%$ & $6.9 \%$ & $4.6 \%$ \\
\hline Generation $\mathrm{X}$ males & $15.6 \%$ & $0.0 \%$ & $0.0 \%$ & $0.0 \%$ & $0.0 \%$ & $0.0 \%$ & $6.3 \%$ & $0.0 \%$ & $3.1 \%$ & $9.4 \%$ & $6.3 \%$ & $6.3 \%$ \\
\hline Millennial females & $11.5 \%$ & $0.0 \%$ & $0.0 \%$ & $0.0 \%$ & $0.0 \%$ & $0.0 \%$ & $0.0 \%$ & $11.5 \%$ & $0.0 \%$ & $11.5 \%$ & $7.7 \%$ & $7.7 \%$ \\
\hline Millennial males & $0.0 \%$ & $0.0 \%$ & $0.0 \%$ & $0.0 \%$ & $0.0 \%$ & $0.0 \%$ & $0.0 \%$ & $13.3 \%$ & $6.7 \%$ & $13.3 \%$ & $6.7 \%$ & $0.0 \%$ \\
\hline
\end{tabular}

*"Foreign" was not a category on the standard product taxonomy

but includes any mention of the words foreign, exotic, names of other countries or languages, etc. 
SOUND EFFECTS: AGE, GENDER, AND SOUND SYMBOLISM

Table I-6

Results of Category Coding of Qualitative Data for the Artificial Word Nahtah

\begin{tabular}{|c|c|c|c|c|c|c|c|c|c|c|c|c|}
\hline Nahtah & & 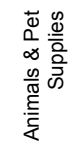 & 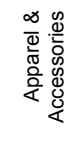 & 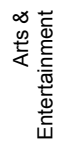 & 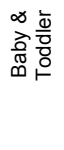 & 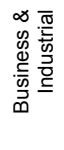 & 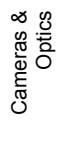 & 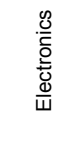 & 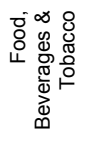 & 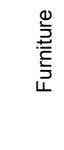 & $\begin{array}{l}0 \\
\frac{0}{\pi} \\
\frac{0}{0} \\
\frac{0}{\pi} \\
\frac{\pi}{1}\end{array}$ & 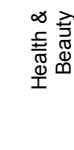 \\
\hline Number of responses & 216 & 6 & 12 & 7 & 7 & 1 & 0 & 3 & 58 & 6 & 2 & 21 \\
\hline Percent of responses & & $2.8 \%$ & $5.6 \%$ & $3.2 \%$ & $3.2 \%$ & $0.5 \%$ & $0.0 \%$ & $1.4 \%$ & $26.9 \%$ & $2.8 \%$ & $0.9 \%$ & $9.7 \%$ \\
\hline Females & 157 & $1.9 \%$ & $7.6 \%$ & $3.2 \%$ & $3.8 \%$ & $0.0 \%$ & $0.0 \%$ & $1.9 \%$ & $23.6 \%$ & $3.2 \%$ & $0.6 \%$ & $10.2 \%$ \\
\hline Males & 59 & $5.1 \%$ & $0.0 \%$ & $3.4 \%$ & $1.7 \%$ & $1.7 \%$ & $0.0 \%$ & $0.0 \%$ & $35.6 \%$ & $1.7 \%$ & $1.7 \%$ & $8.5 \%$ \\
\hline Baby Boomers & 71 & $0.0 \%$ & $5.6 \%$ & $1.4 \%$ & $4.2 \%$ & $0.0 \%$ & $0.0 \%$ & $1.4 \%$ & $23.9 \%$ & $4.2 \%$ & $0.0 \%$ & $14.1 \%$ \\
\hline Generation Xers & 107 & $5.6 \%$ & $4.7 \%$ & $3.7 \%$ & $2.8 \%$ & $0.0 \%$ & $0.0 \%$ & $0.9 \%$ & $32.7 \%$ & $0.9 \%$ & $0.9 \%$ & $9.3 \%$ \\
\hline Millennials & 38 & $0.0 \%$ & $7.9 \%$ & $5.3 \%$ & $2.6 \%$ & $2.6 \%$ & $0.0 \%$ & $2.6 \%$ & $15.8 \%$ & $5.3 \%$ & $2.6 \%$ & $2.6 \%$ \\
\hline Baby Boomer females & 55 & $0.0 \%$ & $7.3 \%$ & $1.8 \%$ & $5.5 \%$ & $0.0 \%$ & $0.0 \%$ & $1.8 \%$ & $20.0 \%$ & $3.6 \%$ & $0.0 \%$ & $10.9 \%$ \\
\hline Baby Boomer males & 16 & $0.0 \%$ & $0.0 \%$ & $0.0 \%$ & $0.0 \%$ & $0.0 \%$ & $0.0 \%$ & $0.0 \%$ & $37.5 \%$ & $6.3 \%$ & $0.0 \%$ & $25.0 \%$ \\
\hline Generation $X$ females & 77 & $3.9 \%$ & $6.5 \%$ & $3.9 \%$ & $2.6 \%$ & $0.0 \%$ & $0.0 \%$ & $1.3 \%$ & $31.2 \%$ & $1.3 \%$ & $1.3 \%$ & $11.7 \%$ \\
\hline Generation $X$ males & 30 & $10.0 \%$ & $0.0 \%$ & $3.3 \%$ & $3.3 \%$ & $0.0 \%$ & $0.0 \%$ & $0.0 \%$ & $36.7 \%$ & $0.0 \%$ & $0.0 \%$ & $3.3 \%$ \\
\hline Millennial females & 25 & $0.0 \%$ & $12.0 \%$ & $4.0 \%$ & $4.0 \%$ & $0.0 \%$ & $0.0 \%$ & $4.0 \%$ & $8.0 \%$ & $8.0 \%$ & $0.0 \%$ & $4.0 \%$ \\
\hline Millennial males & 13 & $0.0 \%$ & $0.0 \%$ & $7.7 \%$ & $0.0 \%$ & $7.7 \%$ & $0.0 \%$ & $0.0 \%$ & $30.8 \%$ & $0.0 \%$ & $7.7 \%$ & 0.0 \\
\hline
\end{tabular}

\begin{tabular}{|c|c|c|c|c|c|c|c|c|c|c|c|c|}
\hline Nahtah & 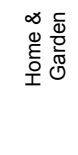 & 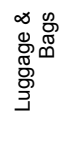 & 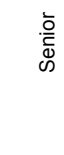 & $\frac{\frac{\pi}{\pi}}{\sum^{\frac{\pi}{2}}}$ & 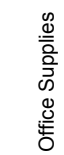 & 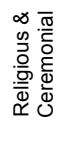 & 竞 & 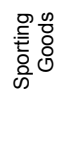 & 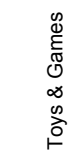 & $\begin{array}{l}\infty \\
0 \frac{n}{\frac{D}{\sigma}} \\
\frac{0}{0} \\
\frac{0}{\bar{D}} \\
>\end{array}$ & 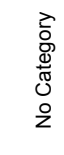 & $\begin{array}{l}{ }^{*} \\
\text { 흠 } \\
\text { 힌 }\end{array}$ \\
\hline Number of responses & 23 & 0 & 1 & 0 & 3 & 1 & 4 & 8 & 9 & 11 & 11 & 28 \\
\hline Percent of responses & $10.6 \%$ & $0.0 \%$ & $0.5 \%$ & $0.0 \%$ & $1.4 \%$ & $0.5 \%$ & $1.9 \%$ & $3.7 \%$ & $4.2 \%$ & $5.1 \%$ & $5.1 \%$ & $13.0 \%$ \\
\hline Females & $12.1 \%$ & $0.0 \%$ & $0.6 \%$ & $0.0 \%$ & $1.9 \%$ & $0.0 \%$ & $1.3 \%$ & $3.2 \%$ & $3.8 \%$ & $4.5 \%$ & $5.7 \%$ & $12.1 \%$ \\
\hline Males & $6.8 \%$ & $0.0 \%$ & $0.0 \%$ & $0.0 \%$ & $0.0 \%$ & $1.7 \%$ & $3.4 \%$ & $5.1 \%$ & $5.1 \%$ & $6.8 \%$ & $3.4 \%$ & $15.3 \%$ \\
\hline Baby Boomers & $8.5 \%$ & $0.0 \%$ & $0.0 \%$ & $0.0 \%$ & $0.0 \%$ & $0.0 \%$ & $1.4 \%$ & $1.4 \%$ & $4.2 \%$ & $4.2 \%$ & $2.8 \%$ & $18.3 \%$ \\
\hline Generation Xers & $9.3 \%$ & $0.0 \%$ & $0.9 \%$ & $0.0 \%$ & $0.9 \%$ & $0.9 \%$ & $2.8 \%$ & $3.7 \%$ & $4.7 \%$ & $5.6 \%$ & $6.5 \%$ & $13.1 \%$ \\
\hline Millennials & $18.4 \%$ & $0.0 \%$ & $0.0 \%$ & $0.0 \%$ & $5.3 \%$ & $0.0 \%$ & $0.0 \%$ & $7.9 \%$ & $2.6 \%$ & $5.3 \%$ & $5.3 \%$ & $2.6 \%$ \\
\hline Baby Boomer females & $10.9 \%$ & $0.0 \%$ & $0.0 \%$ & $0.0 \%$ & $0.0 \%$ & $0.0 \%$ & $0.0 \%$ & $1.8 \%$ & $5.5 \%$ & $3.6 \%$ & $3.6 \%$ & $16.4 \%$ \\
\hline Baby Boomer males & $0.0 \%$ & $0.0 \%$ & $0.0 \%$ & $0.0 \%$ & $0.0 \%$ & $0.0 \%$ & $6.3 \%$ & $0.0 \%$ & $0.0 \%$ & $6.3 \%$ & $0.0 \%$ & $25.0 \%$ \\
\hline Generation $X$ females & $11.7 \%$ & $0.0 \%$ & $1.3 \%$ & $0.0 \%$ & $1.3 \%$ & $0.0 \%$ & $2.6 \%$ & $2.6 \%$ & $2.6 \%$ & $5.2 \%$ & $6.5 \%$ & $11.7 \%$ \\
\hline Generation $\mathrm{X}$ males & $3.3 \%$ & $0.0 \%$ & $0.0 \%$ & $0.0 \%$ & $0.0 \%$ & $3.3 \%$ & $3.3 \%$ & $6.7 \%$ & $10.0 \%$ & $6.7 \%$ & $6.7 \%$ & $16.7 \%$ \\
\hline Millennial females & $16.0 \%$ & $0.0 \%$ & $0.0 \%$ & $0.0 \%$ & $8.0 \%$ & $0.0 \%$ & $0.0 \%$ & $8.0 \%$ & $4.0 \%$ & $4.0 \%$ & $8.0 \%$ & $4.0 \%$ \\
\hline Millennial males & $23.1 \%$ & $0.0 \%$ & $0.0 \%$ & $0.0 \%$ & $0.0 \%$ & $0.0 \%$ & $0.0 \%$ & $7.7 \%$ & $0.0 \%$ & $7.7 \%$ & $0.0 \%$ & $0.0 \%$ \\
\hline
\end{tabular}

*"Foreign" was not a category on the standard product taxonomy

but includes any mention of the words foreign, exotic, names of other countries or languages, etc. 


\section{Appendix J. Comparison of Qualitative Results}

Figure J-1

Three Most Frequently Referenced Product Categories, Percent of Those Responding
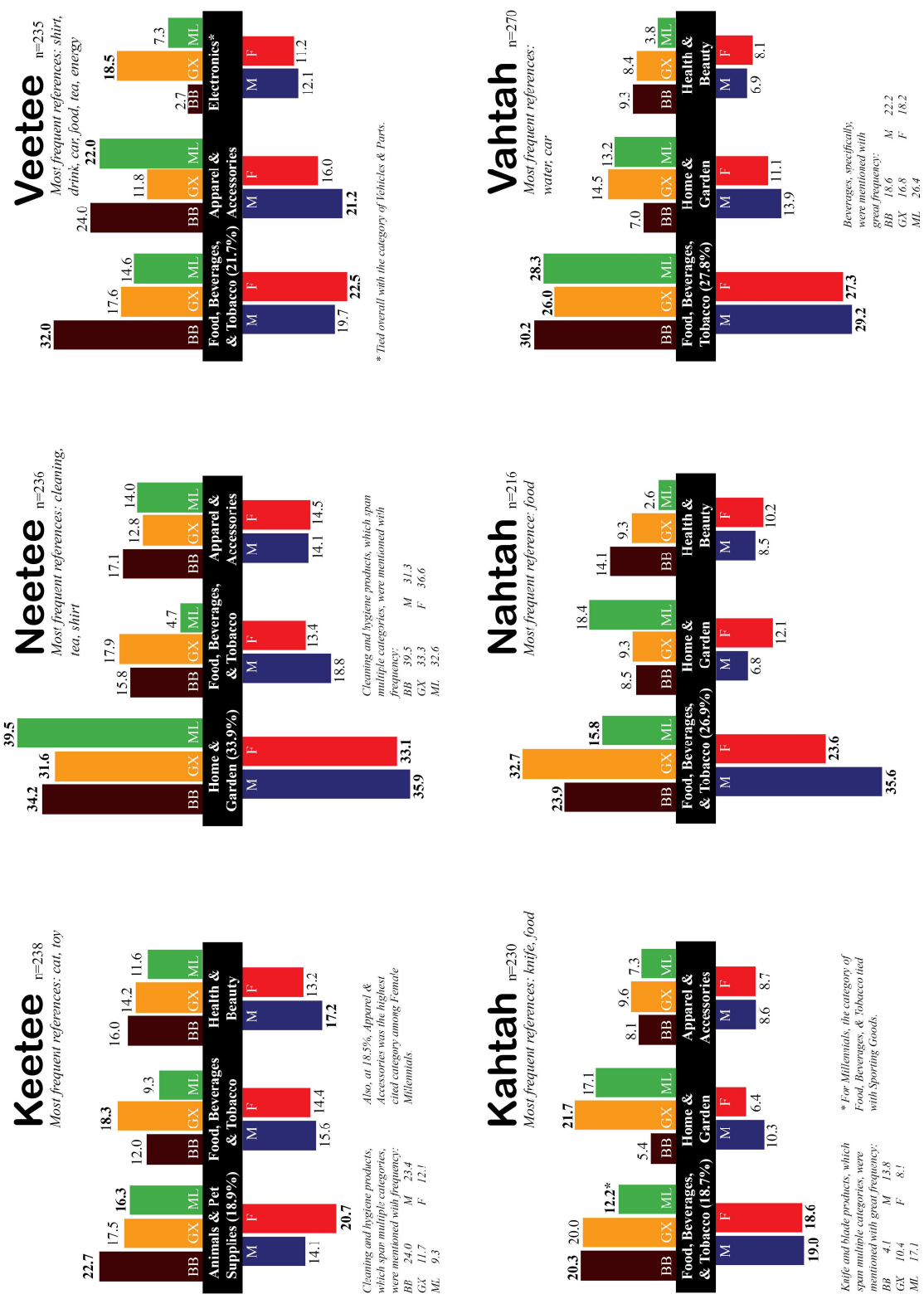